\title{
DRY WELL STORAGE FACILITY CONCEPTUAL DESIGN STUDY
}

FEBRUARY 1979

PREPARED BY:

ROCKWELL HANFORD OPERATIONS AND

KAISER ENGINEERS

\section{MASTER}

PREPARED FOR THE UNITED STATES

DEPARTMENT OF ENERGY 


\section{DISCLAIMER}

This report was prepared as an account of work sponsored by an agency of the United States Government. Neither the United States Government nor any agency Thereof, nor any of their employees, makes any warranty, express or implied, or assumes any legal liability or responsibility for the accuracy, completeness, or usefulness of any information, apparatus, product, or process disclosed, or represents that its use would not infringe privately owned rights. Reference herein to any specific commercial product, process, or service by trade name, trademark, manufacturer, or otherwise does not necessarily constitute or imply its endorsement, recommendation, or favoring by the United States Government or any agency thereof. The views and opinions of authors expressed herein do not necessarily state or reflect those of the United States Government or any agency thereof. 


\section{DISCLAIMER}

Portions of this document may be illegible in electronic image products. Images are produced from the best available original document. 


\section{DRY WELL STORAGE FACILITY CONCEPTUAL DESIGN STUDY}

FEBRUARY 1979

REPORT NO. 79-8-R

This report was prepared an account of work The

United States nor the United States Department of

Energy, nor any of their employees, nor any of their

contractors, subcontractors, or their employees, makes

any warranty, express or implied, or assumes any legal

ablity or responsibility for the accuracy, completeness

or usefulness of any information, apparatus, product or

process disclosed, or represents that its use would not

PREPARED BY:

ROCKWELL HANFORD OPERATIONS

AND

KAISER ENGINEERS

PREPARED FOR THE UNITED STATES

DEPARTMENT OF ENERGY

UNDER CONTRACTS EY-77-C-06-1030 (ROCKWELL)

EY-76-C-06-2195 (KAISER) 


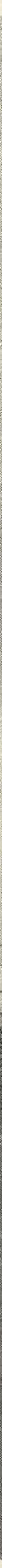




\section{PREFACE}

The United States Government has announced its intent to indefinitely defer chemical reprocessing of spent fuel from the nuclear power industry. To implement this decision, the Department of Energy (DOE) has established the Spent Fuel Handling and Packaging Program to provide a means of encapsulating light water reactor (LWR) spent fuel in a package that will be compatible with the selected surface storage mode (dry well) or with one or more of the geologic repository concepts presently under consideration. Rockwell Hanford Operations (Rockwell) is responsible for overall program management, which includes the conceptual design of the Dry Well Storage Facility described in this report. This facility is to be licensed by the Nuclear Regulatory Commission (NRC).

The Dry Well Storage Facility, sited adjacent to the 200-West Area of the Hanford Reservation as the design reference, provides for 50 years of interim surface storage of all LWR spent fuel assemblies that will have accumulated as a result of commercial nuclear power plant operation through the year 1990.

The facility described in this report is assumed to be located adjacent to or near a Spent Fuel Receiving and Packaging Facility and/or a Packaged Fuel Transfer Facility. 


\section{CONTENTS}

Page

1. Project Title and Estimated Cost

$1-1$

1.1 Project Title 1-1

1.2 Total Estimated Capital Costs 1-1

2. Project Justification 2-1

2.1 Purpose 2-1

2.2 Justification 2-1

2.3 Anticipated Operating Coets 21

3. Project Scope 3-1

3.1 Improvements to Land 3-2

3.1.1 Site Clearing and Grading 3-2

3.1.2 Roads and Parking 3-3

3.1.3 Security Fencing and Barriers 3-5

3.2 Dry Well Storage Facility 3-6

3.2.1 Functional Description 3-7

3.2.2 Dry Well Physical Description 3-8

3.2.3 Storage and Retrieval Operation 3-10

3.2.4 Mechanical Handling Equipment 3-16

3.2.5 Spent Fuel Canister Packages 3-20

3.2.6 Support Facilities and Services 3-21

3.2.7 Dry Well Instrumentation 3-27 
3.3.1 Electrical Systems 3-28

3.3.2 Communications and Fire Alarm Systems $\quad 3-36$

3.3.3 Monitoring and Surveillance 3-38

3.3.4 Fuel 0 il 3-42

4. Performance Requirements 4-1

4.1 Functional Criteria . 4-1

4.1.1. Processing Capacity 4-1

4.1.2 Spent Fuel Canister Acceptance Criteria 4-2

4.1.3 Transporter/Cask Acceptance Criteria 4-3

4.1.4 Radiation Shielding Criteria 4-6

4.1.5 Heat Transfer and Dry Well Spacing. 4-7

4.2 Facility Operating Requirements 4-10

4.2.1 Receiving and Storage 4-11

4.2.2 Accountability 4-11

4.2.3 Security and Surveillance 4-11

5. Quality Levels and Codes and Standards 5-1

5.1 Facilities and Equipment Classifications 5-1

5.1.1 Quality Assurance Level I Items

5.1.2 Quality Assurance Level II Items 5-1

5.1.3. Quality Assurance Level. III Items · 5-2 


\section{CONTENTS (Cont)}

Page

5.2 Engineering and Construction Codes and Standards 5-2

5.2.1 General Design and Quality Assurance and Construction Standards 5-3

5.2.2 Seismic Design Standards 5-3

5.2.3 Wind Design Codes and Standards 5-4

5.2.4 Reinforced Concrete and Structural Steel Codes and Standards 5-4

5.2.5 Industrial Safety Standards 5-4

5.3 Nuclear Safety Design Requirements 5-5

5.3.1 NRC Regulatory Guides and Other Requirements 5-5

5.3.2 Single - Failure Criterion 5-15

5.3.3 Severe Natural Phenomena 5-18

6. Schedule and Methods of Performance 6-1

6.1 Design and Construction Schedules 6-1

6.2 Operation 6-1

6.3 Methods of Performance 6-3

6.3.1 DOE 6-4

6.3.2 NRC 6-4

6.3.3 Program Manager 6-4

6.3.4 Architect/Engineer.6-6

6.3.5 General Contractor 6-6

6.3.6 Operating Contractor 6-6 


\section{CONTENTS (Cont)}

Page

6.4 Procurement Policy

6-7

6.4.1 Design and Inspection 6-7

6.4.2 Construction Phase 6-7

6.4.3. Operating Phase 6-8

6.5 Decommissioning Phase 6-8

$\begin{array}{ll}\text { 7. Special Requirements } & \text { 7-1 }\end{array}$

7.1. Security 7-1

7.1.1 Vital and Protected Areas 7-1

7.1.2 Safeguard Systems 7-1

7.2 Safety $7-6$

7.2.1 Safety Classification of Accidents 7-6

7.2.2 Safety Evaluation 7-7

7.3 Safeguards . 7-7

7.4 Energy Conservation $\quad 7-12$

7.4.1 Energy Consumption : 7-12

7.4.2 Vehicle Energy Consumption at
Storage Site

7.5 Environmental Assessment 7-15

7.6 Decontamination and Decommissioning : 7-15

8. Qualily Assurance Program 8-1

8.1 DOE Policy Statement Defining Quality. Assurance Criteria : 8-1

8.2 Overall Quality Assurance Program 8-1 


\section{CONTENTS (Cont)}

Page

8.3 Applicant's Quality Assurance Program 8-2

8.4 Quality Assurance Programs of Major Participating Organizations 8-3

8.5 Approval of Quality Assurance Programs 8-5

8.6 Summary Matrix $\quad$ 8-5

9. Drawings and Outline Specifications 9-1

9.1 Drawings 9-1

9.2 Outline Specifications 9-1

10. Cusl Estimate 10-1

10.1 Summary of Cost Analys is 10-1

10.1.1 Project Cost Estimate Summary 10-1

10.1.2 Activation Schedule 10-3

10.1.3 Total Life Cycle Costs 10-3

10.2 Expenditure Schedules and Cost Items 10-5

10.2.1 Expenditure Schedule 10-6

10.2.2 Cost Items 10-6

10:3 Cost Estimating Factors and Assumptions 10-9

10.3.1 General Study Criteria 10-9.

10.3.2 Capital Cost Factors and Assumptions 10-11

10.3.3 Operating Costs 10-13

10.4 Capital Cost Estimates 10-15

Appendix A: Major Mechanical Equipment $\quad A-1$

Appendix B: Electric Power Requirements B-1 


\section{PROJECT TITLE AND ESTIMATED COST}

\section{I PROJECT TITLE}

This document is the Conceptual Design Study for a Dry We11 Storage Facility.

\subsection{TOTAL ESTIMATED CAPITAL COSTS}

Cost estimates have been prepared for the Dry Well Storage (DWS) Facility assuming a reference site on the Hanford Reservation for the purposes of the study.

The capital cost estimate for construction of a DWS Facility un the Hanford Reservation totals $\$ 1,727$ million. This estimate includes facility engineering-design and inspection (including licensing activities), escalation, and contingency. Certain costs associated with the power supply, communication, and monitoringsurveillance systems have also been included for equipment that would be installed in an adjacent or nearby Spent Fuel Receiving and Packaging Facility or a Packaging Fuel Transfer Facility and in a Redundant Alarm Monitoring Station.

A summary of the cost estimates is presented in Table 1-1. The estimated initial capital costs, deferred capital costs, and direct and indirect operating and maintenance costs for the DWS Facility are presented in Section 10.

The assumptions and ground rules used for the cost estimates in Table 1-1 include the following: 
Construction Costs:

(a) Improvements to Land

$\$ 27,800,000$

(b) Auxiliary Buildings 300,000

(c) Mechanical Equipment, including Maintenance and Security Vehtcles

$1,500,000$

(d) Dry Well Encasements

$521,000,000$

(e) Area \& Site Perimeter Instrumentation, Communications, Alarm, and Monitoring Vehicles

$36,300,000$

(f) Utilities

$4,900,000$

Subtota 1

$\$ 591,800,000$

Escalation e 153\% $904,800,000$

Subtotal

$\$ 1,496,600,000$

SAY

$\$ 1,497,000,000$

Engineering-design and Inspection*

Escalation o $31.7 \%$

Subtotal

$\$ 4,000,000$

$1,270,000$

$\$ 5,270,000$

SAY

$5,000,000$

Subtotal

$\$ 1,502,000,000$

Contingency @ $15 \%$

$\$ 225,000,000$

Total Capital Cost

$\$ 1,727,000,000$

*Estimated at $7 \%$ of the initial $\$ 57.9$ million facility costs. See Table 10-5. 
(a) The cost estimates are based on the conceptual design described in this study.

(b) The costs for engineering-design and inspection were assumed to be $7 \%$ of construction costs through hot startup and operation of the first storage module. Engineering-design and inspection include Titles I, II, and III and the cost of licensing activities.

(c) The cost estimates are based on mid-1978 dollars for labor, materials, and equipment. Annual escalation rates vary from $9.9 \%$ in mid-1978 to $4.8 \%$ after mid-1989 and were applied on the basis of a projected schedule for expenditures. The overall escalation of construction only was computed to be $153 \%$, based on hot startup and operation of the first storage module by July 1986, and followed by completion of the remaining storage modules over a 14-year construction period.

(d) An indirect construction cost of $19 \%$ is included in the items of construction cost and is applied to allow for a general contractor's home office and field overhead, temporary facilities, bonds, insurance, quality control, and profit.

(e) A $15 \%$ contingency has been applied to the cost of construction, installation, engineering-design and inspection, and escalation. 


\section{PROJECT JUSTIFICATION}

\subsection{PURPOSE}

The purpose of this project is to provide a surface facility for passive, retrievable storage of packaged spent fuel from commercial light water reactors. The facility will be designed to provide fuel recoverability for transfer to reprocessing or permanent disposal facilities.

\subsection{JUSTIFICATION}

Current national policy states that the decision to reprocess spent LWR fuel is to be deferred for an indefinite period. In life cycle studies based on this premise, a surface storage mode (dry wel1) has been identified as a safe, economic method of spent fuel storage until the decision to reprocess or permanently dispose of the fuel is made. This project provides the dry well facility for interim storage.

\subsection{ANTICIPATED OPERATING COSTS}

The anticipated operating costs of the DWS Facility in 1978 dollars without escalation are as follows:

Total labor: 80 persons at $\$ 36,800$ per labor year $\$ 2,944,000$ (composite cost)

Maintenance supplies: $0.0625 \%$ of construction cost 370,000 Dry well materials: 6750 encasements/year e \$11 75,000

Energy: diesel and electrical power requirements 300,000 Total Operating Cost Per Year $\$ 3,689,000$ SAY: $\$ 3,700,000$ 


\section{PROJECT SCOPE}

The DWS Facility provides for the receipt by shield-cask transporter vehicle, placement, and storage of canisters from an adjacent Spent Fuel Receiving and Packaging Facility or a Packaged Fuel Transfer Facility. It will also provide for retrieval of the canisters at any time during the storage period. The storage capacity of the DWS Facility will accommodate all LWR spent fuel assemblies accumulated as a result of commercial nuclear power plant operation through the year 1990. Packaging of the spent fuel assemblies into canisters ready for interim storage in dry wells will occur at the rate of 3,300 metric tons of uranium (MTU) per year.

For the purpose of this study, direct reference is made to the conceptual design of a Spent Fuel Receiving and Packaging (R\&P) Facility as described in Rockwell International Document RHO-CD506 (Draft), dated September 1978. It is assumed, however, that support buildings, structures, utility and security systems, and other essential features that are functionally similar to those in the R\&P Facility would also be available to the DWS Facility as part of a future conceptual design of a Packaged Fuel Transfer (PFT) Facility.

The functional and physical descriptions of the conceptual design for a reference DWS Facility located on the Hanford Reservation are given in this section. Descriptions are included for required improvements to the land, architectural and structural features of the facility buildings and other structures, dry well encasement vessels, mechanical and electrical support systems and utilities, placement and retrieval systems, radiation monitoring and surveillance systems, and security systems for the reference DWS Facility. Descriptions of the associated modifications to an adjacent R\&P Facility are also included. 
Performance requirements for the reference DWS Facility are defined in Section 4 and the quality levels, codes, and standards in Section 5. The schedule and methods of performance are described in Section 6. The initial construction period for the DWS Facility, including one year of canister storage capacity $(6,750$ dry we11s), will be about 24 months. Subsequent construction of the remaining dry well storage areas will be completed over a 14-year period.

\subsection{IMPROVEMENTS TO IAND}

For reference drawings, see Sheet No. 1 and Sheet No. 2 .

Land improvements will consist of clearing and grading approximately 1,000 acres ( 1.5 square miles), constructing roadway access to the first year's inventory of dry wells and surface drainage structures, and building the entire perimeter security fencing. The total storage area will be expanded in modular increments of 6,750 dry wells per year.

\subsubsection{Site Clearing and Grading}

\subsubsection{Site Clearing}

The entire facility area, consisting of approximately 1,000 acres, will be cleared and stripped to provide a clear view of the site for security operations. The clearing and stripping or grubbing will be limited to the removal of vegetation consisting mostly of sage brush and native grasses. Topsoil will be removed and stockpiled for future restoration of disturbed areas.

\subsubsection{Grading}

The entire storage area will be rough-graded to achieve an overall slope of approximately $2 \%$ or less and to allow installation of 
site perimeter fencing and security systems. Areas that require engineered fill to bring them to grade will be cleared and stripped, the subgrade compacted, and the fill material placed and compacted. Grading for site drainage will be on the basis of overland sheet flow collected in open ditches, drainage swales, and trench drains. These, in turn, will carry the discharge to the nearest drain inlet or natural drainage channel. Culverts will be provided to convey storm drainage under roads. Final discharge from the surface and subsurface drainage systems will be to the nearest natural drainage channel. Efforts will be directed toward minimizing erosion during construction.

The sequential construction of each dry well storage area module will include drilling and lining holes fur dry well encasement vessel installation, finish-grading and drainage, and placement of two inches of gravel in noncompacted areas for dust and erosion control.

\subsubsection{Roads and Parking}

Access to the site will be from the adjacent R\&P Facility, located on the east side of the storage area. All roads and other paved areas within the site will be designed for their intended service.

The following four types of roads will be provided:
(a) Primary
(b) Secondary
(c) Tertiary
(d) Patrol

\subsubsection{Primary Road}

The primary road will provide the main access to the DWS Facility from the adjacent R\&P Facility. The primary road will also provide access to a network of secondary roads. Transverse drainage 
slopes of $2 \%$ for the traveled way and $5 \%$ for the shoulders will be used. The primary road will have two 30-foot-wide lanes with 5-foot-wide shoulders. : The roadway will be designed to accommodate the shield-cask transporter vehicles bringing canisters into the facility for storage.

\subsubsection{Secondary Road Network}

A secondary road network will be designed to provide access for transporters and other service vehicles to the tertiary roads that will straddle each line of dry welis in a störage area module. The roads will have two 30-foot-wide lanes. A drainage slope of $2 \%$ will be provided for surface drainage into buried trench drains, ditches, and other drainage structures.

\subsubsection{Tertiary Roads}

Tertiary roads will straddle each line of dry wells within a storage area module. These roads will be designed for transporter and service vehicle access to the dry wells and for interconnection with patrol roads. Each roadway will consist of a single 8-footwide lane, centered between the dry wells, to accommodate a transporter vehicle with a 17-foot wheel tread width. Welding, monitoring and surveillance, maintenance, and patrol vehicles will also operate on the tertiary roadways. Drainage of the tertiary roads as well as of each module will be provided by a general slope of $2 \%$ or less for the entire storage area and by intercepting trench drains and/or ditches alongside the storage area roads.

\subsubsection{Patrol Road}

A 20-foot-wide patrol road will be provided along the inside of the perimeter fence for security patrolling. The construction of this road will be similar to that of the secondary roads. 


\subsubsection{Parking}

The R\&P Facility parking lot will be extended to provide for 80 vehicles. The number of parking stalls provided is based on one vehicle per 1.5 persons working the largest shift, plus the personnel working the next shift. The major parking burden will be imposed by the 80-person dry well construction force.

Drainage of the parking lot extension will be by surface flow to drainage ditches or swales.

Buses will be provided onsite near the security area of the R\&P Facility to transport operating and construction personnel to the DWS Facility.

\subsubsection{Security Fencing and Barriers}

The site will be romplotely surrounded by a 7-foot-high chain link fence. The fence will be topped with three strands of barbed wire on one-foot-high brackets, angled outward and inward, for a total height of 8 feet. The trough formed by the brackets will be filled with concertina-wound (spiraled) razor ribbon. A similar fence will be located 100 feet inside the outer fence. The exclusion zone between the inner and outer fences will be kept free of brush, high grass, or any other view-obstructing material and will bc graded level (plus or minus 3 inches). The exclusion zone soil will be sterilized and covered with gravel to control windblown dust and erosion.

Only one entrance, with a remote-operated sliding-type vehicular gate, will be provided in the site perimeter fencing for primary road access to the DWS Facility. Fencing design will be in accordance with the requirements of the DOE Manual, Appendix 2401, Part II, C.3.a. 
All fencing with be grounded. Man barriers will be provided where the perimeter fence crosses the surface drainage ditches.

A vehicle barrier ditch will be provided outside of the site security exclusion fence to prevent vehicles from breaking through the fence. The ditch will be integrated with the site drainage system.

A third fence of the chain link type, approximately four feet high, will be provided outside of but adjacent to the vehicle Larrier ditch to reduce the tncidelice of animals sctting off false. intrusion alarms.

During the dry well module construction period, temporary barriers and warning devices will be erected around completed storage modules to isolate the ongoing dry well construction activities from canister placement operations and areas with canisters stored in the dry wells.

\subsection{DRY WELL STORAGE FACILITY}

See reference drawing Sheet No. 1 and Sheet No. 2.

The proposed location for the DWS Facility will be on a 1,000-acre site, west of a reference receiving and packaging facility at the Hanford Reservation near Richland, Washington. The dry wells in the DWS Facility storage area will consist of vertical steel encasements buried in the ground in a rectangular array at a uniform 17-foot center-to-center spacing. The storage field will be divided into 15 area modules, each containing 6,750 dry wells, with primary and secondary road systems for canister transport, support equipment, and security vehicles. The complete storage area will be surrounded by exclusion fencing and protective barriers. 
The overall storage capacity of the DWS Facility will be 101,250 dry wells, which will provide for receipt and storage of an average of 6,750 spent fuel canisters per year over a period of 15 years. The storage area will be expanded by modular construction of dry wells to ensure a minimum of one year of storage capacity in advance of ongoing storage operations.

\subsubsection{Functional Description}

The primary function of the DWS Facility will be to store spent fuel canisters (packages) below ground, with individual dry well containment of each canister, for a period of 50 years. The canisters will be retrievable at any time during their storage life at the facility.

The canister will provide primary containment of the spent fuel assembly(ies) and the dry well a secondary containment barrier. The soil around each dry well will provide shielding from radiation and will permit dispersion of decay heat by conduction to the atmosphere. Loose sand fill placed in the dry well encasement space above the canister will complete the radiation shielding of each canister.

Spent fuel assemblies will be received in two different types of canisters. A boiling water reactor (BWR) canister will contain three BWR spent fuel assemblies and a pressurized water reactor (PWR) canister will contain. one PWR spent fuel assembly. The physical configuration of the dry well will be suitable for storage of either type of canister. The storage and retrieval of canisters will be accomplished by means of a shielded transporter vehicle.

A monitoring and surveillance program will be implemented and maintained throughout the life of the DWS Facility. The interior of each dry well will be sampled periodically for pressure and airborne activity through a sample valve located on top of the dry 
well closure. In order to detect any abnormal thermal conditions, a thermocouple will be provided on the exterior of each dry well encasement for periodic measurement of the temperature within the dry well.

\subsubsection{Dry Well Physical Description}

\subsubsection{Dry Well Encasement}

See reference drawing Sheet No. 5 .

Each dry well will consist of a cylindrical carbon steel canister encasement vessel that projects approximately 6 inches above and extends 24 feet below the surface of the ground. The encasement vessels will be shop-fabricated of 18-inch- and 30-inch-diameter pipe joined by a standard pipe reducer. The encasement will be closed at the bottom by a pipe cap welded onto the 18-inchdiameter lower section of the encasement. The closure plate on top of the encasement vessel will be field welded to the encasement to provide secondary containment after placement of a canister.

The canister will be suspended in the dry well by a dish-shaped steel support ring welded to the pipe reducer section of the encasement. A similar dish-shaped ring will have been welded to the upper portion of the canister during fabrication of the callister. In addition to supporting the canister, the dish-shaped rings will provide a seal to retain the sand in the upper compartment of the encasement vessel. The ring configuration will also serve to center the canister in the dry well during placement.

The encasement vessel will be designed, fabricated, and tested in accordance with the current ASME Boiler and Pressure Vessel Code, Section VIII, Division 2. The pressure parts of the dry well encasement, which make up the secondary containment barrier, will be 
fabricated from materials as specified on reference drawing Sheet No. 5. The design internal pressure will be conservatively based on $60 \mathrm{psi}$ and a maximum wall temperature of $700^{\circ} \mathrm{F}$. A corrosion allowance of 0.005 inch per year for a minimum of 50 years of storage will be included in the design of the dry well encasement vessel.

\subsubsection{Dry Well Closure and Temporary Weather Cover}

Each dry we 11 encasement vessel will be furnished complete with a carbon steel plate which will be field-welded to the top of dry well after placement of a canister and shield sand. The field weld will be a two-layer-minimum weld and will include liquid dye penetrant testing in accordance with rurront ASME Code V.

The closure plate will be furnished complete with lifting lugs and a sample valve assembly. The sample valve will be protected by a detachable weather cover. A name plate will be provided on top of the closure plate for identification of the stored canister.

A reusable metal cover will be used to protect empty dry wells from the weather prior to canister placement.

\subsubsection{Dry Well Sand Shield Plug}

A loose sand fill will be placed in the compartment space above the canister in each dry well encasement to create a radiation shield plug. The sand material will consist of a dry silica sand with a density of 100 pounds per cubic foot. Commercial-grade sand will be washed to remove any organic materials and dried to a minimum moisture content. In order to reduce the ground surfacelevel radiation dose to $0.25 \mathrm{mrem} / \mathrm{hour}$, approximately 30 cubic feet will be used for each sand plug to achieve a minimum sand fill of 6 feet above the canister. The sand will be supported by the dish-shaped plate welded to the top of the canister and a similarly shaped plate welded to the inside wall of the dry well 
encasement, as described in Section 3.2.2.1. A stainless steel tube through the sand shield plug will provide a connection between the spaces below and above the sand to permit the dry well interior to be sampled for airborne activity.

\subsubsection{Dry Well Sample Valve and Thermocouple}

A sample valve will be provided on each dry well to obtain air samples and measure pressure inside the dry well.

A stainless steel thermowell attached to the exterior of the dry we11 encasement will protect a thermucuuple used for pcriodic measurements of the dry well encasement exterior surface. (See Section 3.2.7 for a description of the dry well instrumentation.)

\subsubsection{Storage and Retrieval Operation}

\subsubsection{Canister Storage}

See reference drawing Sheet No. 3 .

The canister package and sand shielding material will be transported to the storage field in a shield-cask transporter vehicle. The sequence of the canister placement operations will be in three major steps: dry well preparation, canister placement, and completion of placement. These placement activities may be described as follows:

(a) Dry Well Preparation

The area around each dry well will be cleared and the ground surface finish-graded, as required, in preparation for interfacing the dry well with the bottom of the transporter cask. The temporary weather cover will be removed from the dry well. The dry well closure plate 
will be removed, inspected, cleaned, and prepared for installation on the dry well.

The upper surfaces of the dry well will be cleaned for interfacing with transporter cask seal and closure plate welding. The interior of the dry well will be inspected for evidence of moisture and dried, as required.

A cask positioning fixture will be installed over the dry well to facilitate alignment of the transporter cask on the dry well centerline. A weather shelter will also be placed over the dry well during inclement weather to allow year-round operations.

\section{(b) Canister Placement}

The transporter vehicle will be driven into position over the dry well for placement of the canister. The vertical centerline of the shield cask will then be aligned with the vertical centerline of the dry well by means of shield-cask leveling and horizontal positioning devices. The positioning fixture installed over the dry well and view ports in the bottom flange of the shield cask will be used to match the center of the cask with the center of the dry well when direct viewing of the dry well opening is obscured by the bottom of the cask. The shield cask will then be lowered and pneumatically sealed to the top of the dry well encasement.

Prior to canister placement in the dry well, the coded identification markings on the canister will be visually confirmed by periscope or TV viewing of the canister, and recorded. The dry well closure name plate will receive the same identification coding. 
The bottom gate of the shield cask will be opened and a radiation shield sleeve, located inside of the cask, will be lowered into the dry well. The sleeve will be fabricated from depleted uranium to provide shielding of gamma radiation. When fully extended, the sleeve will extend approximately 5 feet into the dry well and will project into the shield cask with sufficient overlap to prevent radiation streaming at the dry well interface.

The canister, attached to a canister grapple or hook device, will be lowered by a holst mechanisul built into the shield cask. The lowering and positioning of the canister onto its support in the dry well will be monitored through a TV camera in the shield cask. The hoist grapple will then be released from the canister and retracted into the shield cask.

After the canister has been placed in the dry we11; approximately 30 cubic feet of sand will be discharged from the transporter sand hopper into the space above the canister to fill the upper compartment of the dry we11. As the sand fills the compartment, the radiation shield sleeve will be retracted into the shield cask. The construction of the sleeve will include a built-in vibrator for use during sleeve retraction to settle and densify the sand fill.

Upon completion of these tasks, the shielded cask will be lifted into the transport position and the cask bottom gate closed. The transporter will then return to the receiving and packaging facility load-out station for another canister. 
(c) Completion of Placement

The cask positioning fixture will be removed and relocated to the next canister placement operation. The top of the encasement will be cleaned and the closure plate set into position for welding on the dry well.

The closure plate will be welded to the top of the dry well encasement by the submerged-arc welding method. Two semiautomatic welding units will be used to complete the closure weld in two or three passes. The first welding unit will be moved to the next dry well upon completion of the initial pass. The weld will then be brushed and cleaned, and tested by the liquid penetrant method. The second welding unit, using a somewhat larger diameter welding wire and a slower welding speed, will provide the final welding pass(es). The completed closure plate weld will then be brushed and cleaned, and tested by the penetrant method.

The placement operation will conclude with inspection and testing of the sample valve and installation of the weather-protective cover. The thermocouple assembly will be inspected and tested for proper function. The weather. seal of the thermocouple receptacle enclosure will be inspected. The section of the dry well exposed above the ground will be painted for corrosion resistance.

\subsubsection{Canister Retrieval}

See reference drawing Sheet No. 4.

The canister retrieval operation may take place at any time during the 50-year storage period. In general, the retrieval operation will amount to a reversals of the storage operation and 
will be performed with transporter:vehicles similar to those used in the storage operations. The sequence for retrieving a canister consists of three major steps: dry well preparation for canister retrieval, canister retrieval, and dry well temporary closure. The retrieval activities are described in the following paragraphs.

\section{(a) Dry Well Preparation for Canister Retrieval}

The surface of the ground around the dry well will be graded as required lo interface with the bottom of the. transporter cask. The dry well encasement section extending above the surface of the ground will be cleaned and prepared for removal of the closure plate. A weld-cutting machine will be mounted on the top of the dry well and the cover plate weld removed. The closure plate will then be removed and stored near the dry well.

The cask positioning fixture will be installed over the dry well to guide the transporter cask onto the dry well centerline.

\section{(b) Canister Retrieval}

The transporter vehicle will be driven into a retrieval position over the dry well. Transporter cask positioning and preparation for the canister retrieval operations will be accomplished in a manner similar to that described for placement in Section 3.2.3.1.

After mating the transporter cask to the dry well and opening the cask bottom gate, the radiation shield sleeve will be lowered from the cask into the dry well.

The sand removal system will be activated and a suction duct inside the shield cask lowered into the sand. The 
sand will be vacuumed out of the dry well into a hopper mounted on the transporter vehicle. The suction duct head will be remotely controlled and monitored by a TV camera. As the level of the sand is lowered, the radiation shield sleeve will be lowered into the upper dry well compartment. The sleeve vibrator will be used to loosen the settled sand during the removal operation. After removal of the sand to a level sufficient to expose the canister bail to the hoist hook, the sand suction duct will be retracted into the transporter cask. At this stage of the retrieval operation the shield sleeve will be extended approximately five feet into the dry well. The upper portion of the sleeve will projecl inlu lise lrallspurler cask will sufficienl uverlap of the sleeve to prevent radiation streaming.

The hoist hook in the shield cask will be lowered to engage the canister bail and lift the canister into the transporter cask. After the canister is inside the transporter cask the shield sleeve will be retracted and the bottom cask gate closed.

Upon completion of canister retrieval, the shield cask will be raised into the transporter traveling position. The transporter vehicle will be moved enough to allow the evacuated sand to be discharged back into the dry well. The transporter vehicle will then remove the canister from the DWS Facility storage area for further handling and offsite shipment.

\section{(c) Retrieval Completion}

The closure plate and a temporary weather cover will be replaced on the dry well and the cask positioning fixture moved to the next dry well. 


\subsubsection{Mechanical Hàndling Equipment}

\subsubsection{Transporter Vehicles}

The transporter vehicle conceptual design is not part of this study. However, in order to facilitate the interface, placement, and retrieval operations described herein for the conceptual design of the DWS Facility, compliance with the following criteria will be required in the future design of the transporter(s):

(a) Twu Lranspurter vehtcles wiil be required for transport of the canisters from the R\&P Facility load-out station and placement in dry wells at the rate of 27 canisters per day.

(b) The transporter will be capable of operating in the dry well storage areas on engineered roadways. See reference drawing Sheet No. 1 and Sheet No. 2 for type and width of roadways.

(c) The transporter's maximum gruss weight, including shield cask and canister, will be limited to 150 t.nns.

(d) The transporter will be supported by and travel on large ear.thmover-type pneumatic tires in accordance with the following conditions:

- Single wheel load: 75,000 pounds

- Tire pressure: 55 psi

- Contact area: aproximately 1230 square inches

o Tread Width: 17 feet

(e) The transporter speed will be limited to a maximum of 10 miles per hour. 
(f) Duplicate driver controls will be provided, with one set of controls located in a weather-protected cab at each end of the transporter for "front-end" control of transporter travel in either a forward or reversed direction.

(g) The canister will be shielded by a vertical, cylindrical, bottom-loading cask complete with a hoisting mechanism and a grapple or hook device to permit vertical loading and retrieval of the canister.

(h) The transporter will be equipped with positioning mechanisms for vertical, horizontal, and angular adjustment of the cask for alignment with the dry well centerline.

(i) The cask bottom section will be provided with a cask closure gate and a radiation shield sleeve designed to interface with the dry well for safe (shielded) transfer of the canister into the dry well.

(j) The transporter will be capable of handling a canister with maximum dimensions of 18 feet $5 \frac{1}{2}$ inches in length and 16 inches in diameter. The heaviest canister weight will be approximately 3,850 pounds.

(k) The hoist/grappling system will be compatible with the final canister connection design.

(1) The cask and the shield sleeve will be designed so that the entire transfer operation will not permit a radiation exposure dose rate greater. than $0.25 \mathrm{mrem} / \mathrm{hour}$ at a distance of 20 feet.

(m) The radiation shield sleeve will provide gamma ray shielding during the canister placement and retrieval. The sleeve will be retractable and will include a builtin vibrator. In addition, neutron shielding will be 
provided at the interface between. the cask and the surface of the ground. The neutron shielding material may be included in the fabrication of the cask bottom flange that interfaces with the ground around the dry we 11 .

(n). The bottom of the cask will have a sealing device (such as an inflatable seal) to provide complete containment of the canister during placement by direct contact with the dry well closure flange.

(o) TV cameras and monitors and other viewing devices insidc the cask will be used for canister identity verification, and control of the canister placement and retrieval.

(p) For canister placement operations, the transporter will be furnished with a sand placement system, including a 30-cubic foot watertight sand hopper with gate and charging spout.

(q) For canister retrieval operations, the transporter will be furnished with sand removal and replacement systems, including vacuum unit, sand separator tank, filter(s), and retractable duct.

\subsubsection{Welding Vehicles}

Three welding vehicles will be provided for seal-welding the closure plate into the dry well encasements. Each vehicle will be completely equipped with a welding fixture positioner, a semiautomatic submerged-arc welder, a welder power supply generator, a welding wire feeder, a welding flux hopper, a mechanized arcgouging fixture, a weld testing kit, an air compressor, and controls. 
The following requirements will apply to the design of the welding vehicles:

(a) Two vehicles will serve as operating units. The third vehicle will be used as a backup unit. The backup vehicle will have all the equipment necessary for closure plate welding or weld removal.

(b) The vehicles will be furnished with a welding fixture positioner to place the submerged-arc welder on the top of the dry well. The welding fixture will use the dry well closure plate and encasement flange for support and/or guidance during the circumferential closure welding operation.

(c) The submerged-arc welding unit will complete the weld in two or more passes.

(d) The submerged-arc welding control panel will be programmed for electrical variables, such as amperage and arc voltage. The control system will be programmable for mechanical variables such as:

- Wire feed rate for welding passes

- Torch positioning for each weld pass

- Rotational speed control of the welding fixture

(e) Weld removal will be accomplished by a mechanized arcgouging method. The arc-gouging unit will be mounted on the same positioning fixture used for welder.

(f) Each vehicle will carry complete power generator units to supply power for the welding and weld-removal operations.

(g) Each vehicle will include the necessary equipment and materials for weld testing by the liquid dye penetrant method. 
(h) Each vehịcle will be equipped with an air compressor to supply air for weld brushing.

\subsubsection{Forklift Vehicles}

Two 2,000-pound-rated forklift vehicles will be used for closure plate installation and removal. Each unit will be equipped with a fork crane adapter suitable for handling the closure plate.

\subsubsection{Spent Fue1 Canister Packages}

For reference drawings, see Sheet No. 6 and Sheet No. 7.

\subsubsection{Spent Fuel Canister Package for PWR Assemblies}

The spent fuel canister package for PWR assemblies will hold one fuel assembly. The package will have an outside diameter of 14 inches, a maximum length of approximately 18 feet $5 \frac{1}{2}$ inches, and a wall thickness of $1 / 2$ inch.

This package will accommodate a fuel assembly 200 inches long. Many existing PWR fuel assemblies are considerably shorter and will be packaged with either a spacer or a shorter canister. The total weight of the finished package is estimated at 3,250 pounds.

\subsubsection{Spent Fuel Canister Package for BWR Assemblies}

The spent fuel canister package for BWR assemblies will hold three fuel assemb1ies. The package will have an outside diameter of 16 inches, a maximum length of 16 feet $5 \frac{1}{2}$ inches, and a wall thickness of $1 / 2$ inch.

Some BWR fuel assemblies may exist that are shorter than the maximum of 180 inches used for this design. In such cases, a system 
of spacers or shorter canisters may be used to accommodate variations in fuel assembly length. The finished package weight is estimated at 3,850 pounds.

\subsubsection{Support Facilities and Services}

In support of the canister storage or retrieval operations, the facilities and services described in the following paragraphs will be provided by or added to an adjacent R\&P Facility.

\subsubsection{Vehicle Maintenance}

The maintenance building and the rail-car/truck maintenance shop lucaled in the R\&P Facllity w1ll be used tor maintenance and servicing of the DWS Facility vehicles. The staff will be increased, as required, to provide the necessary additional manpower and skills for maintenance, repair, and servicing of the DWS Fácility venicles.

\subsubsection{Sand Storage Station}

A sand storage station will be constructed next to the load-out area of the R\&P building for temporary storage of dry well shield plug sand. The station will occupy an area of approximately 2,000 square feet. A one-story, 1,200-square-foot, Level III weatherproof shelter will be constructed to keep the sand dry during truck unloading and transporter loading operations. A 4,000cubic-foot bin will provide enough storage for approximately one week of placement operations.

The sand will be delivered by truck, gravity-discharged into a below-grade hopper, and then conveyed into the storage bin. $A$ 30-cubic-foot batching system will be provided to load the sand into the transporter vehicle sand hopper. The sand handling system will include a dust collection system and provisions to receive and maintain the sand in a dry condition. 
The building material for the sand storage station will be as listed below.

o Floor: concrete

- Frame: steel

- Exterior Walls: preformed metal panels with metal rollup door

o Roof: preformed metal panels

The interior surface finishes will be as listed below.

- Floors: concrete

- Walls: paint

o Ceilings: paint, exposed structure, and insulated metal panels

The shelter will be designed in accordance with the DOE Manual, Appendix 6301, and the Uniform Building Code.

Selected work areas in the shelter will be spot-heated by steam heaters supplied with steam from the R\&P Facility distribution system. Adjustable gravity ventilators will be provided for natural ventilation.

Portable fire extinguishers will be provided for fire protection.

Electrical service for lighting and power for conveyor motors and instrumentation will be extended from the R\&P Facility.

\subsubsection{Transporter Cask Maintenance and Decontamination}

The rail-car/truck maintenance shop in the R\&P Facility will be used for transporter vehicle servicing and maintenance. 
Transporter cask decontamination, if required, will be performed in the R\&P building cask decontamination area. One of the preparation area air-lock doors will be enlarged to accommodate a transporter vehicle. The 125-ton crane in the shipping cask receiving area will be used to lift and transport the cask from the transporter to the wash and decontamination pits.

\subsubsection{Health Physics, Counting Room and Lab Services}

The health physics room in the R\&P building will be used by the personnel providing health physics services to the DWS Facility.

The counting room and laboratory in the R\&P building will be increased by approximately $1, \overline{500}$ square feet for analysis of gas samples taken during the monitoring and surveillance of the dry wells. In addition, a storage room of approximately 600 square feet will be provided for sample cylinder receiving and storage.

The counting room and laboratory materials will be the same as the existing construction listed below.

- Floor: concrete

- Frame: concrete

o Exterior walls: insulated preformed metal panels

o Interior walls: metal studs with gypsum board

o Roof: concrete

The interior surface finishes will include:

- Floors: seamless vinyl

- Walls: painted per DOE Manual, Appendix 6301

- Ceilings: painted suspended acoustical tile

The extensions will be designed as Level II structures in accordance with the DOE Manual, Appendix 6301, and the Uniform Building Code. 
Electric power, heating and ventilating, and fire protection systems will be extended from the existing R\&P building systems.

\subsubsection{Dry Well Road and Storage Area Maintenance}

A11 road and storage area maintenance and repair materials, equipment, and personnel will be provided by the R\&P Facility maintenance personnel. However, the number of maintenance personne] will be increased, as required, to accommodate the additional workload. The anticipated routine maintenance and repair operations will include inspection and supervision; maintenance and repair of roads, surfaces and subgrade, storage field, graveled surfaces, and fencing and drainage systemis; stockpiling of materials for maintenance and repair work; dust control; and snow and ice removal. A $1 \frac{1}{2}-$ ton service truck equipped with an extending boom and platform will. be provided to service the 30-foot-high and 70-foot-high area light standards.

\section{2:6.6 Standby Generator Building}

The standby generator building will be a one story, Level II, reinforced-concrete structure designated as a vital area. The 960-square-foot building will contain the standby electrical power generation equipment necessary to maintain reliable and safe operation of the facility in the event of an interruption of normal power.

The building materials will be as listed below.
- Floor: concrete
o Exterior walls: insulated concrete
- Roof: concrete with built-up roofing over insulation
o Doors and louvers: missile resistant 
The interior finishes will be as follows:

- Floors: concrete with surface-hardener treatment

o Walls: painted concrete

- Ceilings: painted concrete

The building will contain a two-ton service crane and be designed to meet the requirements of Level II construction, in accordance with the DOE Manual, Appendix 6301, and the Uniform Building Code. Internal pressure will be relieved by the use of "blow-out" panels.

The building will be steam-heated and have powered ventilation units. The primary function of llie lieating and ventilating system will be to protect equipment from freezing, overheating, and the accumulation of vapor and dust.

Fire protection will be provided by extensions of the R\&P Facility emergency diesel generator building sprinkler and Haton 1301 systems.

Electrical service will be supplied from new switchgear located in the building.

\subsubsection{Storage Area Gatehouse}

The storage area gatehouse building will be; a one-story, Level III prefabricated structure. The 150-square-foot building will provide weather protection for a gateman and space for gate controls, monitoring and other security equipment, telephone, and daily record storage.

The interior finishes will be as listed below,

- Floors: vinyl asbestos tile

- Walls: painted

- Ceilings: painted 
The building will be heated by electricity and will have a powered ventilation unit.

Fire protection will be by portable fire extinguishers.

Electrical service will be provided through a step-down transformer from the DWS Facility $4.16 \mathrm{kV}$ feeder.

\subsubsection{Security Console Areas}

The serurity coneolc areas of tle R\&P Facility will be expanded lo accommodate the duditional alarms, signals, and TV monitors required by the DWS Facility.

These extensions (approximately 100 square feet of the Level II security building structure and 50 square feet of the Level I control room structure in the R\&P building) will be designed in accordance with the DOE Manual, Appendix 6301, and the Uniform Building Code.

The building extensions will use the construction materials listed below.

- Floors: concrete

- Interior walls:

- Security building: metal studs with gypsum board - R\&P building: concrete

o Roofs: concrete with built-up roofing over insulation

The interior finishes will be as listed below.

- Floors: vinyl asbestos tile

- Walls: paint

o Ceiling: suspended acoustical tile 
The necessary electrical power, heating and ventilating, and fire protection systems will be extensions of the existing R\&P Facility systems.

\subsubsection{Dry We11 Instrumentation}

See reference drawing Sheet No. 5 .

Each dry well encasement will include provisions for direct measurement of the dry well temperature and pressure and for sampling the interior of the encasement to detect helium or krypton-85 leakage from a canister. The instrumentation and provisions for measurement at each dry well are described in the following paragraphs.

\subsubsection{Dry Well Encasement Temperature}

A sheathed thermocouple within a protective tube, with its sensing junction positioned opposite the midheight of the canister, will be used to measure the exterior surface temperature of each dry well encasement vessel. The thermocouple junction will be located at the lower end of the tube, and the tube will be strap-fastened to the encasement for at least one foot to provide good thermal contact. The upper end of the tube will open into a groundsurface junction box to provide weather protection of the thermocouple leads at the upper end of the tube. The junction box and thermocouple tube will allow easy replacement of the thermocouple.

The temperature measured at the thermocouple junction will be read by a temperature indicator with a digital output, local display, and local alarm capability to indicate unusual temperatures. The indicator output will be recorded asynchronously in a computer format on magnetic tape. The temperature indicator-recorder will be mounted on a monitoring service truck. 


\subsubsection{Dry Well Encasement Pressure and Radioactivity}

A sampling tube in the dry well cover plate will be terminated with a needle valve closure followed by the plug half of a quickconnect, two-way, shutoff coupling. The coupling will permit connection of a gas sampling bottle and pressure transducer but retain encasement integrity. Pressure readings will be transmitted to a pressure indicator-recorder system mounted on a monitoring.service truck. The pressure indicator will have local alarm capability to indicate abnormal pressure. A gasketed, bolted cover will be provided over the valve and quick=cunnecl coupling for protection both against the weather and against accidental mechanical damage. from the transporter or from the monitoring and surveillance or other service vehicles.

Prenumbered and evacuated standard-size (approximately $150 \mathrm{cc}$ ) sample bottles will be delivered by the monitoring service truck to each of the dry wells. After filling a bottle through a portable sampling manifold, the residual volume in the manifold will be purged into a waste gas cylinder. The gas sample bottles will be delivered to a laboratory in the receiving and packaging facility for analysis, decontamination, and reuse.

\subsection{UTILITIES}

\subsubsection{Electrical systems}

Normal and standby electrical power systems will provide a reliable, economical, and safe electrical power supply, for normal operations and standby power for essential demands when the normal power is interrupted. The standby electrical power equipment area will be classified as a vital area. Both the normal and the standby power supply equipment will be installed alongside similar equipment in the R\&P Facility located to the east of the DWS Facility. 
The normal power supply equipment, switchgear, and feeders to the DWS Facility will be sized for the ultimate load. The standby power system and equipment will also be sized for the ultimate load, but only one diesel generator will be installed in the initial phase of construction. A second generator with the same rating will be added to the system when the electrical load reaches half of the ultimate demand.

The power supply bus will supply two storage area feeders. One feeder will supply the security systems on the area perimeter. The other feeder will supply the larger but less critical storage area lighting power demand.

\subsubsection{Applicable Cúdes dild Standards}

The design of the electrical power systems will be in accordance with the latest issue of the following standards and codes as a reference, and adhered to where applicable:

(a) IEEE - Institute of Electrical and Electronic Engineers

(b) NEMA - National Electrical Manufacturers Association

(c) IPCEA - Insulated Power Cable Engineers Association

(d) UL - Underwriters Laboratories, Inc.

(e) ANSI - American National Standards Institute

(f) NESC - National Electric Safety Code

(g) NEC - National Electrical Code (NFPA No. 70 ANSI CI)

(h) IES - Illuminating Engineering Society (Lighting Handbook)

(i) FIA - Factory Insurance Association (Recommended Good Practice for Transformer \& Switchgear Installation)

(j) DOE - Department of Energy (Manual Appendix 6301)

(k) OSHA - Occupational Safety and Health Act 


\subsubsection{Design Requirements}

(a) The electrical system must provide a reliable supply of power.

(b) Voltage regulation of not more than $\pm 5 \%$ will be provided to extend the life and operation of the electrical equipment.

(c) Normal power will be obtained from a commercial utility, and standby power will be provided from a separate source by diesel generators.

(d) To obtain the required reliability, the design must provide for isolation of faults with minimum disturbance to the rest of the system and to generation of standby power.

(e) Upon loss of normal power, all loads on the distribution system must restart automatically when standby power becomes available.

(f) When nnrmal pnwer again becomes available after a power outage, the return to the normal mode of operation must require deliberate action on the part of the operator to switch the standby bus back to normal power.

(g) The safety requirements will include protection of personnel from contact with live components and protection of electric equipment.

(h) Each power system and its components must be accessible for inspection and maintenance.

(i) Upon interruption of normal power, the standby power equipment must be reliable and capable of supplying all load demands essential to safety and security. 
(j) Motors rated less than $200 \mathrm{hp}$ and greater than $1 / 3 \mathrm{hp}$ and speciality machines will generally be supplied at $480 \mathrm{~V}, 3$ phase, $60 \mathrm{~Hz}$.

(k) All intrusion-detection systems will be provided with a standby power supply.

\subsubsection{Power Quality}

Power will be supplied to structures, systems, and components in accordance with the three quality levels, as described below. Quality level requirements are defined in Section 5.

(a) Quality Level I - extension of Level I systems in the R\&P Facility as required by the DWS Facility.

Power will be supplied to each quality Level I structure, system, or component from either of two independent offsite commercial sources. Each commercial power source will be backed by its own independent, onsite, standby diesel-electric generator unit.

(b) Quality Level II - the DWS Facility within the storage area perimeter limits, and also the gatehouse and generator building located in the R\&P Facility.

Each quality Level II structure, system, or component will be supplied with commercial power. The standby power will be supplied by a standby generator unit or units. Systems and components that would fail to function due to commercial power interruption will be supplied from a single standby power source. This single source will serve only the systems and components within the confines of any Level II structure of area. 
(c) Quality Level III - extension of systems in the R\&P Facility as required by DWS Facility.

Each quality Level III structure, system, or component will be supplied with commercial power as described for Level I. Onsite standby power will not be provided.

\subsubsection{Power Description}

\subsection{Normal Power Supply}

Commercial power will be supplied from one of the two $13.8-\mathrm{kV}$, 3-phase, $60-\mathrm{Hz}$ buses located outdoors at the adjacent R\&P Facility substation.

\subsection{Standby Power Supply}

The standby power will be supplied by diesel-generator sets (one initially and one in the future) to the instrumentation, alarms, and lighting. Each standby diesel-generator set and associated switchgear and control equipment will be rated for $750 \mathrm{~kW}$. An essential function of the standhy generators will be to reslure power to cssential qualily level if loads that must maintain security functions but that can accept up to a one-minute interruption in power supply. Upon loss of normal power, the dieselgenerator sets will start automatically. The generators will provide standby power at $4.16 \mathrm{kV}, 3$ phase, $60 \mathrm{~Hz}$, wi.th voltage variation not exceeding $\pm 5 \%$.

Standard metering devices will monitor the generator loads and performance. These devices will include voltmeters, ammeters, and power factor meters. Ground relaying will be installed with an alarm to announce major faults. Standard phase overcurrent protective relaying will be at the generator. 


\section{3.1.5 Power Distribution}

\subsection{Substation}

Commercial power from the R\&P Facility 13.8-kV main substation will be fed via direct buried cable to a 13.8/4.16-kV transformer located adjacent to the DWS Facility standby diesel-generator building. The 4.16-kV secondary transformer will be connected via 5-kV cable in duct and terminated at the 5-kV switchgear inside the generator building.

\subsection{Switchgear}

The indoor switchgear will consist of an assembly of 5-kV metalclad switchgear, including standard protective devices and metering.

The switchgear lineup will consist of two main breakers with automatic transfer equipment, two feeder breakers, and one fuse switch. All breakers will be air-break type, $5 \mathrm{kV}, 1,200 \mathrm{~A}$, with 250 kVA (nominal) interrupting capacity.

\subsection{Distribution Cables}

A 5-kV direct buried cable from one 5-kV feeder breaker will supply eight power centers for the perimeter fence lighting via pad-mounted switches with current-limiting fuses.

A 5-kV direct burial cable from the other 5-kV feeder breaker will supply the four power centers in each dry well storage module for area lighting via pad-mounted switches with current-limiting fuses.

All direct buried cables in the dry well areas will be subjected to above-normal ambient soil temperature due to decay heat from the spent fuel assemblies in the dry wells. Cables will be sized and materials selected to allow for this temperature condition. 


\subsection{Generator(s)}

Standby power will be generated by a diesel electric generator rated to supply $750 \mathrm{~kW}$ at $4.16 \mathrm{kV}$ to the $5-\mathrm{kV}$ switchgear main bus via $5 \mathrm{kV}$ cable in duct.

This generator will be furnished'with all. the provisions for individual operation or parallel operation with a future standby diesel-generator set of the same rating.

\subsubsection{Perimeter Lighting}

Security lighting will be provided by a total of 25030 -foot-high pole assemblies located inside the inner perimeter fence at 100foot intervals. Each of these assemblies will have a 400-W highpressure sodium lighting fixture to provide 0.2 footcandle of illumination throughout the exclusion zone.

\subsubsection{Storage Area Lighting}

During construction of the storage area modules, the yearly increment of storage area lighting will consist of eight 70-foot-high light pole assemblies, with eight 1,000-W high-pressure sodium lighting fixtures on each pole.

\subsubsection{Mobile Lighting}

Two mobile lighting assemblies consisting of a diesel electric generator and pole-mounted lighting fixtures will provide local canister placement area lighting with 100 footcandles at ground level. 


\subsubsection{Principles of Operation}

\subsection{Normal Conditions}

(a) 15-kV Switchgear

Under normal conditions the offsite power will be supplied via a normally closed incoming breaker.

(b) 5-kV Switchgear

The 5-kV switchgear assembly will be energized. The automatic transfer switch will be normally open to the standby generator(s).

(c) $480-V$ Switchgear

The incoming main breakers normally will be closed. Lighting in the storage area and for the exclusion zone will be photo-cell-controlled with remote control override from the site security control center.

\subsection{Failure of Normal Source}

\section{(a) 15-kV Switchgear}

Upon failure of the $13.8-\mathrm{kV}$ source, the main breaker will be opened by manual remote control. Failure of the 13.8-kV sources will deenergize all services of offsite power.

(b) 5-kV Switchgear and Standby' Power Generator

Failure of the power feeder to the 5-kV switchgear lineup will initiate starting of the standby dieselgenerator set(s). The sequencer panel control circuit 
will include an exerciser that will start and stop the diesel engine automatically at regular selected intervals, simulating operation during offsite power interruption. Transfer from normal to standby power will be accomplished automatically with provision for manual override.

\section{(c) $480-V$ Switchgear}

The main breaker connected to the interrupted source will be opened manually.

\subsection{Return to Normal Source}

When offsite power is restored to a stable condition, the transfer from standby to normal power will be by manual. control only.

\subsection{Manual Operation}

Local control of all switchgear and generators will be provided with selector switches, push buttons, indicating lights, and metering.

Remote-control devices will be provided on a panel located in the control room in the R\&P building. The control panel will include a graphic or schematic layout of the DWS Facility electrical power distribution system. Selector switches, push buttons, indicating lights, and metering will also be provided. These devices will control and monitor the loads and performance of each circuit.

\subsubsection{Communications and Fire Alarm Systems}

Communication systems for the facility will include a public address system and a telephone system for inside calls. Security communications will be handled primarily through the adjacent R\&P Facility radio station, which also will have contact with other Hanford patrol activities. Evacuation, radiation alert, and fire alarm systems will be extended from the R\&P Facility. 


\subsubsection{Public Address System}

The public address system will be used for paging and for emergency instructions. This system will be extended from the R\&P Facility and provided with portable speakers for location in active work areas.

\subsubsection{Telephone System}

The telephone system will be an extension of the onsite R\&P telephone system. The system will be extended yearly as the storage areas are expanded.

\subsubsection{Radio Equipment}

Both portable and mobile radio units will be used by the security forces to communicate with the alarm console in the serurity building of the R\&P Facility.

\subsubsection{Fire Alarm System}

The fire alarm system of the R\&P Facility will be extended to serve the new DWS Facility diesel electric generator building. When a fire alarm sounds the following events will occur.

(a) Coded signals, which will identify the location of the alarm, will be transmitted over the paging system. These signals will take priority over all other calls on the paging system.

(b) Fire alarm signals will be transmitted automatically to the central fire station.

(c) Lights on a readout located on the security building's environmental and security consoles will light to show the location of the fire.

(d) A local alarm will sound to warn personnel to evacuate. 


\subsubsection{Monitoring and Surveillance}

The canister in each dry well will be monitored and kept under surveillance throughout its storage life at the DWS Facility: A monitoring and surveillance program will be instituted and maintained to verify that the storage conditions established for the DWS Facility are maintained and the integrity of the dry wells is not compromised or breached.

$\Lambda$ dry well monitoring and surveillanse schedule based on the potential for thermal stress in the encasement vessel will be established for the monitoring and surveillance program. Encasement temperature and pressure are expected to rise quickly during the first year of canister storage, slowly reach a maximum in five to seven years, and then decrease with time. The greatest resultant stress in each dry well encasement will occur in approximately six years. 'Therefore, the frequency of monitoring and surveillance will be greater during the early years of canister storage.

\subsubsection{Monitoring Parameters}

The parameters established for the monitoring and surveillance program will include encasement temperature and pressure, and the presence of helium or radioactive gases. The allowable upper parameter limits established for storage of canisters of spent fuel at the facility will include the following:

(a) Temperature of dry well encasement: $630^{\circ} \mathrm{F}\left(630^{\circ} \mathrm{F}\right.$ corresponds to a maximum fuel element temperature of $675^{\circ} \mathrm{F}$. See Section 4.1.5 for further discussion of heat transfer and temperature considerations.)

(b) Pressure in the dry well encasement: 60 psig (design pressure)

(c) Level of radioactivity in and around the facility: not to exceed 'values in $10^{\circ}$ CFR $20^{\circ}$ 
The objectives of monitoring for radioactivity will be twofold. First, the monitoring activities will determine whether significant amounts, if any, of radionuclides are being released by the DWS Facility. The second objective will be to ensure that the radiation levels in the area around the DWS Facility are not appreciably altered by the operation of the facility.

\subsubsection{Dry Well Monitoring}

Measurement of encasement temperature and pressure, as well as sampling of the encasement interior environment, wi11.be conducted according to an overall schedule established for the facility monitoring and surveillance program. Monitoring service trucks with portable thermocouple and pressure readout and recording instrumentation, pressure gauge and gas sampling manifolds, and sample bottles will be used to measure the environment within each dry well periodically.

Measurement of the dry well encasement exterior surface temperature will provide an indirect measurement of the fuel element temperature and will simplify the encasement design and fabrication by avoiding a thermocouple penetration through the encasement she11. (Heat transfer calculations indicate that an encasement temperature of $630^{\circ} \mathrm{F}$ will correspond to a peak fuel element temperature of $675^{\circ} \mathrm{F}$ conservatively selected as a maximum allowable fucl element temperature for the monitoring and surveillance program at the DWS Facility.)

The pressure in each dry well will also be measured on a scheduled basis to detect any abnormal changes in pressure. Because the partial pressure of the air in the encasement will increase during the first few months after placement of the canister due to an increase in temperature, the pressure will be monitored periodically. Excessive pressure will be relieved through a sampling manifold into an evacuated waste-gas cylinder. 
Samples of encasement air will be withdrawn into an evacuated sample bottle and analyzed in the receiving and packaging or the transfer facility laboratory for evidence of helium or krypton-85 leakage from the stored canister.

\subsubsection{Area and Perimeter Radiation Monitors}

Short-term radiation monitoring will be accomplished with continuous air monitors (CAMs) and ion-chamber-type dosimeters placed strategically around the outside boundary of the citc; with the heaviest concentration of units located downwind from the facility. The CAMs will be of the fixed-filter type and designed to withstand exposure to adverse elements of the environment. The CAMs will activate an audible alarm and lights on the environmental console in the security building of the adjacent receiving and packaging facility and the RAM panel or console at the patrol headquarters if above-normal radiation is detected. The CAMs will be supplied with 120 -volt ac power and will be hard-wired back to the security building. Local indicators will be incorporated into the field electronics to permit calibration checks. The filter papers from the CAMs will be collected periodically and brought to the counting room in the receiving and packaging facility main building for counting.

The ion-chamber-type dosimeter is a fairly sensitive unit for dose measurements and will be used to determine monthly trends of integrated dose rates. These units will be installed at the boundary fence in strategic locations chosen by health physics personnel on the basis of site conditions prior to construction of the dry wells.

Should any of these monitoring devices detect above-normal radioactivity, a truck equipped with a portable moving-filter-type monitor will be used to locate the source of radioactivity. 
The long-term monitoring of the area surrounding the DWS Facility will be conducted using thermoluminescent devices (TLDs). TLDs are less expensive (but also less sensitive) than the ion-chambertype dosimeters and will be used extensively for offsite monitoring to determine long-term integrated dose rates. For comparison, the data on general radiation levels in the area will be collected prior to the time the DWS Facility starts receiving the canistered fuel assemblies. In addition to the TLDs surrounding the facility, TLDs will be strategically located away from the facility in a staggered manner. The heaviest concentrations of TLDs will be in the direction of the closest occupied structures and downwind of the prevailing winds.

\subsubsection{Other Radiation Monitoring Equipment}

Other radiation monitoring and auxiliary equipment will include:
(a) Counting room equipment, including a multichannel analyzer
(b) Hand and foot monitors
(c) Portable survey instruments
(d) Equipment decontamination system

All of the instruments will be off-the-shelf standard production equipment of the latest design. They will be similar to instruments used in other contemporary nuclear facilities. Solid-state circuitry, plug-in component boards, and digital readouts will be used.

The counting room equipment will be located in an adjacent receiving and packaging or transfer facility building. All dosimeters (ion chamber type and TLDs) will be collected periodically and brought into the counting room, where the dose to which they have been exposed will be determined. 


\subsubsection{Wildlife Activity}

Wildlife in the area may activate the exclusion fencing intrusiondetection system. Therefore, a cyclone fence (approximately four feet high and without electronic intrusion detection) located outside of the outer exclusion fence and beyond the vehicle barrier ditch will be provided to minimize the number of false alarms.

Wildlife in the area will be trapped and examined for radioactive contamination or exposure.

\subsubsection{Fuel 0 i1}

No. 2 fuel oil will be used by the facility vehicles and the diesel-electric generator(s). The fuel oil will be delivered to two storage tanks sized for seven days of operation. The storage tanks will be underground and designed to meet quality Level II earthquake requirements.

Two fuel oil transfer pumps will deliver fuel oil to individual day tanks serving the diesel electric generator(s). Two fuel dispensing pumps will be used to deliver fuel to the facility vehicles. 


\section{PERFORMANCE REQUIREMENTS}

The DWS Facility will provide the facility and equipment for interim surface storage of spent BWR and PWR fuels for 50 years.

\subsection{FUNCTIONAL CRITERIA}

The DWS Facility conceptual design will be in accordance with the following criteria:

(a) The planned iife of the facility is 65 years.

(b) The planned storage life of canisters in dry wells is 50 years.

(c) The facility will be licensed by the NRC.

(d) The facility will be operational in July 1986 for storage of spent fuel discharges from commercial power reactors in the United States accumulated through $\mathrm{CY}$ 1990.

(e) The facility will be designed to facilitate decommissioning when its useful life is ended.

(f) Provisions will be made to meet all DOE and NRC safeguard requirements.

(g) The canisters will be retrievable throughout their 50-year storage life.

\subsubsection{Processing Capacity}

(a) The facility will store spent. PWR and BWR fuel assemblies at an annual rate of 3,300 MTU. 
(b) The facility will receive packaged spent fuel from a Spent Fuel Receiving and Packaging facility ${ }^{1}{ }^{2}$ or a Packaged Fuel Transfer Facility ${ }^{3}$ ready for storage in a drywe11.

Each canister will contain either one PWR fuel assembly or three BWR fuel assemblies, with a maximum of one kilowatt of decay heat per canister.

(c) The average processing rate will be 13 MTU per operating day.

(d) Receiving System

Type: dual cab transporter

Capacity: one canister per transporter

Receiving Ratio: ratio of PWR/BWR assemblies received will be $2: 3$.

\subsubsection{Spent Fuel Canister Acceptance Criteria}

(a) The nominal age of fuel received at the site after reactor discharge will be five years. For purposes of heat transfer calculations, all fuel in storage will be conservatively assumed to be five-year-old PWR fuel. The facility will be capable of occasionally handling fuel as young as two years out-of-reactor.

1. W. H. Kelso, "Functional Design Criteria, Spent Unreprocessed Fuel Receiving, Lag Storage, and Packaging Facility," RHO-CD223 (unclassified), December 16, 1977.

2. "Spent Fuel Receiving and Packaging Facility Conceptual Design Report," Draft, RHO-CD-506 (unclassified), September 1978.

3. S. M. Berry and W. H. Peter, "Functional Design Criteria, Packaged Fuel Transfer Facility," RHO-CD-436 (unclassified), July 1978. 
(b) The facility will receive all BWR and PWR spent fuel that will be produced through CY 1990, in accordance with Table 4-1.

(c) Spent fuel physical characteristics will be in accordance with Table 4-2.

(d) The design maximum center pin cladding temperature will be $715^{\circ} \mathrm{F}$.

(e) Nominal thermal decay heat for five-year-old fuel will be $0.964 \mathrm{~kW}$ for one PWR. fuel assembly per canister and $0.930 \mathrm{~kW}$ for three BWR assemblies per canister.

\subsubsection{Transporter/Cask Acceptance Criteria}

(a) Canister containment during loading, transport, and unloading will be provided by a vertical cylindrical shield cask. The cask will be provided with a bottom gate for loading and unloading.

(b) The shield cask will be mounted on a transporter vehicle.

(c) The transporter will be capable of vertically aligning the cask and centering it over a dry well for placement or retrieval of a canister.

(d) Gravity sand-plug placement and vacuum removal systems will be mounted on the transporter.

(e) The cask will have a hoisting mechanism to permit canister placement and retrieval. 
TABLE 4-1

Quantities of LWR Spent Fuel Assemblies Discharged

$\begin{array}{rrrrr}\text { Year } & \text { BWR } & \text { PWR } & \text { Total } & \text { Cumulative } \\ 1977 & 3,300 & 2,200 & 5,500 & 15,900 \\ 78 & 3,750 & 2,250 & 6,000 & 21,900 \\ 79 & 4,200 & 2,550 & 6,750 & 28,650 \\ & & & 7,600 & 36,250 \\ 1980 & 4,800 & 2,800 & 7,600 & 44,550 \\ 81 & 5,250 & 3,050 & 8,300 & 53,800 \\ 82 & 5,550 & 3,700 & 9,250 & 64,500 \\ 83 & 6,450 & 4,250 & 10,700 & 76,550 \\ 84 & 7,200 & 4,850 & 12,050 & 89,550 \\ 85 & 7,800 & 5,200 & 13,000 & \\ & & & & 13,850 \\ 1986 & 8,250 & 5,600 & 13,850 & 103,400 \\ 87 & 8,850 & 5,850 & 14,700 & 118,100 \\ 88 & 9,150 & 6,250 & 15,400 & 133,500 \\ 89 & 9,750 & 6,600 & 16,350 & 149,850 \\ 90 & 10,500 & 7,000 & 17,500 & 167,350 \\ & & & & \\ 1991 & 11,100 & 7,450 & 18,550 & 185,900 \\ 92 & 11,850 & 7,900 & 19,750 & 205,650 \\ 93 & 12,600 & 8,350 & 20,950 & 226,600 \\ 94 & 13,200 & 8,850 & 22,050 & 248,650 \\ 95 & 13,950 & 9,300 & 23,250 & 271,900 \\ & & & & \\ 1996 & 14,550 & 9,800 & 24,350 & 296,250 \\ 97 & 15,300 & 10,200 & 25,500 & 321,750 \\ 98 & 15,900 & 10,650 & 26,550 & 348,300 \\ 99 & 16,650 & 10,950 & 27,600 & 375,900 \\ 2000 & 16,950 & 11,350 & 28,300 & 404,200\end{array}$

NOTE: This table is based on Hanford Engineering Development Laboratory (HEDL) projections of 400 GWe for the year 2000. 
TABLE 4-2

Physical Characteristics of Unirradiated LWR Fuel Assemblies

$\begin{array}{lcc} & \frac{\text { BWR }}{4.57} & \frac{\text { PWR }}{5.08} \\ \text { Overall Assembly Length }(\mathrm{m}) & 14.0 \times 14.0 & 21.7 \times 21.7 . \\ \text { Cross Section (cm) } & 4.17 & 4.11 \\ \text { Fuel Element Length }(\mathrm{m}) & 3.81 & 3.81 \\ \text { Active Fuel Height }(\mathrm{m}) & 1.45 & 1.12 \\ \text { Fuel Element OD (cm) } & 8 \times 8 & 17 \times 17 \\ \text { Fuel Element Array } & 275.0 & 680.0 \\ \text { Assembly Total Weight (kg) } & 183.3 & 461.4 \\ \text { Uranium/Assembly (kg) } & 208.0 & 523.4 \\ \text { UO,/Assembly (kg) } & 57.9^{\mathrm{a}} & 108.4^{\mathrm{b}} \\ \text { Zircaloy/Assembly }(\mathrm{kg}) & 9.77^{\mathrm{c}} & 26.1^{\mathrm{d}} \\ \text { Hardware/Assembly }(\mathrm{kg}) & 67.7 & 134.5 \\ \text { Total Metal/Assembly }(\mathrm{kg}) & & \end{array}$
a. Includes Zircaloy fuel element spacers.
b. Includes Zircaloy control rod guide thimbles.
c. Includes SS tie-plates and Inconel springs.
d. Includes $10 \mathrm{~kg}$ SS nozzles and Inconel 718 grids. 


\subsubsection{Radiation Shielding Criteria}

Shielding for the facility will be designed so that the exposure of personnel will be maintained "as low as reasonably achievable" (ALARA), considering the magnitude of dose rates from equipment, facility layout, and time for operations, such as canister placement or retrieval, maintenance, monitoring and surveillance, and testing, etc. In addition, the radiation shielding will be designed so that the radiation levels specified in 10 CFR 20 are not exceeded during normal operation or abnormal operational occurrences.

\section{1:4.1 Source Term}

The neutron and gamma ray source term will be based on five-yearold spent fuel assemblies that have received an average exposure of 33,000 MWD/MTU at a specific power of $37.5 \mathrm{MW} / \mathrm{MTU}$ for PWRs, and an average exposure of 27,500 MWD/MTU at a specific power level of 25. $9 \mathrm{MW} / \mathrm{MTU}$ for BWRs.

\subsubsection{Zone and Dose Requirements}

Dose rates at various zones within the facility boundary are established by considering the access time required in each zone. These rates are summarized in Table 4-3. 
TABLE 4-3

\section{Radiation Dose Rates}

RadiationLevel Zones

1
2

\section{Access Time}

Unlimited

access

Controlled un-

limited access

for 40 hour/week
Area

Designation

All roadways and patrol space

Dry well storage
Dose Rate

(mrem/hour)

Less than

0.25

$0.25-2.5$

\subsubsection{Heat Transfer and Dry Well Spacing}

A rectangullar dry wcll array will a dry well spacing of 17 feet was selected for the 50-year storage of canisters containing 5-year-old spent fuel assemblies. The selection was made after evaluation of two-dimensional thermal analyses of the dry well exterior and two-dimensional analyses of the dry well interior. 1 This spacing was conservatively based on results for a soil thermal conductivity of $0.15 \mathrm{~B} \mathrm{hr}^{-1} \mathrm{ft}^{-1} \mathrm{~F}^{-1}$, the lowest value anticipated at the Hanford reference site. The analyses indicate that this spacing will result in a maximum fuel rod cladding temperature conservatively below the maximum allowable temperature of $715^{\circ} \mathrm{F}$ for the fuel rod cladding recommended by BNWL. 2

Figures 4-I and 4-2 illustrate isotherms calculated for characteristic storage times of 5 years and 35 years, respectively. In the reference region outlined in each figure, the soil temperatures are shown to be substantially higher than the level of $63^{\circ} \mathrm{F}$ assumed to exist prior to canister placement in the dry well.

1. "Spent Fuel Handling and Packaging Drywell Concept Transient Heat Trasfer Calculation," BNWL Letter Report from C. Beck to K. Henry of RHO, May 16, 1978.

2. "Spent Unreprocessed Fuel Facility Engineering Studies,: Report RHO-LD-2, February 1978.

3. Ibid. 


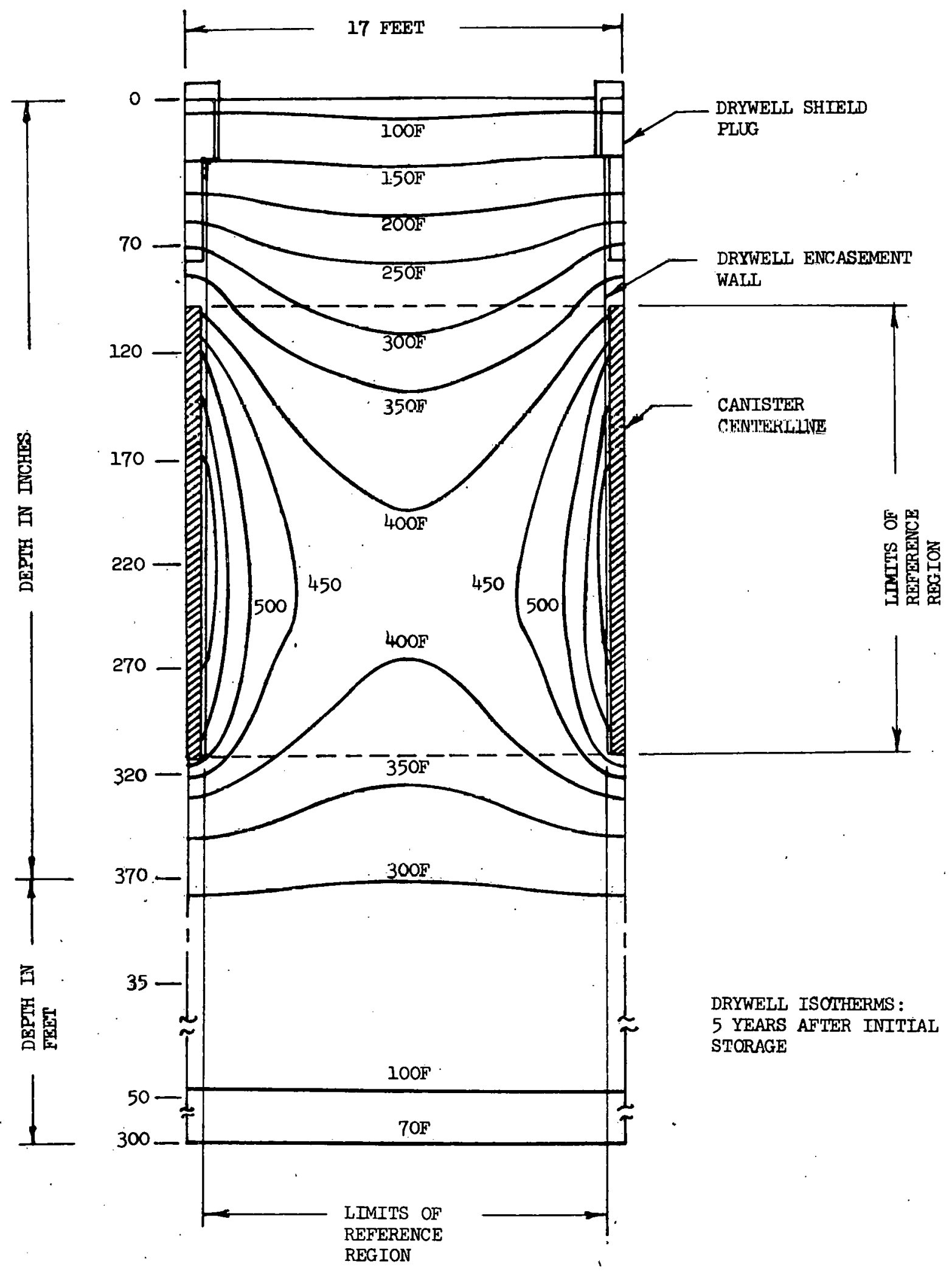

FIGURE 4-1 


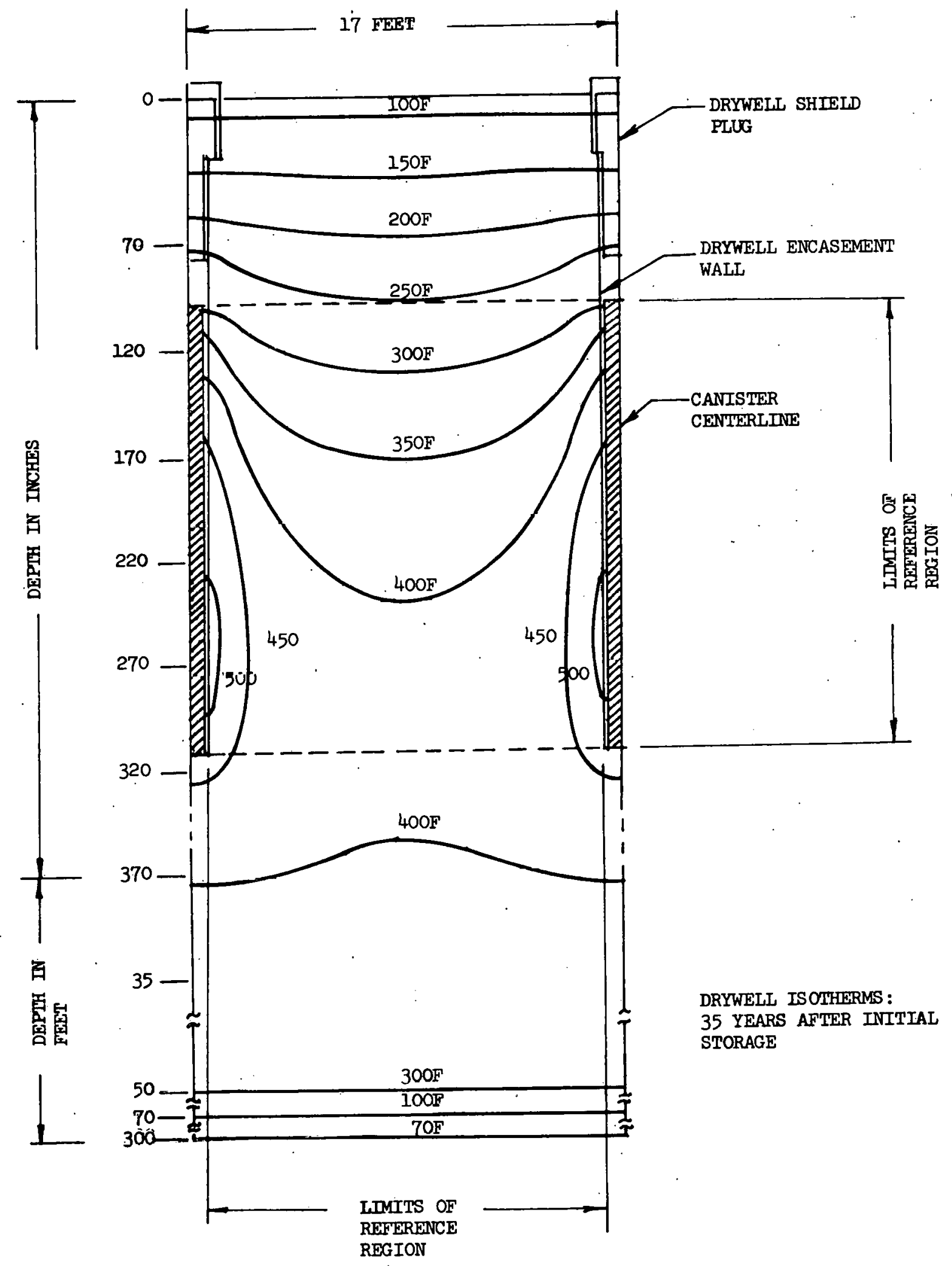

FIGURE $4-2$ 
During the first year of storage, temperatures in the reference region will rise to within $100^{\circ} \mathrm{F}$ of those shown in Figure 4-1. Temperatures in the reference region will then continue to rise steadily to peak levels, which will be achieved approximately 6 years after initial storage, and will subsequently decrease to the temperatures shown in Figure 4-2. In contrast, a temperature of approximately $85^{\circ} \mathrm{F}$ will be maintained at the ground surface due to convection of heat to the ambient air.

Although not shown, a peak canister temperature of $635^{\circ} \mathrm{F}$ and an' encasement wall temperature of $630^{\circ} \mathrm{F}$ were calculated to occur 6.2 years after initial storage. The corresporiding maximum fuel rod cladding temperature was $675^{\circ} \mathrm{F}$. These temperatures will be we 11 below the maximum allowable temperature of $715^{\circ} \mathrm{F}$ for the fue 1 rod cladding recommended by BNWL.

\section{2 FACILITY OPERATING REQUIREMENTS}

The operation of the DWS Facility is based on a steady supply of canisters containing LWR spent fuel assemblies with decay heat and dimensional characteristics within the boundaries set forth in the spent fuel canister acceptance criteria.

Operating requirements include:

(a) A storage system compatible with spent fuel canister acceptance criteria, the use of dual-cab transporters, and transport-cask handling systems

(b) Isolation and confinement of radioactive materials to meet all federal, state, and local regulations

(c) Strict accountability of spent, fuel inventory

(d) Security, monitoring, and surveillance 
The following paragraphs discuss these operating. requirements in further detail.

\subsubsection{Receiving and Storage}

(a) Number of operating days per year: 250

(b) Receiving-storage shifts: 5 days per week, three 8 -hour shifts

(c) Receiving-storage capacity: average of 27 canisters per day

(d) Redundancy: all transporters, casks, and mechanical equipment, including welding and cutting equipment, will be provided with onsite backup.

\subsubsection{Accountability}

Strict control of canister inventory will be maintained from the time the canisters arrive at the storage area through the time they are retrieved and shipped to a repository. Accountability will include a physical count and verification of item identification codes, using manual and data acquisition accounting methods and cross-checking to positively establish and maintain the identity, location, and physical condition of each canister throughout its storage life at the DWS facility. Overall accountability control will be maintained by an Accountability Control and Data Center located in a receiving and packaging facility or transfer facility.

\subsubsection{Security and Surveillance}

Security and surveillance will be in accordance with applicable federal regulations. Physical protection will be provided for the 
facility, and additional protection and safeguards will be provided for designated vital areas. Protection of nuclear material will be continuous from the time it passes through the storage facility perimeter exclusion fence until it is returned to a receiving and packaging facility or transfer facility for protective custody and subsequent handling. 


\section{QUALITY LEVELS AND CODES AND STANDARDS}

\subsection{FACILITIES AND EQUIPMENT CLASSIFICATIONS}

The purpose of the facilities and equipment classification system is to provide a basis for determining the relative stringency of design requirements and the levels of quality to be applied to structures, systems, and components of the DWS Facility. This facility will be licensed by the NRC.

Structures, systems, and components will be classified into three levels on the basis of their importance to nuclear safety, operational requirements, and required level of quality.

Section 3 identifies Level I, II, and III structures. The quality assurance programmatic requirements are discussed in section 8 .

\subsubsection{Quality Assurance Level I Items}

Quality assurance Level I items are those systems or portions of systems, structures, or components whose failure might cause or increase the severity of a release of radioactivity or of materials hazardous or toxic to the environs, structures, and components vital to the safe shutdown or isolation of the process system.

Examples of quality assurance Level I items are dry well encasement vessels, nuclear safety instrumentation, effluent monitors, and transport shield casks.

\subsubsection{Quality Assurance Level II Items}

Quality assurance Level II items are those systems or portions of systems, structures, or components that are important to the operation of the process or system, but are not essential to safe shutdown and isolation. 
Examples of quality assurance Level II items are monitoring instrumentation and fire detection systems.

\subsubsection{Quality Assurance Level III Items}

Quality assurance Level III items are structures and equipment that are related to the process or system operation, that are not essential to safe shutdown, but that do provide a function or service to the facility.

Quality assurance Level III also applies to those items that are commercial, off-the-shelf items for which existing commercial quality control practices are adequate. Quality assurance Level III commercial items may be used in $Q A$ Level I and QA Level II systems with appropriate testing or documented analysis to verify utility in the particular application.

Examples of quality assurance Level III items are heating and air conditioning systems, potable water systems, sewage systems, cold drain systems, low-pressure steam systems, lighting systems, transportation systems, and brick and mortar facilities, except where quality Levels I or II definitions dictate otherwise.

\subsection{ENGINEERING AND CONSTRUCTION CODES AND STANDARDS}

The design and construction of the facility structures, systems, and components of quality Level II and Level III will be in accordance with the applicable sections of the latest edition of the "National Consensus" codes and standards as developed by organizations such as those listed below. Nuclear safety design requirements for quality Level I items are discussed in Section 5.3 . 


\subsubsection{General Design and Quality Assurance and Construction}

Standards

DOE Manual, Appendix 6301, "Facilities General Design

Criteria"

DOE Manua1, Chapter 0505, "Construction Safety"

DOE Manual, Chapter 0550, "Occupational Safety"

American Association of State Highway and Transportation Officials Standards

American Concrete Institute

American Institute of Steel Construction

American National Standards Institute

American Society of Heating, Refrigeration and Air Conditioning Engineers

American Society of Mechanical Engineers

American Society for Testing and Materials

Institute of Electrical and Electronics Engineers

Instrument Society of America

National Fire Protection Association

Occupational Safety and Health Administration

Underwriters Laboratories, Inc.

Uniform Building Code

10 CFR 50 Appendix B

Rockwell Hanford Operations QA Manual

\subsubsection{Seismic Design Standards}

Seismic design and construction standards will comply with the applicable requirements of the following:

DOE Manual, Appendix 6301, "Facilities General Design

Criteria"

Hanford Plant Standards, SDC-4.1, "Design Loads for

Structures"

Uniform Building Code 


\subsubsection{Wind Design Codes and Standards}

Wind design and construction standards will comply with the applicable requirements of the following:

DOE Manual, Appendix 6301, "Facilities General Design

Criteria"

Hanford Plant Standards; SDC-4.1, "Design Loads for

Structures"

ANSI A58.1, "Building Code Requirements for Minimum Design Loads in Buildings and Other Structures"

\subsubsection{Reinforced Concrete and Structural Steel Codes and Standards}

Concrete and steel building and structure design and construction will comply with the applicable requirements of the following:

DOE Manual, Appendix 6301, "Facilities General Design Criteria"

ACI-318, "Building Code Requirements for Reinforced Concrete" AISC "Specifications for the Design, Fabrication and Erection of Structural Steel for Buildings"

ANSI N101.6, "American National Standard Concrete Radiation Shields"

\subsubsection{Industrial Safety Standards}

Design and construction of the entire facility will specifically comply with the requirements of the Occupational Safety and Health Administration Standards and Regulations, Volume I, "General Industry Standards," and all other applicable standards referenced in DOE Manual, Chapter 0550. Where conflict exists, the more stringent will apply. 


\subsection{NUCLEAR SAFETY DESIGN REQUIREMENTS}

\subsubsection{NRC Regulatory Guides and Other Requirements}

\subsubsection{Regulatory Guides}

While not specifically written to apply to spent fuel storage facilities, some NRC Regulatory Guides provide meaningful guidance. for the design of such a facility. The following regulatory guides are to be considered in the conceptual design of the facility:

Regulatory Guide 1.6, "Independence Between Redundant Standby (On-site) Power Sources and Between Their Distribution Systems"!

Regulatory Guide 1.9, "Selection of Diesel Generator Set Capacity for Standby Power Supplies"

Regulatory Guide 1.13 (Rev. 1), "Spent Fuel Storage Facility Design Basis"

Regulatory Guide 1.21 (Rev. 1), "Measuring, Evaluating and Reporting Radioactivity, in Solid Wastes and Releases of Radioactive Materials in Liquid and Gaseous Effluents from Light Water Nuclear Power Plants"

Regulatory Guide 1.23, "On-site Meteorological Programs" Regulatory Guide 1.25, "Assumptions Used for Evaluating the Potential Radiological Consequences of a Fuel Handling Accident in the Fuel Handling and Storage Facility for Boiling and Pressurized Water Reactors"

Regulatory Guide 1.29 (Rev. 2), "Seismic Design

Classification"

Regulatory Guide 1.75 (Rev. 1), "Physical Independence of Electric Systems"

Regulatory Guide 1.76, "Design Basis Tornado for Nuclear Power Plants"

Regulatory Guide 1.101, "Emergency Planning for Nuclear Power Plants" 
Regulatory Guide 1.102 (Rev. 1), "Flood Protection for Nuclear Power Plants"

Regulatory Guide 1.120 (Rev. 1), "Fire Protection Guidelines for Nuclear Power Plants".

Regulatory Guide 1.60, "Design Response Spectra for Seismic Design of Nuclear Power Plants"

Regulatory Guide 1.61, "Damping Values for Seismic Design of Nuclear Power Plants"

Regulatory Guide 3.24, "Guidance on the License Application, Siting, Design, and Plant Protection for an Independent Spent Fuel Storage Installation"

Regulatory fulde 3.4, "Nuclear Criticality in Safety.

Operation with Fissionable Material Outside Reactors" Regulatory Guide 5.12, "General Use of Locks in the Protection and Control of Facilities and Special Nuclear Materials"

Regulatory Guide 5.29, "Nuclear Material Control Systems for Nuclear Power Plants"

Regulatory Guide 5.44, "Perimeter Intrusion Alarm System" Regulatory Guide 5.52, "Standard Format and Content for the Physical Protection Section of a License Application (For Facilities other than Nuclear Power Plants)"

Regulatory Guide 5.7, "Control of Personnel Access to Protected Areas, Vital Areas, and Material"

Regulatory Guide 8.8, "Information Relevant to Ensuring That Occupational Radiation Exposures at Nuclear Power Stations Will be as Low as is Reasonably Achievable"

\subsubsection{General Requirements}

In addition to the NRC-promulgated regulatory guides, the following general requirements (based on existing or proposed NRC guidance) will be used in the facility design and construction. 


\subsection{Quality Standards and Records}

Level I structures, systems, and components will be designed, fabricated, erected, and tested in accordance with the quality assurance criteria discussed in Section 8.1 of this document. Appropriate records of the design, fabrication, erection, and testing of structures, systems, and components important to nuclear safety will be maintained by or under the control of the facility licensee throughout the life of the facility.

\subsection{Protection Against Environmental Conditions, Natural Phenomena, and Missiles}

Structures, systems, and components important to safety will be designed to withstand the effects of and to be compatible with the facility environmental conditions associated with operation, maintenance, facility shutdown, testing, and accidents.

Structures, systems, and components important to nuclear safety will be designed to withstand the effects of natural phenomena such as earthquakes, tornadoes, lightning, hurricanes, and floods without impairing their capability to perform safety functions. The principal design criteria for these structures, systems, and components will include:

(a) Resistance to the most severe of the natural phenomena reported for the site and surrounding area, with appropriate modifications to take into account the limited quantity of the historical data and the period of time in which the data have been accumulated

(b) Safety features to cope with combinations of the effects of accident conditions and the effects of natural phenomena 
(c) Features that provide for the function of safety equipment under emergency conditions, confinement of radioactivity during the emergency, and return to normal operation after the emergency

Capability for determining the intensity of natural phenomena that may occur for comparison with design basis of structures, systems, and components important to safety will be provided.

Structures, systems, and components will be appropriately protected against dynamic effects of events that could occur either inside or outside of facility structures.

\subsection{Protection Against Fires and Explosions}

Structures, systems, and components important to nuclear safety will be designed and located so as to continue to perform their safety functions effectively under fire and explosion exposure conditions. Noncombustible and heat-resistant materials will be used whenever practical throughout the facility, particularly in locations vital to the functioning of confinement barriers and systems. Explosion and fire-detection, alarm, and suppression systems will be designed and provided with sufficient capability to minimize the adverse effects of fires and explosions on structures, systems, and components important to safety. The design of the fire suppression system will include provisions to protect against adverse effects in the event of system operation or failure.

\subsection{Sharing of Structures, Systems, and Components}

Structures, systems, and components important to safety will not be shared with other plants of any type. 


\subsection{Testing and Maintenance of Systems and Components}

Systems and components that have nuclear safety-related functions will be designed to permit inspection, maintenance; and testing to assure their continued functioning for the life of the facility.

\subsection{Emergency Capability}

Structures, systems, and components important to nuclear safety will be designed to assure the proper performance of safety equipment and expeditious handling of an emergency. The design will assure the capability of onsite facilities and the availability for use, as necessary, of offsite facilities and services, such as hospitals, fire and police departments, ambulance service, and utility personnel.

\subsection{Confinement Barriers and Systems}

The total confinement system will consist of two or more individual confinement barriers and systems that successively prevent the release of radioactivity to the environment. The confinement system will be designed to protect against radiation release due to accidents or external natural phenomena and will be fabricated, erected, tested, and maintained to preclude abnormal leakage, rapid failure propagation, or gross rupture during the design life.

\subsection{Instrumentation and Control Systems}

Instrumentation systems will be provided to monitor nuclear safetyrelated variables over anticipated ranges for normal operation, for abnormal operation, and for accident conditions. These systems will be provided with engineered safety features in the redundancy required to assure adequate safety of the storage operations. The variables that require constant surveillance include the overall 
confinement system and each dry well confinement barrier. Instrumentation will be designed to assure a demonstrated acceptable state if conditions, such as loss of energy or motive power, or adverse environmental conditions, are experienced.

All safety monitoring systems will fail to the alarm mode and indicate alert as well as alarm conditions. These two-level alarms will be used to detect changes in conditions and will alert personnel who may then take the necessary corrective action, unless cost-benefit analyses indicate this approach to be too cưstly.

\subsection{Nuclear Criticality Safety Margins}

The design of storage systems will include margins of safety for the nuclear criticality parameters that are commensurate with the -uncertainties in the process and storage conditions, in the data and methods used in calculations, and in the nature of the immediate environment under accident conditions. All storage systems will be designed to maintain a subcritical state ( $\left.K_{\text {eff }} \leq 0.95\right)$ and to assure that no nuclear criticality accident can occur unless at least two unlikely, independent, and concurrent or sequential changes have occurred in the conditions essential to nuclear criticality safety.

\subsection{Access Control}

The facility will be designed so that access to the facility will be controlled to mitigate the potential spread of contamination within or from the facility. The facility will be designed so that the spread of contamination can be monitored and controlled. In addition, access will be controlled to safeguard the facility and to provide sufficient security measures to assure the protection required for facility licensing. 


\subsection{Radiation Shielding}

Shielding will be designed to assure that dose rates in accessible areas are compatible with practical exposure times and that resulting doses are consistent with regulations pertaining to radiation protection.

\subsection{Radiation Alarm Systems}

Radiation alarm systems will be provided to warn facility personnel of significant increases in radiation levels in normally accessible spaces and of excessive radioactivity releases in plant effluents. Such systems will be designed with redundancy and with the capability to test their efflclency of operation.

\subsection{Effluent Monitoring}

All facility effluent systems will be designed to include means for measuring and recording the amount of radionuclides in any effluent. The flow of environmental diluting media, either air or water, will also be determined.

\subsection{Effluent Control}

The design of the facility will include means to control the release of radioactive effluents, whether gas, liquid, or solid, during normal operations as well as under accident conditions. Systems provided to guard against the release of radioactive materials will be designed to be monitored and tested and will be provided with alarms.

\subsection{Fuel Storage Systems}

Fuel storage and other systems that might contain or handle radioactive materials will be designed to assure adequate safety under normal and accident conditions. These systems will be designed with the following features: 
(a) Capability to test components important to nuclear safety

(b) Suitable shielding for radiation protection under normal and accident conditions

(c) Confinement systems

(d) Heat-removal capability that is testable and reliable to a level that reflects the importance of nuclear safety

\subsection{Assurance of Quality for Physical Security}

The structures, systems, components, and equipment of the facility with features important to physical protection against radiological sabotage will be designed, fabricated, erected, and tested to provide adequate assurance that such structures, systems, components, and equipment will perform satisfactorily in service.

\subsection{Process, Components, and Material Isolation}

The design will include provisions for isolation (e.g., controlled access, automation, or remote-handling techniques) of vital areas to limit access to such areas to individuals with authorized access for essential purposes.

\subsection{Equipment Design and Location}

Equipment not identified as process equipment or vital equipment, to the maximum extent practicable, will not be located in a vital area. When such equipment is located in a vital.area, provision will be made to limit the necessity for access to such equipment. 


\subsection{Physical Barriers}

The design will incorporate a double barrier concept consisting of an outer physical barrier that encompasses one or more inner physical barriers, passage through each of which is controlled. The outer physical barrier will be separated from the inner physical barrier or barriers so that the intervening area can be monitored or checked periodically to detect the presence of individuals or vehicles between the barriers and approaching either barrier in sufficient time to initiate the necessary guard action or notify the local law enforcement agency or both.

Barrier provisions will be made for protection of vital areas; however, functions that do not require access to such areas (e.g., food service and administrative functions) wili be carried on outside the vital area barrier.

\subsection{Facility Isolation}

The design will include an exclusion zone on both sides of the outer physical barrier. This zone will be provided with a monitoring system to detect the presence of individuals or vehicles in sufficient time to initiate the necessary guard action or to notify the local law enforcement authority or both. Parking facilities inside the outer barrier will be limited to authorized service vehicles.

\subsection{Protective Lighting}

Clear areas between the inner and outer barriers, the exclusion zone around the outer barrier and vital arca perimeters, and the entire dry well storage area will be provided with illumination of at least 0.2 footcandle. 


\subsection{Personnel, Package, and Vehicle Control}

The design will include provision for control of all points in the outer and inner physical barriers used for personnel, package, or vehicle access so that identity and authority for access can be verified. Any unmanned exits in a physical barrier, such as emergency doors or gates, will be operable from the inside only. All passage points in each inner physical barrier and all emergency exits in the outer physical barrier will be provided with tamperindicating alarm systems.

The design will include provigions at all dicess pulnts in the outer barrier to allow search of entering individuals and packages for items that could be used for radiological sabotage and/nr removal of nuclear material. Any equipment or procedures used will be able to detect the presence of items such as firearms, explosives, and incendiary devices.

\subsection{Surveillance Capability}

The design will include provisions (e.g., illumination, line-ofsight, etc.) that will permit continual direct or remote observation of vital areas. Provision also will be made for vital areas to be locked and protected by intrusion alarm systems when unoccupied.

\subsection{Emergency Monitoring Capability}

The design will include provisions for backup systems, such as standby power, redundant hardware, and procedural options, so that in the event of power failure, equipment malfunction, or guard incapacitation, a level of protection consistent with safety requirements can be provided commensurate with that afforded by the provisions of Sections 5.3.1.2.19 through 5.3.1.2.23. The standby. power system will be independent of any outside power source. 


\subsection{Intrusion Alarm System}

A11 monitoring-system alarms (in compliance with provisions of Sections 5.3.1.2.19, .20,.23, and .24) will annunciate in a continuously manned alarm station located within the protected area and in at least one other continuously manned station, not within the protected area; so that a single action cannot prevent a.call for assistance or other response to an alarm. All alarms will be self-checking and tamper-indicating. The annunciation of an alarm at the onsite central alarm station will indicate the type of alarm (e.g., intrusion alarm, emergency exit alarm, etc.) and location.

\subsection{Communications}

The design will include provisions for two-way radio voice communication, which will terminate at a continuously manned central alarm station within the outer barrier of the receiving and packaging facility. There will also be telephone service via the manned central alarm station between local law enforcement authorities and the facility. The design also will include provisions to permit continuous. communications between the central alarm station and each guard or watchman on duty at the DWS Facility.

\subsubsection{Single-Failure Criterion}

Level I systems and components will be considered important to nuclear safety and as such will be designed against a single failure.

\subsubsection{Definition}

Appendix A of 10 CFR 50 defines single failure in the following way: 
A single failure means an occurrence which results in the loss of capability of a component to perform its intended safety functions. Multiple failures resulting from a single occurrence are considered to be a single failure. Fluid and electric systems are considered to be designed against a single failure if neither (1) a single failure of any active component (assuming passive components function properly) nor (2) a single failure of a passive component (assuming active components function properly) results in a loss of the capability of the system to perform the safety functions.*

*Single failures of passive components in electrical systems should be assumed in designing against a single failure. Ihe conditions under which a single railure of a passive component in a fluid system should be considered in designing the system against a single failure are under development.

The following definitions are associated with single failure:

\section{(a) Active Component Failure}

An active component is one in which mechanical movement must occur for the component to achieve the intended function. An active failure is the failure of an active component to function in its required manner, but with no loss of structural integrity.

(b) Passive Component Failure

A passive component is one in which no mechanical movement is required for the component to achieve its intended function. A passive failure is the structural failure of a passive component so that it cannot perform its intended function.

(c) Single Operator Failure

A single operator failure is any single incorrect or omitted action by a human operator. 


\subsubsection{Application}

The definitions presented in Section 5.3.2.1 will apply when considering the single-failure criterion. Multiple failures resulting from a single occurrence are considered to be a single failure, as defined in Section 5.3.2.1.

Fluid systems or portions thereof that are important to nuclear safety will be designed to ensure that, for onsite electric power system operation (assuming offsite power is not available) and for offsite electric power system operation (assuming onsite power is not available), the system can accomplish its nuclear safety function assuming a single failure (as defined in Section 5.3.2.1).

In the evaluation of an active failure of a component, the loss of that component's ability to function in its required manner as a result of mechanical, hydraulic, pneumatic, or electrical malfunction associated with the component should be considered. The loss of the component's structural integrity need not be considered in the evaluation; it would be considered separately as a passive failure.

Systems that are important to nuclear safety and that require manual operations to initiate or control the required nuclear safety functions will be designed so that, without a concurrent active or passive failure, the system can perform its safety function with a single operator failure. Where it can be shown that suitable time (a minimum of 30 minutes, but possibly longer depending on the situation) and means for detection and evaluation of the operator failure are available, correction of the operator failure may be assumed.

In applying the single-failure criterion, the evaluation will include the system performing the nuclear safety function and the related service (or supporting) systems that it requires in order 
to perform that function. While each of the systems referred to will be designed to meet the single-failure criterion, only one single failure will be assumed to occur in the aggregate of the safety systems and related service (or support) systems in the plant.

\subsubsection{Severe Natural Phenomena}

With respect to Section 5.3.1.2.2, the following guidance and clarification are provided.

\subsubsection{Sejsmic Events}

\subsection{Design Basis Earthquake (DBE)}

Structures, systems, and components classified as Level I will be designed so that there will be no loss of nuclear safety functions when subjected to the DBE. For the purpose of the conceptual design effort, the seismic event that has a horizontal component of acceleration of $0.25 \mathrm{~g}$ at the site was defined as the DBE. The vertical component of acceleration is $0.167 \mathrm{~g}$.

\subsection{Operating Basis Earthquake (OBE)}

The OBE is defined as that seismic event that structures, systems, and components required for normal facility operation are designed to withstand with no loss of operability. The OBE is defined as having a vibratory ground motion at least one half that of the DBE.

\subsubsection{Tornado and Tornado-Generated Missiles}

\subsection{Design Basis Tornado (DBT)}

The DBT that Level I structures, systems, and components are designed to withstand, or be protected from, with no loss of 
nuclear safety function is a tornado that has the characteristics. defined in NRC Regulatory Guide 1.76; "Design Basis Tornado for Nuclear Plants," for Region III.

\subsubsection{Operating Basis Wind (OBW)}

The OBW is defined as the fastest mile of wind for the site with a 100-year mean recurrence velocity, based on ANSI A58.1.

\subsubsection{Design Basis Flood (DBF)}

The DBF is defined as the worst-probable flood at the facility site that the Level I structures, systems, and components must be designed to withstand to maintain their nuclear safety function. Examples of such flood conditions, together with attendant windgenerated wave activity, include the following:

(a) The probable maximum flood (PMF)

(b) A seismically induced flood

(c) A flood caused by severe local precipitation

\subsubsection{Design Requirements}

\subsection{Leve1 I}

Structures, systems, and components classified as Level I will be designed to provide their defined nuclear safety functions in conjunction with normal operating loads during and after any of the following phenomena:
(a) $\mathrm{DBE}$
(b) $\mathrm{OBE}$
(c) $\mathrm{DBT}$
(d) $O B W$
(e) $\mathrm{DBF}$ 
Level I structures, systems, and components will provide their defined nuclear safety, functions when subjected to the loads resulting from the simultaneous application of forces arising from any one of the above natural phenomena in conjunction with a postulated event and concurrent with normal operating conditions.

Level I structures, systems, and components or portions thereof will be subjected to the requirements of a $Q A$ program established in accordance with Appendix B of 10 CFR 50.

\subsection{Level II}

Structures, systems, and components classified as Level. II will be designed to provide continued normal operation, without undue risk to the health and safety of the public or operating personnel, in conjunction with normal operating loads during and following any of the following natural phenomena:
(a) $\mathrm{OBE}$
(b) $\mathrm{OBW}$

\subsection{Level III}

Structures, systems, and components classified as Level III will be designed to endure natural phenomena in conjunction with normal operating loads and within the intent of the following:

(a) The seismic event equivalent to that defined in the Uniform Building Code seismic risk map for the site location

(b) $\mathrm{OBW}$ 


\subsection{Interfaces}

The design of the facility will be such that the failure of Level II and/or Level III structures, systems, or components will not jeopardize the nuclear safety function of Level I structures, systems, or components. 


\section{SCHEDULE AND METHODS OF PERFORMANCE}

\subsection{DESIGN AND CONSTRUCTION SCHEDULES}

Title I, preliminary design, is estimated to have a duration of 6 months and Title II, final design, a 9-month duration. Title III, construction inspection services by the architect-engineer, is estimated to have a duration of 39 months and to terminate with hot startup and operation of the facility. A 9-month period has been allowed between Title II and Title III for coordination with R\&P Facility construction. Subsequent construction inspection services for completion of additional storage modules will be provided by the facility operating contractor.

The construction schedule shown in Figure $6-1$ is based on the following assumptions:

(a) The hot startup date will be July 1, 1986.

(b) The NRC licensing procedure is not a constraint on the hot startup date.

(c) The design and construction program will be coordinated with the design and construction of an adjacent R\&P or PFT facility.

(d) There will be no labor or procurement constraints.

\subsection{OPERATION}

Because of its geographical location on the Hanford Reservation, the facility does not require all the operating personnel that would be necessary to make it a self-sufficient unit. For certain 
FIGURE $6-1$

PRELIMINARY CONSTRUCTION SCHEDULE BASED ON THE CONCEPTUAL ESTIMATE ${ }^{\prime}$

\section{DRY WELL STORAGE FACILITY}

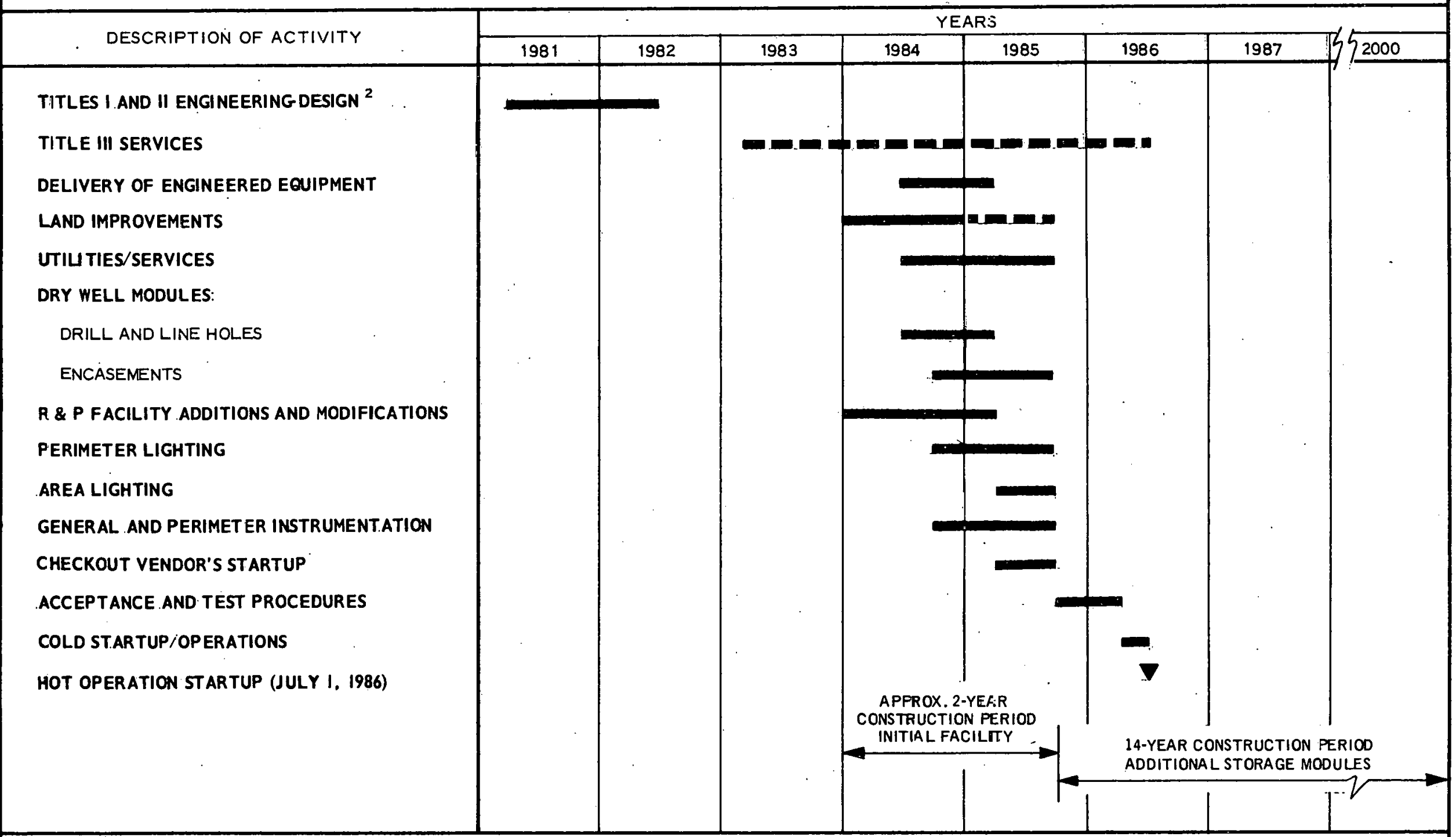

1. CONSTRUCTION SCHEDULE THROUGH COMPLETION OF FIRST AREA STORAGE MODULE. FOLLOW-ON CONSTR J ZTION OF MODULES WILL CONTINUE THROUGH COMPLETION OF FINAL MODULE IN YEAR 1999.

2. DWS FACILITY TITLES I AND II ENGINEERING-DESIGN SCHEDULEO FOR COORDINATION WITH TITLE II ENGIVEERING-DESIGN OF R\&P FACILITY. 
major maintenance and repair, as well as for medical, fire protection, and other community services, the operating contractor will rely on existing Hanford capabilities outside the DWS Facility.

The total number of personnel required to operate the facility is estimated to be approximately 80 . These personnel will operate the facility 24 hours per day, five days per week. Their areas of responsibility will include accountability, canister storage, area maintenance, health physics, administrative support, and quality assurance. Security will be maintained at the facility 24 hours per day, seven days per week.

There will also be an independent construction force of approximately 80 personnel that will be responsible for surveying, grading, and drilling; installing dry well encasements and instrumentation; extending communication and area lighting systems; and performing all other work associated with the construction of additional dry wells after completion of the first storage area module by the general contractor. These personnel will have separate work facilities and will not be the responsibility of the DWS Facility.

It is expected that, after the operating contractor is selected, some of the contractor's key technical personnel will be assigned for project indoctrination and training purposes. This technical group will be enlarged during the period prior to operation to assist in the preparation of operating procedures and operational safety analyses.

\subsection{METHODS OF PERFORMANCE}

The project participants will include the U.S. Department of Energy, the U.S. Nuclear Regulatory Commission, the Rockwell Hanford Operations program manager, an architect/engineer who may a) so act as construction manager, a general contractor, and an 
operating contractor. Overall direction and administration of the project will be the responsibility of DOE. The functions of each organization in the project are described below.

\section{3 .1 DOE}

DOE will furnish overall project direction, coordination, and funding; initiate procedures for selection of the Architect/ Engineer, the general contractor and approval of subcontractors; provide prints of construction drawings for bidding purposes; adiiniuisler the design, construction, and operating cunlracts; and arrange for the required foundation exploration work and for land leases and purchases (if required) through appropriate governmental agencies.

DOE will coordinate reviews for licensing and safety analysis. It will be assisted in this function by the RHO program manager, the operating contractor, and the architect/engineer.

\section{3 .2 NRC}

The NRC will act as the licensing agency under the appropriate portions of the Code of Federal Regulations applicable to this facility at the start of Title I design.

\subsubsection{Program Manager}

Technical direction of the project has been assigned to Rockwell, which has prepared the basic project criteria for the conceptual design of the DWS Facility. Rockwell will provide planning, direction, evaluation, and coordination throughout the entire project; establish and maintain the project plan and schedule; direct and approve the preparation and editing of project documentation and funding schedules; review and approve Title I and Title II documents prepared by the architect/engineer; procure certain equipment; assist in training of operating contractor personnel; and assist DOE in licensing and safety analyses. 
Project-related research and development programs will be conducted by Rockwell and other agencies, as required, under Rockwell's technical cognizance. These programs include but are not limited to:

(a) Analysis, projection of quantities, and characterization of spent fue I

(b) Development of criteria for storage and retrieval of fuel canisters

(c) Preparation and refinement of the environmental statement

(d) Preparation of preliminary estimates of storage costs based on full recovery of capital and operating costs

(e) Engineering and testing of certain specific equipment and components

(f) Geological, ecological, hydrological, and environmental studies necessary to ensure the safe operation of the facility, including

- Planning, direction, and evaluation of the environmental program

- Preparation and maintenance of a detailed plan for the ecological, geological, and hydrological investigations necessary to establish the adequacy of the site

- Continuation of the ecological review to determine the effects, if any, of the operation of the facility on the area. 


\subsubsection{Architect-Engineer (A-E)}

Engineering for the conceptual design has been performed by Kaiser Engineers, Inc., under contract with the Richland Operations Office of DOE. DOE will award a single new contract for A-E services for preliminary engineering (Title I), for definitive engineering and design (Title II), and for $A-E$ services required during the initial construction phase (Title III). Rockwell will maintain technical direction of the $A-E$ at all stages of the design. The A-E will prepare the appropriate construction drawings, specifications, quality assurance program, and cost estimate.

\subsubsection{General Contractor}

Initial facility construction will be contracted to one general contractor and a number of subcontractors under prime DOE contracts. The construction activities will include construction of all facilities above and below ground; procurement, inspection, and installation of certain items of fixed and operating equipment; and maintenance of quality assurance standards.

Construction, procurement (except for certain items of equipment purchased by the operating contractor, Rockwell, or DOE), and installation will be accomplished either by a general construction contractor with fixed-price subcontractors performing the construction work on the basis of competitive bidding or by one or more fixed-price or cost-plus-fixed-fee (CPFF) construction contractors. Where fixed-price bidding is not practical, CPFF contracts will be negotiated.

\subsubsection{Operating Contractor}

Facility operation will be the responsibility of an operating contractor under prime contract to DOE. The contractor will be selected through established selection procedures. 
The responsibilities of the operating contractor before beginning facility operation will include:

(a) Assisting in preparation of operating procedures

(b) Assisting in preparation of operational safety analyses and licensing presentations

(c) Preparing and implementing acceptance test procedures

(d) Training operators

(e) Purchasing special equipment

(f) Inspection of construction following hot startup and initial facility operation

\subsection{PROCUREMENT POLICY}

All procurement will be the direct responsibility of DOE and will occur in four phases as described below.

\subsubsection{Design and Inspection}

The conceptual cost estimate and schedule are based on the assumption that DOE will procure all phases of facility design (Title I and II) and construction inspection services (Title III) under a single contract. This would allow effective coordination of the DWS and R\&P facilities' engineering-design and construction activities.

\subsubsection{Construction Phase}

Following the Title II design period, DOE will initiate general contractor selection to permit the start of construction. This assumes no licensing constraint. The general contractor will 
select subcontractors with the approval of DOE. During the first phase of DWS Facility construction, the $A-E$ will provide the necessary Title III construction inspection services and will monitor the QA programs of the general contractor and his subcontractors.

\subsubsection{Operating Phase}

Operations will be the responsibility of an operating contractor under prime contract to DOE. Early selection of an operating contractor is necessary because the operating contractor will not only develop staffing requirements, but will also assist in the preparation of acceptance test procedures and operating procedures, operational safety analyses, and operator training programs before the start of operations and inspection of the onguing storage module construction. The design and arrangement of administrative, service, and packaging facilities can also benefit from early involvement of the operating contractor.

\subsection{DECOMMISSIONING PHASE}

As retrieval of canisters from each area module and offsite shipment from an adjacent or nearby receiving and packaging facility or transfer facility are accomplished, an overlapping decommissioning and retrieval phase, assumed to last 15 years, will be initiated. For purposes of cost estimating and scheduling, it is assumed that DOE will contract with a decommissioning contractor who will mobilize his resources and initiate decommissioning operations after completion of retrieval activities in each dry well area. Decommissioning will be in accordance with Regulatory Guide 1.86, "Termination of Operating Licenses for Nuclear Reactors," Part C2, Paragraph C, which at the option of DOE requires removal, volume reduction, dismantling, and disposal of all facilities containing radioactive materials. 


\section{SPECIAL REQUIREMENTS}

\subsection{SECURITY}

The DWS Facility will incorporate the physical protection measures in the design that are required to meet existing and proposed government regulations. The security system will comply with RHO-CD-353, "Spent Fuel Storage Facility Safeguards Physical Protection Criteria," dated April 17, 1978. The purpose of the security system is to provide early detection of unauthorized access, a means of correctly assessing the situation and providing effective delay barriers, and the initiation of a response that can effectively handle any breach of security.

\subsubsection{Vital and Protected Areas}

Protected areas are all areas within the perimeter fences. Vital areas are the areas where nuclear material is handled and the areas that contain equipment or utilities essential to the handling, storage, transfer or protection of the nuclear materials or protection of the facility. Vital areas include the dry well storage areas within the security fencing and the standby generator building, the fuel supply area, the electrical substation, and the security building within the Spent Fuel Receiving and Packaging (R\&P) Facility security fencing. All other areas are considered protected areas. Entrance to vital areas will require, as minimum security provisions, a specially coded card for the card reader and observation by a guard or closed-circuit TV.

\subsubsection{Safeguard Systems}

Several types of safeguard systems will be provided for the patrol force to maintain the security requirements. The proposed systems are described in the following sections. 


\subsubsection{Alarm Station}

The alarm station, located in the R\&P Facility hardened security building, will include equipment for monitoring area access, intrusion alarms, and closed-circuit television (CCTV) surveillance systems, and it will be the communications center for the facility security force. Area access will be controlled by a computerized card system. The perimeter will be monitored and significant events recorded. These records will include the time when personnel enter and leave designated areas, whether unauthorized access has been attempted, and where and when an intrusion through the security perimeter has been attempted. Any unauthorized entry nr breach of security will trigger both an audible and a visual alarm and the location of the breach of security will be shown.

CCTV monitoring and control of pan, tilt, and zoom on each security camera will. be accomplished from the alarm station control console.

A1l physical protection alarms, CCTV, and communication systems will also be monitored at the redundant alarm monitoring (RAM) station located in the patrol headquarters in the 200-East area. Control of the CCTV and communications system can be transferred to the RAM station on demand. Certain RAM systems related to the processing operations in the R\&P building will be included on the panels in the R\&P building control room.

\subsubsection{Protected Areas}

A11 components of the dry well storage area will be located within the confines of a protected area, as defined in 10 CFR 70, Part 73, NRC Rules and Regulations. Personnel will be allowed to enter 
the protected area at only one location, which will be under the control of a guard at the gatehouse station. The guard will be responsible for inspection and personnel identification. The gatehouse will house personnel-surveillance devices and accessidentification equipment.

Surrounding the protected area will be two fences made of wire fabric with barbed wire on top, for a total height of eight feet. The two fences will be separated from each other by at least 100 feet. The exclusion zone between the fences will be maintained as a clear, uncluttered area. Illumination will be maintained at a minimum of 0.2 footcandle throughout the exclusion zone. The gatehouse will be located between the R\&P and DWS facilities on the main access road into the DWS Facility. Fences connecting the inner and outer fences will border the facility access road on both sides.

Intrusion detectors will be provided in the exclusion zone between the two perimeter fences. Two independent systems will be used for detection and both will be operated continuously. All intrusion equipment will be equipped with tamper alarms.

Closed-circuit television cameras will cover the entire outer perimeter. These will be located within the protected area and will be used for evaluation of alarm conditions. These cameras will have pan, tilt, and zoom capabilities.

The facility's protected area will also be surrounded by a passive vehicle barrier, such as a continuous trench or railroad rail anchored in concrete, designed to restrict entry and exit of land vehicles. The barrier will be designed so that it is virtually impossible to cross with a land vehicle, thus increasing the time required for overland penetration or egress. 
An outer, low-level wire fabric fence, beyond the vehicle barrier, will be provided as an additional barrier to minimize the possibility of wildlife entering the exclusion area or initiating false alarms.

\subsubsection{Access Control}

All access to the storage areas will be controlled by a guard at the gatehouse, which will be located at the entrance to the protected area between the DWS and R\&P facilities. The location will provide an unobstructed view of both pedestrian and vehicular traffic along the exciusion zone and surrounding terrain.

The DWS facility entrance gatehouse will be equipped with mechanized. identification equipment and radiation, metal, and explosives detectors to screen personnel and vehicles entering and leaving the facility. The entrance gate will also be equipped with a vehicular radiation detector.

An identification check will be required to enter the facility. Entrance will be restricted to those who have a legitimate need and authorization to enter. Personnel parking will be outside the R\&P Facility perimeter barriers. Breaches of entry and exit will produce alarms in the security building and in the RAM station at patrol headquarters in the 200-East area.

Vehicle barriers and access controls that prevent unauthorized vehicular entry or exit will be incorporated into the facility design. These controls will regulate vehicle access to the receiving area and facility grounds. Only authorized spent fuel canister transporters, monitoring and surveillance, maintenance, and service vehicles will be permitted access to the facility grounds. Private and unauthorized government vehicles will be excluded from the protected area. 


\subsubsection{Communications}

Security communications will be provided by radio with base stations located in the security building and a backup base station at the RAM station. All security guards will have portable twoway radio transmitting/receiving equipment. Patrol vehicles will have mobile two-way radio transmitting/receiving equipment. Onsite security communications will be augmented by the use of the telephone and intercom systems. In case of emergency, other law enforcement authorities can be contacted either by telephone or by radio.

\subsubsection{System Tests}

Provisions will be made for periodic testing of all security equipment. Checks will consist of an integrated system of automatic on-line testing of equipment that has built-in test capability and simulated or actual testing of the other equipment. A periodic maintenance program will be carried out.

The radio system, intercom, and telephone systems will be tested by use or by test at least once per shift and more often if directed.

\subsubsection{Emergency Procedures and Systems}

Emergency procedures for the facility will be written to cover potential design basis threat* emergencies. Control and direction during an emergency will come from the security building or the RAM station at patrol headquarters.

*Letter, "Threat Guidance," Document No. SAS-4170, from ERDA-RL to ARHCO, et al., dated January 18, 1977 (Confidential). 


\subsection{SAFETY}

\subsubsection{Safety Classification of Accidents}

A safety evaluation has been made of the DWS Facility to determine whether any abnormal or accident conditions can be postulated that would result in an unacceptable release of radioactivity to the general public or to operating personnel.

To facilitate the evaluation, the following safety classifications of accidents were studied: normal operations, abnormal occurrences, and design basis accidents.

\subsubsection{Normal Operations}

Hazards associated with the emplacement, storage, monitoring, and decommissioning of canistered fuel assemblies in dry wells may result in accidents. These accidents shall not increase the risk of radiation exposure to the general public above normal operations. Appendix I of 10 CFR 50 provides guidance to ensure that radiation exposure to the general public will be maintained "as low as reasonably achievable" (ALARA). The dose rate to operating personnel will not exceed the maximum permissible values given in 10 CFR 20 and, additionally, every reasonable effort will be made to maintain radiation exposures "as low as reasonably achievable."

\subsubsection{Abnormal 0ccurrences}

Abnormal occurrences are those that might result from unusual equipment failures, human errors, or umplanned process variations that might occur during the lifetime of the facility. This safety classification includes events that are not expected to occur but have a high enough probability to warrant design features to 
mitigate their potential consequences. Abnormal occurrences will not result in exposure to the general public in excess of the normal operating limits.

The dose rate to operating personnel will not exceed the permissible dose values of 10 CFR 20 and, additionally, every reasonable effort will be made to maintain radiation exposure "as low as reasonably achievable."

\subsubsection{Design Basis Accidents}

These are highly improbable accidents that conceivably could result in offsite dose rates in excess of 10 CFR 20 guidelines: However, the radiation release will be mitigated by appropriately engineered safety features so as not to exceed the guideline dose levels of 10 CFR 20 for offsite exposure.

\subsubsection{Safety Evaluation}

The safety evaluation of the Dry Well Storage Facility is summarized in Table $7-1$.

\subsection{SAFEGUARDS}

DWS Facility safeguards will incorporate the physical protection measures of the facility security plan, discussed in Section 7.1 to prevent theft or sabotage of nuclear material. The design will also incorporate the more stringent of DOE and NRC requirements as interpreted by the Rockwell Safeguards and Security Organization. Strict accountability for the inventory and condition of spent fuel canisters (packages) and dry well encasements will be included in the safeguard provisions. 
TABLE 7-1

Safety Evaluation - Dry Well Storage Facility

(1) - Events

Safety Classification

(2), (3) etc. - Mitigation

Release of Radioactivity

To Envirónment

Normal Operations

Canister leaking

(1) Possible leakage from canisters containing

None

failed fue 1 in estimated $2 \%$ of total

inventory.

(2) Fission gases released into encasement:

$30 \% \mathrm{Kr}$. 10\% I, 10\% Xe (Req. Guide 1.25).

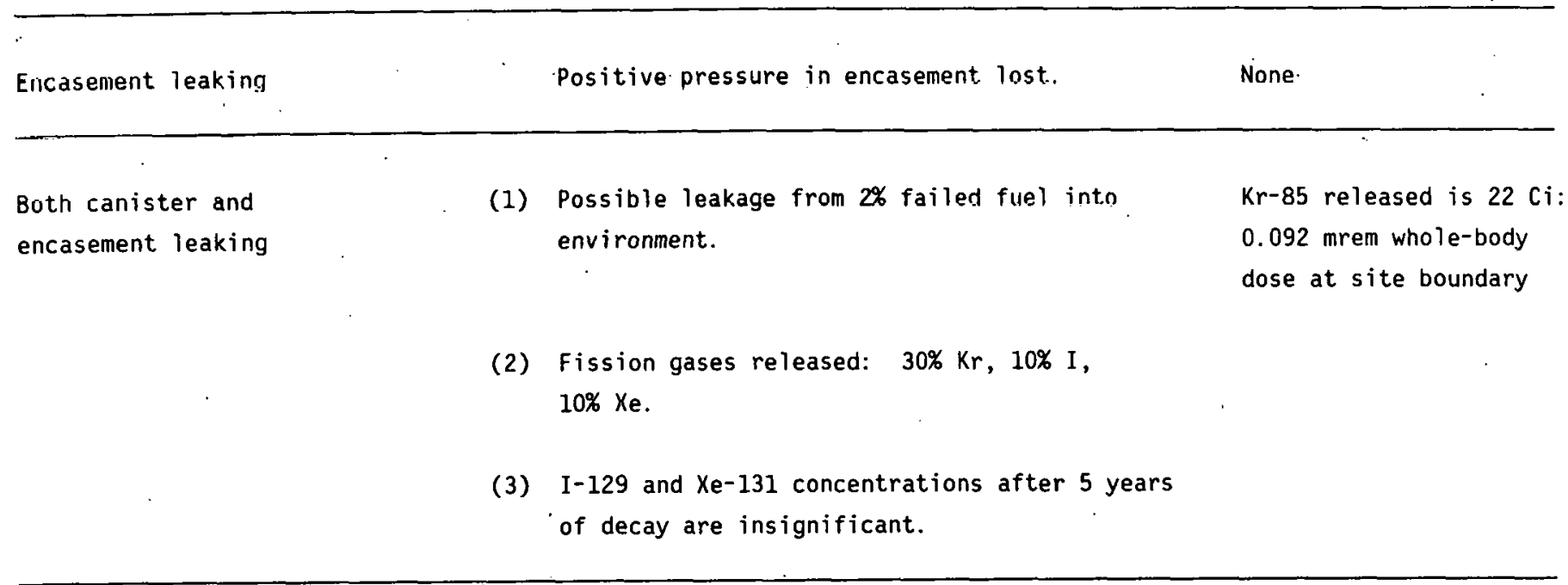

Abnormal Occurrences

Transporter hoist grapple

Failure of canister suspension during canister emplacement (i) Canister falls to the bottom of encasement. None

(2) Encasement and canister withstand impact.

(3) Fuel assembly ruptured.

(4) Canister returned to R\&P Facility for reencapsulation of fue 1 elements.
Transporter runs over dry well containing canister
Sampling valve assembly is protected by an extra-strong bolted cover that remains undamaged.
None 
TABLE 7-1 (Cont)

Safety Evaluation - Dry Well Storage Facility

(1) - Events

Release of Radioactivity

Safety Classification

(2), (3) etc. - Mitigation

To Environment

Abnormal Occurrences

Sampling valve is left open

The secondary valve (the plug half of the

quick-connect two-way shutoff coupling)

maintains the secondary barrier of dry well

intact.

None

Design Basis Accident

Earthquake

(1) Vibratory ground motion and surface faulting None

(2) Facility withstands seismic loads imposed by postulated, operating basis earthquake in accordance with the designated QA level.

Tornado

(1) Violent local storm, high velocity whirlwinds

None of tremendous force.

(2) Facility withstands postulated maximum tornado forces.

(3) Class I portions of R\&P facility supporting OWS Facility will be housed within missileresistant structures.

(ref. RHO-CD-506)

Wind

(1) High velocity horizontal air movement.

None

(2) Facility withstands postulated maximum wind forces.

Fire

(1) Facility is designed with noncumbustible

None material.

(2) Fire-protection system will be designed for those portions of the R\&P Facility providing critical support to OWS Facility. 
TABLE 7-1 (Cont)

Safety Evaluation - Dry Well Storage Facility

Safety Classification

Design Basis Accident

Flooding

Criticality

(1) The canister and encasement both develop leaks. Fuel contained in ruptured fuel elements (estimated $2 \%$ of total) is oxidized.

(2) The canister and encasement are flooded during rainy season.

(3) Oxidized fuel contained in ruptured fuel elements fall into water and settle to bottom of encasement.

(4) Canister remains subcritical ( $\left.k_{\text {eff }}<0.95\right)$.
None

Release of Radioactivity To Environment

None

. 


\subsubsection{Storage Areas}

All spent fuel canisters, when not contained in transporter casks, will be stored (contained) in dry well encasement vessels at the DWS Facility. The storage areas will be classified as vital areas and, as such, will require controlled access by means of a specially coded card for a card reader. Observation by a guard or closedcircuit TV to gain access will also be required.

\subsubsection{Accountability}

The accountability control center, located in the R\&P Facility, will be a computer data processing and control center that acquires spent fuel assembly and encapsulation data at key points throughout llie receiving and packaging operations and also during subsequent storage in the DWS Facility. The center will be used to track bare spent fuel assemblies and canistered fuel assemblies throughout their life cycle at the R\&P and DWS facilities. It. will process data by computer logic, account for the assemblies, maintain current condition reports on canisters in storage, and identify any potentially abnormal or unsafe condition. Unusual delays or occurrences during canister placement or retrieval will be recorded in the control center. In addition to the facility accountability staff, independent audits of assemblies processed and canisters placed in storage or retrieved will be performed by persons who are not associated with the facility, but who may be located at Hanford.

During the packaging procedure, the spent fuel assembly identification number will be stamped into a metal identification label firmly affixed to the exteriur of the canister in which that assembly is placed. As a canister is placed into a dry well, the canister will have its serial number verified and entered on a storage or retrieval $\log$ in the control center. 
Further, each canistered assembly will be logged with respect to its indexed position in the DWS Facility. Dry wells will be assigned a permanent row and a column-locating number for indexed storing of canisters.

As the spent fuel package is loaded from an R\&P Facility weld and test cell into the transporter cask, the assembly number, the fuel characteristics and condition, the number of the transporter vehicle, the date, and the assignment of a dry well for storage will be entered in the storage $\log$ and central data logger. Duplicates of this $\log$ will form the basis for a bill of lading given to the transporter operator to accompany each canister consigumint leaving the R\&P Facility for storage at the DWS Facility.

\subsection{ENERGY CONSERVATION}

At the spent fuel storage site, area lighting, perimeter fence lighting, and intrusion detection and instrumentation will consume electrical energy. In addition, energy will be consumed in the form of fuel for facility servicing and sampling vehicles.

\subsubsection{Energy Consumption of Electrical Systems}

The estimated electrical energy usage and distribution are summarized below in Table 7-2. 


\section{TABLE 7-2}

Energy Distribution

\begin{tabular}{|c|c|c|}
\hline Maximum Requirements & $\begin{array}{l}\text { Hourly Demand } \\
\text { (Kilowatts) }\end{array}$ & $\begin{array}{l}\text { Percentage of Total } \\
\text { Electrical Energy }\end{array}$ \\
\hline $\begin{array}{l}\text { Area and Building Lighting } \\
\text { (at 15th year) }\end{array}$ & 1,042 & 83 \\
\hline Perimeter Fence Lighting & 104 & 8 \\
\hline Perimeter Fence & & \\
\hline $\begin{array}{l}\text { Intrusion Detection } \\
\text { and Instrumentation }\end{array}$ & 80 & 7 \\
\hline Miscellaneous. & 24 & 2 \\
\hline Subtotal & 1,250 & 100 \\
\hline $20 \%$ Contingency & 250 & \\
\hline TOTAL & 1,500 & \\
\hline
\end{tabular}

The lighting system will be designed in accordance with 10 CFR 73, "Physical Protection of Plants and Machines."

For dry well general area lighting, high-pressure sodium-vaportype lamps will be used. Although low-pressure sodium-vapor-type lamps would consume less energy, they are not readily available in the domestic market. 


\subsubsection{Vehicle Energy Consumption at Storage Site}

Approximately 50\% of the total energy consumed at the DWS Facility will be in the form of fuel used by transporter, maintenance, servicing, and sampling vehicles. The estimated energy consumed by various types of vehicles operating during the first 15 years of canister placement is shown in Table 7-3.

TABLE 7-3

Vehicle Energy Consumption

Tota]

Type of

Vehicle

Nu. of Total tquivalent* Fupi

\section{Total}

Percentaye

(kilowatts) (gal/hr) Energy

Lighting Service

and Maintenance

1

28

21

2

1

Spent Fuel

Transporter

2

300

224

18

14

Patrol Security

1

100

75

6

5

Sampling

8

800

600

48

37

Welding

Diesel Generator

3

402

300

24

18

Welder

3

180

134

11

8

Fork Lift.

2

.70

52

4

3

Pickup Truck

2

200

149

12

9

Health Physics

$1 \quad 100$

75

6

1630

131

5

TOTAL

23

2180

1630

$100 \%$ * Mechanical horsepower per hour multiplied by 0.745 equals kilo-
watts per hour 
One of the energy conservation techniques proposed for the conceptual design will be to equip all vehicles with diesel engines. The diesel engine is considered a more efficient engine than the gasoline engine, it consumes less and cheaper fuel, and it requires less engine maintenance and service than the gasoline engine. The use of diesel engines could result in an energy savings of between $15 \%$ and $30 \%$ over the 65 -year placement, storage, and retrieval period.

\subsection{ENVIRONMENTAL ASSESSMENT}

Potential environmental consequences of the proposed DWS Facility. are discussed in a separate document entitled "Dry Well Storage Facility Conceptual Design Study, Environmental Assessment."

\subsection{DECONTAMINATION AND DECOMMISSIONING}

When the DWS Facility is no longer required, it will be decontaminated and decommissioned (D\&D). The D\&D program will have the following objectives:

(a) Decontamination so that there will be no risk to human health

(b) Decontamination so that possible subsequent natural phenomena, such as floods or earthquakes, will not release harmful amounts of radioactivity to the environment

(c) Demolition of structures, such as equipment foundations, removal of fencing and light poles to existing grade, and leveling or grading the site to natural contours 
As canisters are removed from area modules of the DWS facility, the dry well encasement vessels in each area module will be decontaminated and decommissioned. This will be accomplished in the following steps:

(a) Each empty encasement will be monitored for contamination and decontaminated if necessary.

(b) The encasement cover will be removed and the encasement filled with soil to within approximately six feet of the top of the encasement:

(c) A cutting torch mechanism will be lowered into the encasement, and two circumferential cuts will be made to remove the top few inches of the transition section approximately six feet below the top of the encasement. The resulting ring will be removed, cut into small pieces, and placed in the encasement.

(d) The encasement cover will be replaced, and the cover and upper six-foot section of the encasement will be vibrated into the ground around the lower part of the encasement until the top of the encasement and cover are approximately six feet below grade.

(e) The hole above the cover will be filled with soil to grade and leveled.

(f) Fencing, light poles, and instruments will be removed, but underground conduit and cable will remain in place.

(g) Equipment, such as transformers, will be removed and foundations removed to grade. 
Preparations leading to D\&D of the facility will begin approximately one year before canisters are removed from the first area module. During this period a D\&D plan will be prepared, necessary licensing activities completed, the staff assigned and trained, and special equipment designed and procured to perform the D\&D activities.

During the decontamination phase, the encasements will be considered satisfactorily decontaminated when the contamination levels have been reduced to those listed as acceptable in Regulatory Guide 1.86, "Termination of Operating Licenses for Nuclear Reactors." Any components retaining amounts of radioactivity above disposition criteria levels will be removed and packaged in DOEand DOT-approved containers and shipped to an approved radioactive waste disposal facility.

The sampling and welding vehicles will account for nearly $75 \%$ of the fuel consumption at the facility during canister placement, but during the subsequent 35-year storage and 15-year retrieval periods the fuel consumption will be reduced by $38 \%$ because closure plate welding will not be required.

The major opportunities for energy savings will depend on the following:

(a) Efficient operating schedules and efficient usage of vehicles

(b) Use of diesel engines instead of gasoline engines

(c) Use of new NEMA design energy-efficient electric motors with the welding and placement equipment 


\section{QUALITY ASSURANCE PROGRAM}

\subsection{DOE POLICY STATEMENT DEFINING QUALITY ASSURANCE CRITERIA}

The definition of quality assurance criteria appropriate to the DWS Facility should be documented in a DOE policy statement and included in a program description and criteria manual to be prepared by the Architect/Engineer and imposed on major contractors. The policy should state that the quality assurance criteria for the safety-related aspects of the project will be in accordance with 10 CFR 50, Appendix B, "Quality Assurance Criteria for Nuclear Power Plants and Fuel Reprocessing Plants," and with ANSI N45.2, "Requirements for Quality Assurance Program for Nuclear Power Plants," and applicable daughter documents, or with such new DOE quality assurance source documents as may be prepared espe= cially for the project.

\subsection{OVERALL QUALITY ASSURANCE PROGRAM}

The license applicant will prepare and implement an overall quality assurance program for the location, design, construction, testing, and operation of the structures and systems of the DWS Facility. This program, which will comply with the requirements of the aforementioned DOE policy statement, will be described in the quality assurance program plan. The overall quality assurance program plan will include a summary description of organizational interfaces and will require future input from the major participating organizations. The DWS Facility quality assurance program plan will outline all those planned and systematic quality assurance actions necessary to provide adequate confidence that the desiyn, construction, and operation of all specified nuclear safety-related structures and systems will comply with applicable codes, specifications, drawings, and procurement document requirements. The overall program will include identification of the known major participating organizations together with their designated functions. Nuclear safety-related structures and systems to 
be covered by the overall quality assurance program for the DWS Facility will be classified into three quality (Q) levels. Each $Q$ level denotes the degree of applicability of the quality assurance program to those items. The requirements of 10 CFR 50, Appendix $B$, apply only to those items classified $Q$ Level I. The structures, systems, and components classified $Q$ Levels II and III are not nuclear safety-related, but they will require a quality assurance program of lesser magnitude.

\subsection{APPLICANT'S QUALITY ASSURANCE PROGRAM}

The applicant may elect to delegate the work of implementing and conducting an effective quality assurance program to a prime contractor as the applicant's representative. For this purpose, the prime contractor's quality assurance manager will have functional independence from schedule, cost, and construction considerations and unimpeded access to higher management. The Quality Assurance Manager will plan and execute a quality assurance program for the applicant and will be responsible for coordinating the quality assurance effort of all major participating organizations on this project.

The applicant will implement the quality assurance program for the DWS Facility as early as is practical. The program will be documented by written policies, procedures, and instructions.

The applicant will assure that the program provides adequate control over activities affecting the quality of the identified nuclear safety-related items to an extent consistent with their importance to safety.

The program must assure that verification of quality by inspections and tests will be proven with adequate tools and controls

under specified and environmental conditions. The personnel who perform activities that affect quality will be provided with sufficient indoctrination and training to achieve and maintain 
suitable proficiency levels in these activities. The applicant and management of major participating organizations will, through planned and systematic audits, regularly review the status and adequacy of the quality assurance programs that they are executing.

The applicant and participating organizations will schedule the above quality assurance program tasks using a format similar to Figure 8-1.

\subsection{QUALITY ASSURANCE PROGRAMS OF MAJOR PARTICIPATING ORGANIZATIONS}

To assure that the overall program goals are achieved, the applicant w111 request all major participating organizations to prepare and submit for review quality assurance plans that meet the requirements of 10 CFR 50, Appendix B. These plans, to be included as part of the overall quality assurance program. for the DWS Facility, will provide the bases for a planned comprehensive program, beginning with the geological survey, facility design, and all phases of procurement, erection, testing, construction, and operations. Particular emphasis will be placed on quality and compliance to applicable codes and specifications on those structures and systems that prevent or mitigate the consequences of postulated accidents that could cause undue risk to the health and safety of the public.

The major participating organizations in the DWS Facility will be:
(a) Applicant
(b) Geological Consultant
(c) Architect/Engineer(s)
(d) Project Field Management/Construction Contractors
(e) Operations Contractor 
FIGURE 8-1

QA PROGRAM TASK SCHEDULE

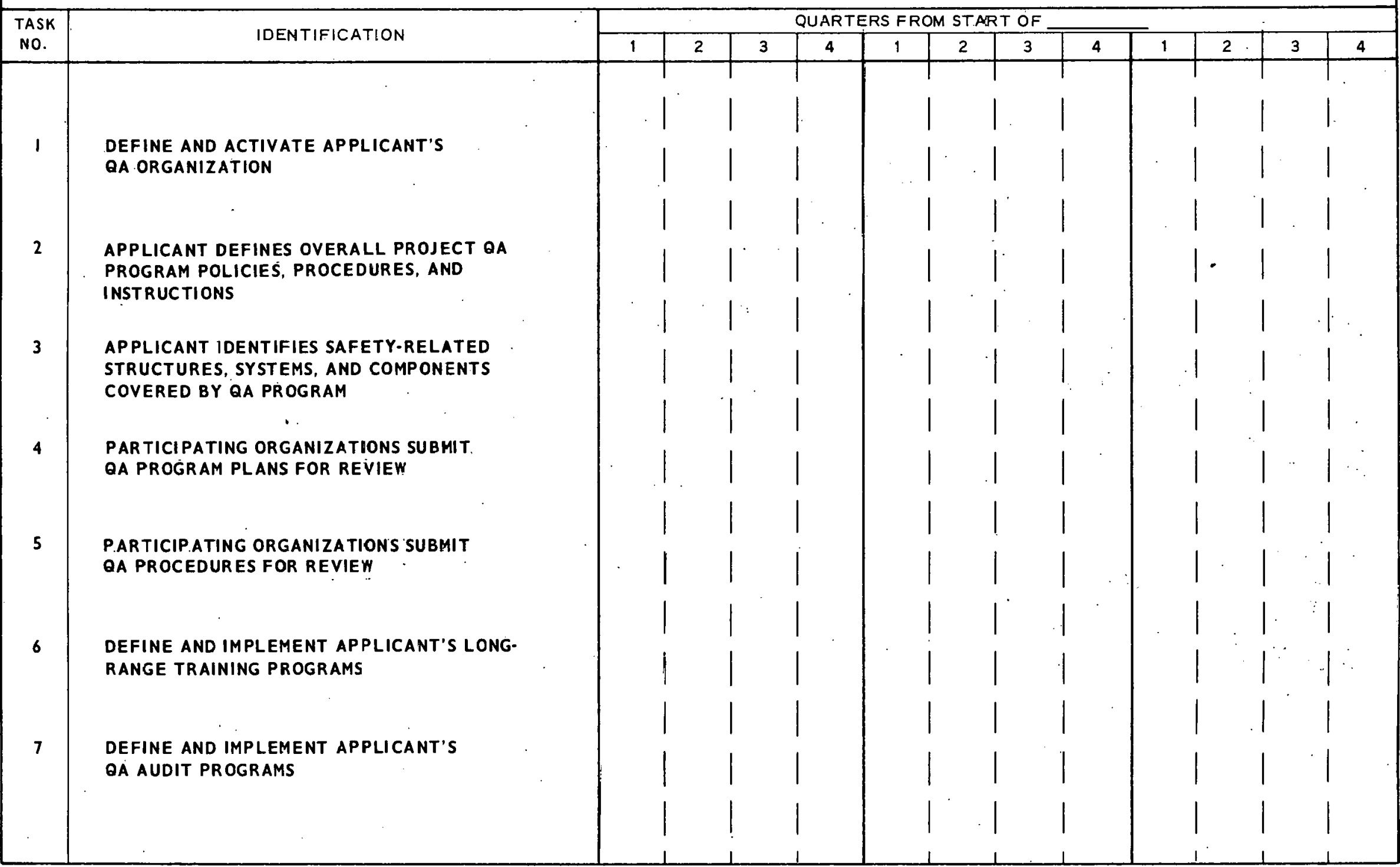




\subsection{APPROVAL OF QUALITY ASSURANCE PROGRAMS}

Quality assurance programs of major participating organizations will be reviewed and approved by the applicant or his designated representative prior to implementation. Figure $8-2$ ' shows review and approval levels of responsibility.

\subsection{SUMMARY MATRIX}

Figure $8-3$ is a tabular summary of the relativity of the 18-point criteria of Appendix B 10 CFR 50 to the applicant, the geological consultant, the architect/engineer, the project field management (constructor), and the operations contractors.

The purpose of this matrix is to indicate in broad terms the degree of participation that is required of each major participating organization. The " $R$ " that appears in certain blocks of the matrix indicates that each individual requirement of that criterion should be addressed by the major participating organization in its Quality Assurance Program. When "R/C" is shown, the organization's Quality Assurance Program need address specific requirements of a criterion only. 


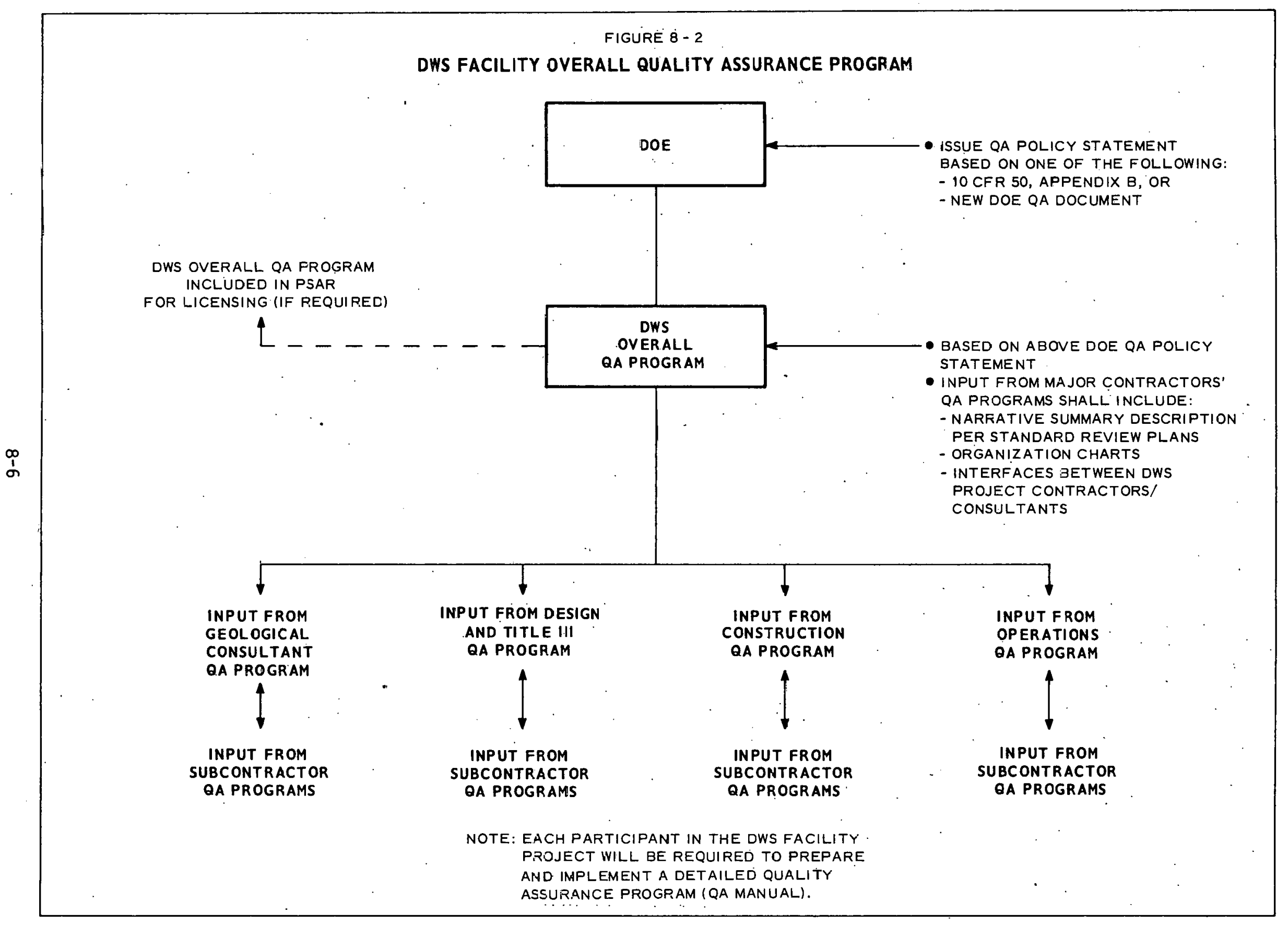


FIGURE 8 - 3

OVERALL QA PROGRAM FOR DWS FACILITY.

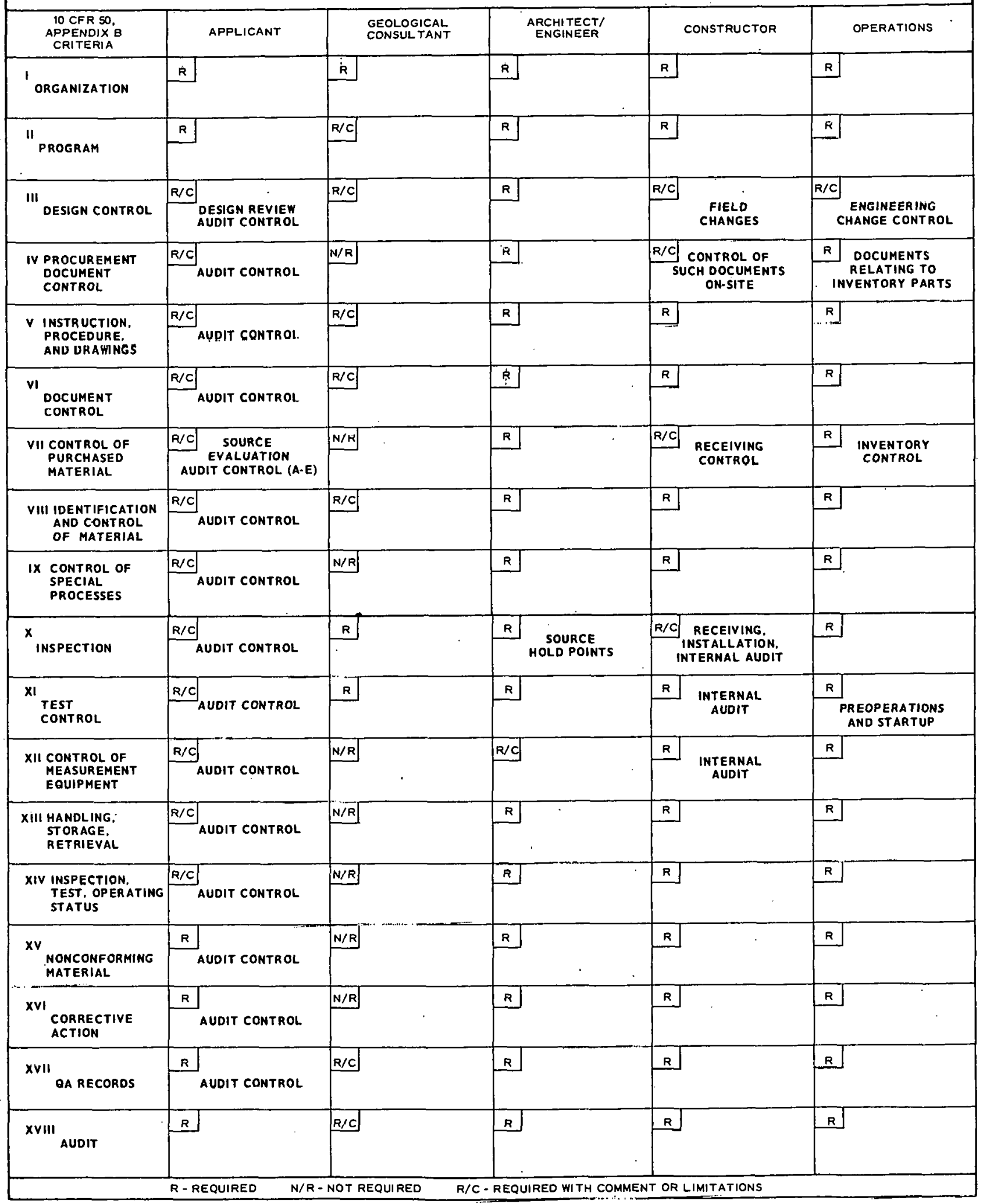




\section{DRAWINGS AND OUTLINE SPECIFICATIONS}

\subsection{DRAWINGS}

The conceptual design drawings listed below are included in this report.

Sheet No. Drawing No.

Tit]e

\begin{tabular}{|c|c|c|}
\hline 1 & SK-2-56400 & Site Plan: Storage Field \\
\hline 2 & SK-2-56401 & Module Plan \& Details: Storage Field \\
\hline & SK-2-56430 & $\begin{array}{l}\text { Placement Operating Sequence and Block } \\
\text { Diagram }\end{array}$ \\
\hline & SK-2-56431 & $\begin{array}{l}\text { Retrieval Operating Sequence and Block } \\
\text { Diagram }\end{array}$ \\
\hline & SK-2-56433 & $\begin{array}{l}\text { Dry Well Arrangement: Section and } \\
\text { Details }\end{array}$ \\
\hline & SK-2-56435 & $\begin{array}{l}\text { Spent Fuel Package Concept: PWR } \\
\text { Canister }\end{array}$ \\
\hline & SK-2-56436 & $\begin{array}{l}\text { Spent Fuel Package Concept: 3-BWR } \\
\text { Canister }\end{array}$ \\
\hline & SK-2-56480 & Electrical: One Line Diagram \\
\hline
\end{tabular}

\subsection{OUTLINE SPECIFICATIONS}

DIVISION 1 - GENERAL REQUIREMENTS

Section Title

Summary of Work

DIVISION 2 - SITE WORK

Section Title

Subsurface Exploration

Clearing and Grubbing 
Section Title

Site Earthwork

Trenching and Backfill

Structural Excavation, Engineered Fill, and Backfill

Soil Treatment

Dry Well Drilling

Site Drainage

Erosion Control

Paving and Surfacing

Fences añd fiates

DIVISION 3 - CONCRETE

Section Title

Forms

Concrete Reinforcement

Cast-In-Place Concrete

Precast Concrete

DIVISION 4 - MASONRY

Section Title

Concrete Unit Masonry

DIVISION 5 - METAL

Section Title

Structural Steel

Steel Joists

Metal Decking

Miscellaneous Metals

DIVISION 6 - WOOD AND PLASTICS

(Not Used) 
DIVISION 7 - THERMAL AND MOISTURE PROTECTION

\author{
Section Title \\ Membrane Waterproofing \\ Building Insulation \\ Preformed Roofing and Siding \\ Membrane Roofing \\ Flashing and Sheet Metal \\ Roof Accessories \\ Calking and Sealants \\ DIVISION 8 - DOORS AND WINDOWS \\ Section Titie \\ Hollow Metal Doors and Frames \\ Rol1-up Doors \\ Metal Windows \\ Glass and Glazing \\ Hardware and Specialties \\ DIVISION 9 - FINISHES \\ Section Title \\ Gypsum Wallboard \\ Acoustical Ceilings \\ Resilient Tile Flooring \\ Special Flooring \\ Special Coatings \\ Painting \\ DIVISION 10 - SPECIALTIES \\ Section Title \\ Lockers \\ Louvers and Vents
}


DIVISION 11 - EQUIPMENT

Section Title

Maintenance. Equipment

Operation and Maintenance and Service Vehicles

Sampling Equipment Decontamination Unit

Laboratory Equipment

DIVISION 12 - FURNISHINGS

(Not Used)

DIVISION 13 - SPECIAL CONSTRUCTION

Section Title

Instrumentation

Prefabricated Buildings

Raised Flooring for Control Room

DIVISION 14 - CONVEYING SYSTEMS

Section Title

Conveyors

Elevator

DIVISION 15. - MECHANICAL

Section Title

Mechanical Basic Materials and Methods

Dry Well Encasements

Pumps

Air Compressors

Piping Specialities

Insulation

Vacuum Pumps

Dust Collection Equipment 
Section Title

Welding Equipment

Fire Protection

0il Storage Tanks

Heating and Ventilating Units

Fans

Ductwork

Duct Accessories

Air Filter Assemblies

Controls and Instrumentation

DIVISION 16 - ELECTRICAL

Soction Tit?e

Electrical Basic Materials and Methods

Substation

Switchgear

Motor Control Centers

Transformers

Underground Service

Grounding

Lightning Protection

Lighting

Emergency Engine Generators

Storage Batteries

Communications

Intrusion Detection Systems

Television Systems

Electric Heaters

Controls and Instrumentation 


\section{COST ESTIMATE}

This section provides the estimated cost for the life cycle of the DWS Facility. The estimate includes initial capital costs, deferred capital costs, and direct and indirect operating costs. The costs were estimated in mid-1978 base dollars, escalated to the approximate expenditure year and contingency added. The escalated expenditures, including contingencies, were discounted to present values to produce a "normalized" cost estimate for the facility.

This section provides cost summaries for the facility, figures defining the overall and detailed expenditure schedule, cost estimating tactors and assumptions, and capltal and annud uperdiny cost amounts.

\subsection{SUMMARY OF COST ANALYSIS}

\subsubsection{Project Cost Estimate Summary}

The estimated cost to design, construct, and outfit the facility is shown in Table 10-1 and, including escalation and contingency, is summarized below:

$\begin{array}{lrl}\text { Design costs: } & \$ 4 & \text { million (Base, } 1978 \text { costs) } \\ \text { Construction costs: } & 592 & \text { (Base, } 1978 \text { costs) } \\ \text { Escalation:* } & 906 & \\ \text { Contingency: } & \underline{225} \\ \quad \text { Total Estimate } & \$ 1,727 & \text { million }\end{array}$

* Escalation based on construction of storage modules in annual increments over a 15-year period and a total period of 22 years for completion of the DWS Facility, including 15 storage modules. 
TABLE 10-1

\section{Project Cost Estimate Summary}

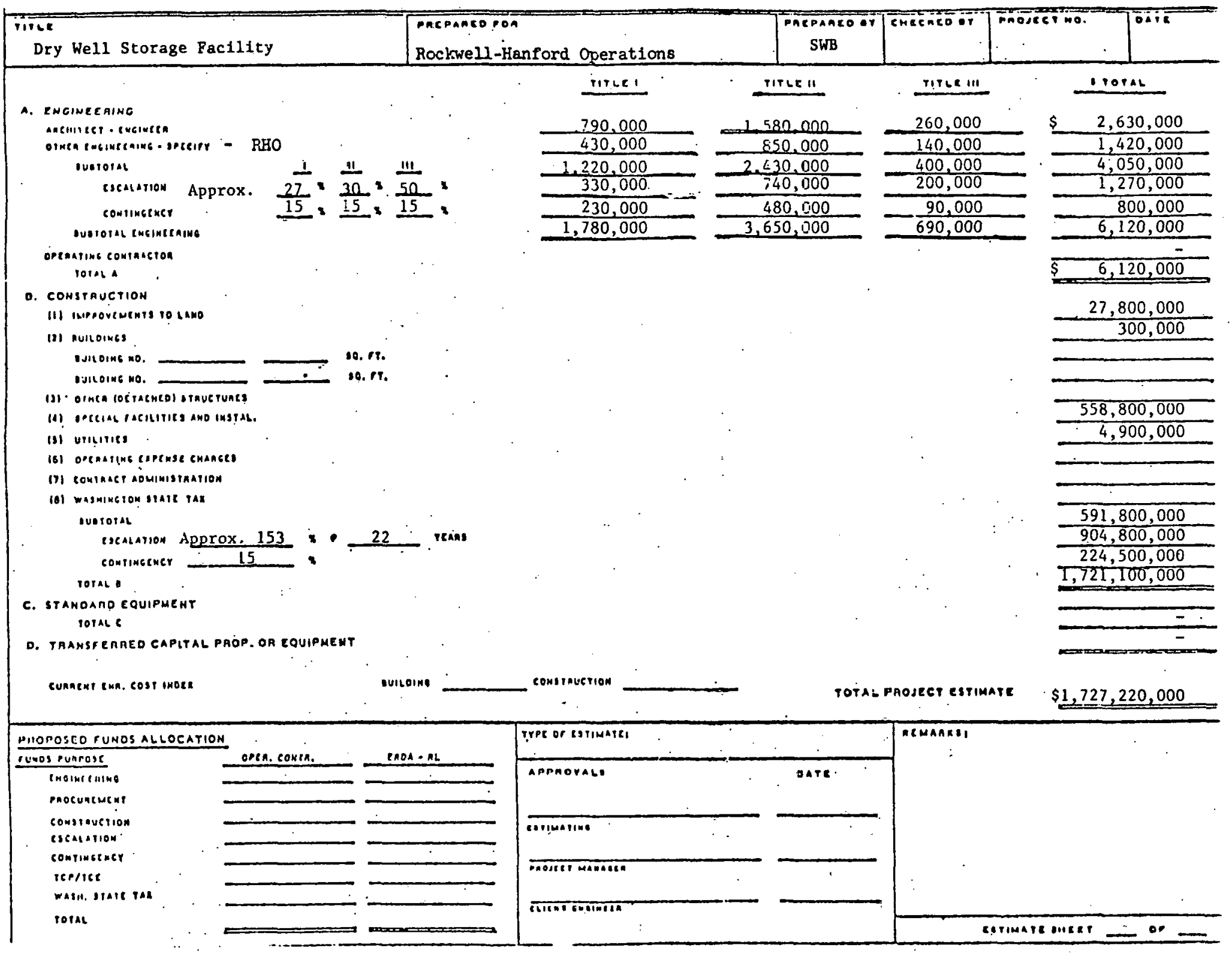




\subsubsection{Activation Schedule}

A schedule of the DWS Facility activities, prepared to define project years and activity durations, is shown in Figure 10-1. The forecasted expenditures for capital and operating costs are scheduled accordingly.

The storage and surveillance period of 65 years includes a 15 year receiving and packaging period, 50 years of first in, first-out storage of the canistered fuel elements and a.15 year retrieval period.

Retrieval during the final 15-year period of facility operation is assumed to be a constant activity on a declining balance of fuel elements in storage. Decommissioning would begin sequentially as all canisters in each of the 15 storage areas are completely vacated and would continue until one year after the last storage area was vacated.

\subsubsection{Total Life Cycle Costs}

The estimated total life-cycle cost (capital and operating cost) is presented in four ways:
Total cost, 1978 base dollars:
$\$ 0.75$ billion
Total cost, 1978 base dollars
with escalation:
$\$ 3.37$ billion
Total cost, with contingency:
$\$ 3.95$ billion
Present value of total cost
using a $10 \%$ discount rate:
$\$ 0.50$ billion

The present-value method equitably considers escalation and the time value of money. The results could be used for other cost analyses: 


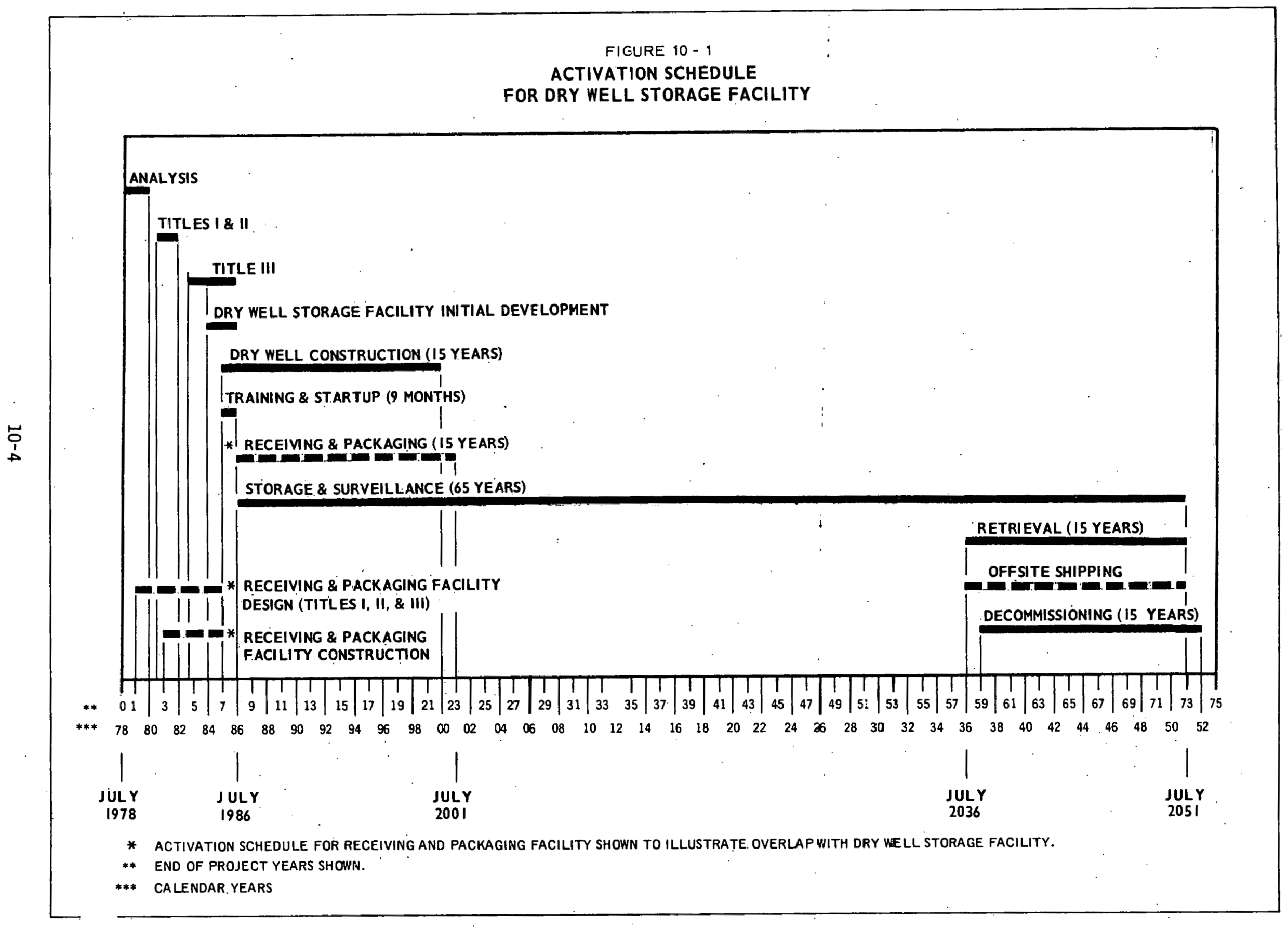


The estimated total present value of capital and operating costs is summed over the 74-year project analysis period and is listed in Table 10-2.

TABLE $10-2$

Estimated Total Present Value of Capital and Operating Costs

Present Value at 10\% Discount Rate Cost Item (\$ millions)

CAPITAL INVESTMENT:

Design and engineering

$\$ \quad 4.3$

Construction

445.0

Equipment replacement

0.1

Decommissioning

.9

Subtotal

450.3

OPERATING COSTS:

Labor

Exempt and non-exempt 37.0

Materials

Dry well materials

0.7

Maintenance materials and supplies

3.3

Energy

Diesel Fuel

4.5

Electrical power

2.5

Subtotal $\$ 48.0$

TOTAL \$ $\$ 498.3$

\subsection{EXPENDITURE SCHEDULES AND COST ITEMS}

This section presents the expenditure schedule used to define scheduling parameters included in the life cycle cost model. The 
model computed cash flows for 1978 base costs, escalated those costs, added contingencies, and computed the present values. The 1978 base costs for capital investments and operating costs are provided in this section.

\subsubsection{Expenditure Schedule}

The items included in the capital investment and operating costs are scheduled using the project year calendar shown in Figure 10-1. An expenditure schedule for the concept is provided in Figure 10-2. (See Figure 6-1 for details of the construction schedule on an expanded timc scalc). Notc that the construction costs for facility development are scheduled during three project years $(6,7$ and 8$)$, using the percentages shown in Figure 10-2. During Project years 6 and 7 work items within the R\&P Facility that directly support the DWS Facility would be accomplished. The construction of the initial 6,750 dry wells would begin during project year 7. Dry well construction would continue to the end of project year 22, when the 15th year of receiving at the DWS Faci1ity would begin. Area lighting and roads would be installed in annual increments. Total decommissioning costs were scheduled evenly over 15 years, although costs during year 74 would be somewhat higher in order to include removal of perimeter fences and other structures and regrading to restore the original site. The training period is shown as a 9-month span and would include acceptance and test procedure development and cold startup.

\subsubsection{Cost Items}

The estimated base cost for capital investments and operating cost items is provided in Table 10-3. The costs shown for construction and equipment replacement were derived from the construction cost estimate. The estimated labor costs were computed from labor force estimates and an average annual personnel cost. 


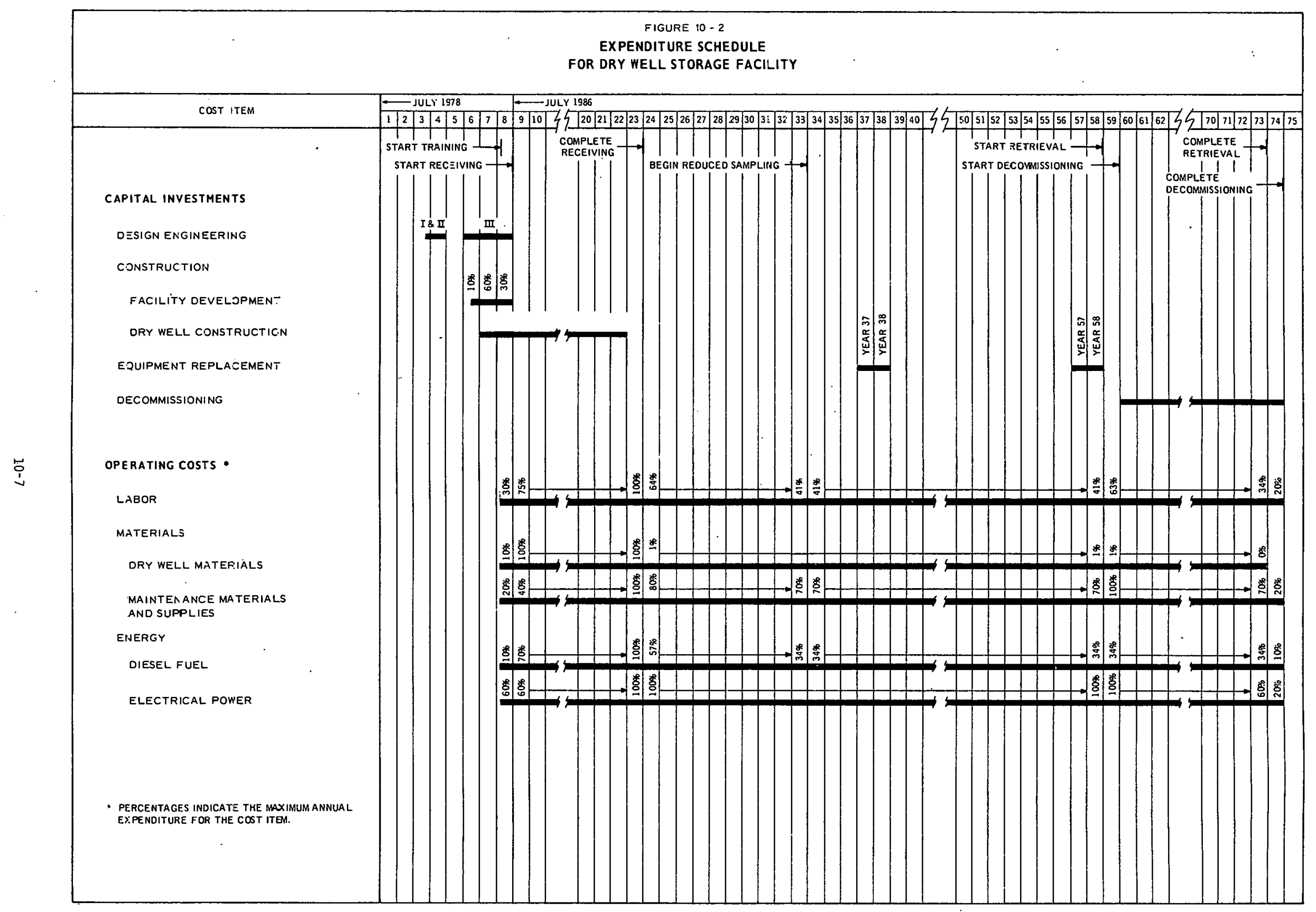


TABLE 10-3

Estimated Itemized Costs

1978 Base Cost Without Escalation

or Contingency

Cost Item

( $\$$ millions)

CAPITAL INVESTMENTS

Design and engineering

4.1

Facility construction

19.6

Dry wel. construction

572.3

Equipment replacement

.6

Decommissioning

15.4

TOTAL

611.9

OPERATING COSTS:*

Labor

Exempt and non-exempt

Materials

Dry well materials

0.075

Maintenance materials and

supplies

0.370

Energy

Diesel fuel

0.220

Electrical power

0.084

TOTAL $\quad 3.689$

*Amounts are the maximum annual expenditure for the cost item expected during project year 23 in 1978 dollars, the last year of placement of canisters. 


\section{3 COST ESTIMATING FACTORS AND ASSUMPTIONS}

This section presents the assumptions and factors used to make the life-cycle cost analysis.

\subsubsection{General Study Criteria}

\subsubsection{Time Period.}

Figure 10-1 presents the principal activities over the period of study. The following assumptions were used to develop the schedule shown in Figure 10-1:

$\begin{array}{ll}\text { Start of first project year } & \text { July } 1978 \\ \text { Start of hot operations } & \text { July } 1986 \\ \text { Duration of receiving operations } & 15 \text { years } \\ \text { Duration of storage for each fuel element } & 50 \text { years } \\ \text { Duration of retrieval operations } & 15 \text { years } \\ \text { Duration of decommissioning } & 15 \text { years (overlapping } \\ & 14 \text { years of off- } \\ & \text { site shipping) }\end{array}$

\subsubsection{Escalation}

The escalation rates were estimated for construction-related items, labor-related items, materials and supplies, and energyrelated items, as shown in Table 10-4.

The escalation factor (EFACT) for any one year (N) was calculated with that year's escalation rate (ERATE), using the formula:

$$
\operatorname{EFACT}(N)=\operatorname{EFACT}(N-1) \times[1+\operatorname{ERATE}(N)]
$$

An item's escalated cost (ECOST) for any one year (N) was calculated from the base 1978 cost (BCOST), using the formula:

$$
\operatorname{ECOST}(N)=B \operatorname{COST} \times \operatorname{EFACT}(N)
$$


TABLE 10-4

Escalation Factors Used in Cost Estimate

\begin{tabular}{lccccc}
$\begin{array}{l}\text { Project } \\
\text { Year }\end{array}$ & Construction & $\begin{array}{l}\text { Engineering } \\
\text { and Design and } \\
\text { Operating } \\
\text { Labor }\end{array}$ & $\begin{array}{l}\text { Maintenance } \\
\text { Materials and } \\
\text { Supplies }\end{array}$ & Energy \\
\cline { 2 - 3 } 2 & 9.9 & 7.3 & & 7.9 & 12.6 \\
3 & 8.9 & 7.3 & 7.0 & 11.2 \\
4 & 9.3 & 7.3 & 7.4 & 11.8 \\
5 & 8.0 & 5.5 & 6.9 & 10.4 \\
6 & 6.8 & 5.5 & 5.7 & 8.6 \\
7 & 6.5 & 5.5 & 5.4 & 8.1 \\
8 & 5.9 & 5.5 & 4.9 & 7.4 \\
9 & 5.5 & 5.5 & 4.8 & 6.9 \\
10 & 5.3 & 4.7 & 4.6 & 6.2 \\
11 & 5.0 & 4.7 & 4.6 & .9 .9 \\
12 & 4.8 & 4.7 & 4.6 & 5.9 \\
13 & 4.8 & 4.7 & 4.4 & 5.6 \\
$14+$ & 4.8 & 4.7 & 4.4 & 5.6 \\
& 4.8 & 4.7 & 4.4 & 5.2
\end{tabular}

\subsubsection{Contingency}

Escalated costs were increased to include contingency as follows:

Engineering

Facility development

Dry well construction

Equipment replacement
15\% Decommissioning

$15 \%$ Labor

15\% Dry well materials

$10 \%$ Maintenance materials

$$
\text { supplies }
$$

Energy
$10 \%$ $20 \%$

$20 \%$

$10 \%$ $50 \%$ 


\subsubsection{Discount Method.}

The life cycle cost of the facility was calculated using the present-value method, which equates the estimated cost of diverse future sums to current values; an interest/risk factor of $10 \%$ per year, which is in accordance with government guidelines, was used

The continuous discounting method, which assumes expenditures were uniform during the year, was used for this analyses, as identified below.

Using the continuous discounting method, the present value factor (PVFACT) for any one year (N) was calculated with the prescribed discount rate (DRATE) using this formula:

$$
\operatorname{PVFACT}(N)=\frac{1}{(1+\text { DRATE })} N \times \frac{\text { DRATE }}{\text { LOG }_{e}(1+\text { DRATE })}
$$

The first term in the equation provides the end-of-the-year present-value factor, and the second term computes a weighting factor; the discount rate therefore approximates midyear values.

\subsubsection{Capital Cost Factors and Assumptions}

For this economic analysis, the capital costs in this section 10.3.2 are defined in 1978 dollars as facility development and dry well construction, equipment replacement, and decommissioning costs. Design engineering, inspection, and contractors' overhead are included as indirect capital costs.

\subsubsection{Construction Costs}

The initial facility development costs include perimeter fences, ditches and intrusion-detection devices, all rough grading, utility and guard structures, most vehicles, and necessary additions 
to the R\&P Facility. Dry well construction costs consist of dry wells (including permanent covers), area fencing, roads, grading and drainage, sampling vehicles, encasement instrumentation, and area lighting.

\subsubsection{Equipment Replacement}

In general, the vehicles and other operating equipment should have an average service life of more than 20 years if they are operated at low speeds and if high levels of maintenance are provided. It is assumed that the original equipment., estillaled al $\$ 300,000$ will be replaced during the monitoring and surveillance period at project years 37 and 38 .

It is also assumed that, prior to initiating the retrieval phase in project years 57 and 58 , equipment estimated at $\$ 330,000$ (including the closure, plate cutoff equipment) will be replaced).

\subsubsection{Decommissioning}

Decommissioning costs were estimated to be $\$ 15,400,000$, with no credit taken for salvage value.

\subsubsection{Capital Cost Estimating Factors}

\subsection{Indirect Costs}

Construction costs estimated in 1978 base dollars were increased by $19 \%$ to allow for the following:

$\begin{array}{lc}\text { General Contractor's Field Overhead } & \\ \text { Labor cost } & 12 \% \\ \text { Indirect expense } & 2 \\ \text { Contractor's plant and equipment } & 1 \\ \text { Contractor's fee Subtotal } & \frac{2}{17 \%}\end{array}$


General Contractor's Home Office Support.

Supervision and expense

Procurement and expediting

TOTAL INDIRECT COST

\subsection{Design Engineering and Inspection}

The total design costs were estimated as $7 \%$ of the facility development costs plus the dry well construction cost for the first. year of receiving. Titles I, II, and III costs are estimated as follows:

$$
\begin{aligned}
& \text { Title I - } \quad 30 \% \text { of total design } \\
& \text { Title II - } \quad 60 \% \text { of total design } \\
& \text { Title III - } \quad 10 \% \text { of total design }
\end{aligned}
$$

\subsubsection{Operating Costs}

Operating costs, for the storage, surveillance, and retrieval periods include costs for materials used when placing the canistered fuel elements into storage, operating and overhead labor, maintenance of the facility, supplies; and energy.

\subsubsection{Labor}

The total number of personnel required to operate the Dry Well Storage Facility is estimated to be 80 , exclusive of construction activities. The peak personnel requirement would occur in the 15th year after initiating storage operations. Approximately 53 people would be required for transportation, dry well closure welding, and monitoring and surveillance operations. The balance of the facility staff would perform health physics, security patrol, inspection, and supervisory or administrative functions. 


\subsubsection{Materials}

\subsection{Dry Well Materials}

Materials for one dry well include 30 cubic feet of shield plug sand and approximately 4 pounds of deposited weld metal. The cost of supplies during one year of placement operations for 6,750 dry wells is estimated as follows:

30 cubic feet sand at $\$ 0.27 / \mathrm{CF}=\$ 8.10$

4 pounds of weld at $\$ 0.67$

per pound for wire and flux - $\$ 2.68$

SAY $\$ 11.00$ per drywell

The annual material cost would be 6,750 wells $0 \$ 11.00=\$ 74,250$, SAY $\$ 75,000$

\subsection{Maintenance Materials and Supplies}

Dry well encasement costs will amount to about $88 \%$ of the total construction costs; maintenance of this investment will be negligible. However, it is estimated that the remaining $12 \%$ costs will require $0.5 \%$ of original cost for annual maintenance. This maintenance will be required each year for supplies and materials to repair or service welding equipment, mobile equipment, roads, fences, lighting, instruments, and structures, including janitorial functions. Supplies would include protective clothing and storeroom items. Service would also include maintenance of CCTV and radio communication systems. 


\subsection{Utilities}

\subsection{Diesel Fuel}

The maximum fuel requirements for vehicles and stationary motor generators is estimated to be 560,000 gallons per year at $\$ 0.40$ per gallon (no taxes added). The annual estimated cost of fuel will be $\$ 224,000$ per year; say $\$ 220,000$ per year.

\subsection{Electrical Power}

Electrical power requirements were estimated for the perimeter fence lighting, the perimeter intrusion system, and the area lighting to be a maximum of 7 million kWh per year. Industrią power costs of this volume in the Richland, Washington, area have averaged $\$ 0.0074$ per $\mathrm{kWh}$. However, because rate increases are expected to average $60 \%$ in 1979, the 1978 base cost rate used is $\$ 0.012$ per kWh to account for this unusual escalation. The annual electrical power cost would be $\$ 0.012$ per kWh times 7 million $\mathrm{kWh}$, or $\$ 84,000$.

\subsection{Labor Rates}

A composite labor force of $10 \%$ supervisory staff (exempt) and 90 percent direct labor (nonexempt) was assumed, and a composite labor cost rate was computed to be $\$ 36,800$ per year per employee, based on prior labor cost experience at the Hanford Reservation:

\subsection{CAPITAL COST ESTIMATES}

The construction elements of cost are shown in Table 10-5 in 1978 base dollars. 
TABLE $10-5$

DWS Facility

Summary of Construction Capital Cost Estimate*

Facility Development Costs ( $\$$ millions)

Civil-Structural

Mechanical

Electrical

Subtotal

$\$ .13 .0$

1.5

$\underline{5.0}$

$\$ 19.5$

Dry Well Construction Costs** (\$ millions)

\section{Civil-Structural}

Electrical

Instrumentation

Dry Well Encasement

Subtotal
$\$ 1.1$

0.2

2.4

34.7

Subtotal Facility Development and Dry Well

first year construction

38.4

2nd year construction cost

$3 r d$

4 th

5 th

6 th

7 th

8 th

9th

10th

11 th

12 th

13 th

14 th

15 th

Total Construction Cost

$\$ 57.9$

38.1

38.1

38.1 .

38.2

38.1

38.3

38.1

38.2

38.1

38. 1

38.1

38.2

38.1

38.1

$\$ 591,800$

* Uses mid-1978 cost base and includes $19 \%$ for general contractor's field overhead and home office support.

** Includes 6,750 dry well encasements, area lighting, associated instrumentation, and civil works for first year consignment of spent fuel canisters to storage. Breakdown is typical for subsequent 14 years. 


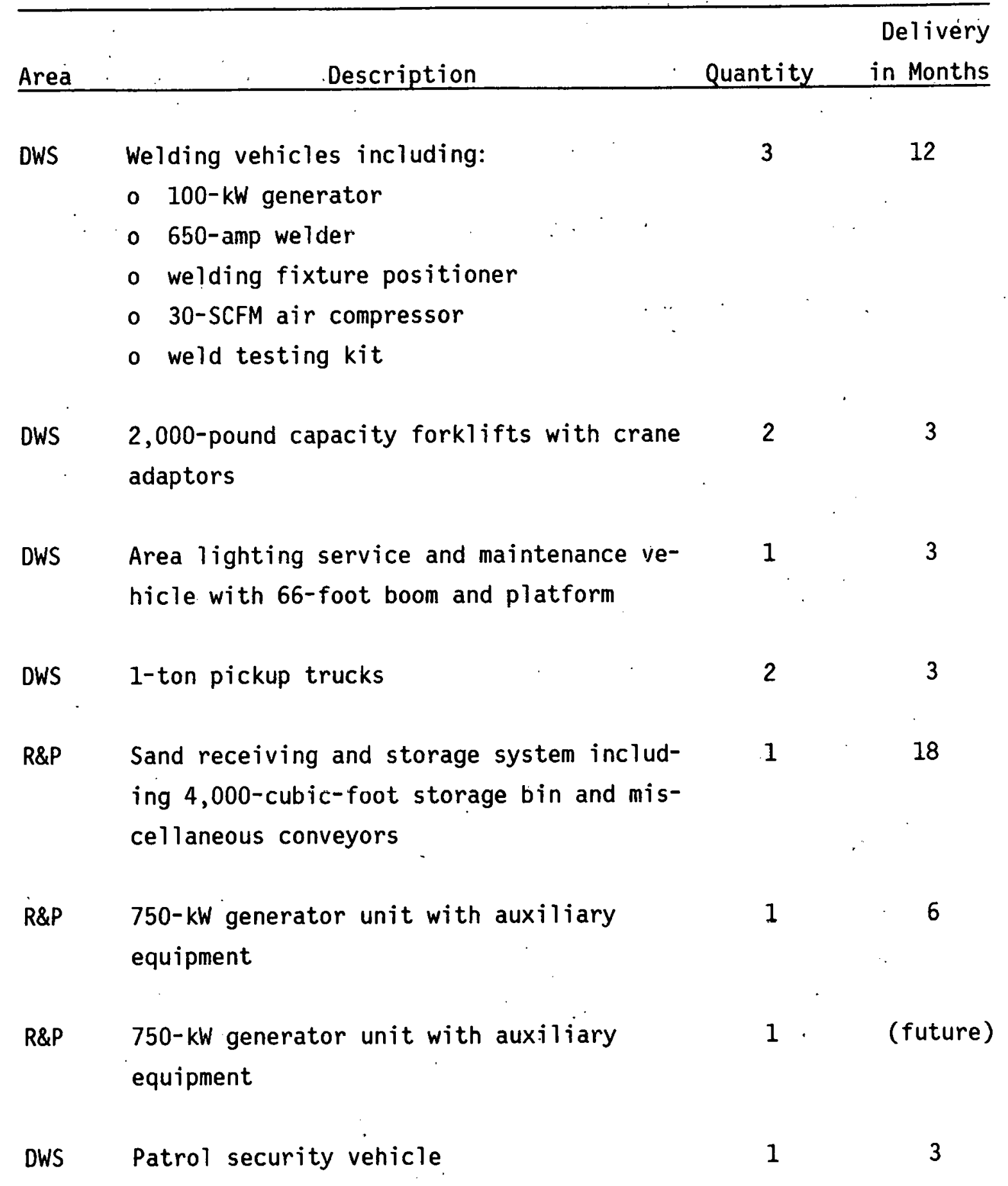


APPENDIX A

Major Mechanical Equipment (Cont)

\begin{tabular}{|c|c|c|c|}
\hline Area & Description & Quantity & $\begin{array}{l}\text { Delivery } \\
\text { in Months }\end{array}$ \\
\hline DWS & Monitoring and surveillance trucks & 2 & 3 \\
\hline DWS & Monitoring and surveillance trucks & 6 & (future) \\
\hline DWS & Health physics vehicle & 1 & 3 \\
\hline
\end{tabular}




\section{ÁPPENDIX B}

Electric Power Requirements (kilowatts)

\begin{tabular}{lccc}
\hline \multicolumn{1}{c}{ Area } & $\begin{array}{c}\text { Connected } \\
\text { Load }\end{array}$ & $\begin{array}{c}\text { Operating } \\
\text { Load }\end{array}$ & $\begin{array}{c}\text { Standby } \\
\text { Power }\end{array}$ \\
\hline $\begin{array}{l}\text { Storage Area and Building Lighting } \\
\text { (at 15th year) }\end{array}$ & 1042 & 1042 & 1042 \\
Perimeter Fence Lighting & 104 & 104 & 104 \\
Storage Area & & & \\
Intrusion Detection and & 80 & 80 & 80 \\
Instrumentation & & & 8 \\
Diesel Gcnerator Building & 8 & 8 & 3 \\
Gate House & 3 & 3 & 7 \\
Sand Handling Station & 7 & 7 & 6 \\
Miscellaneous & & & \\
\hline
\end{tabular}




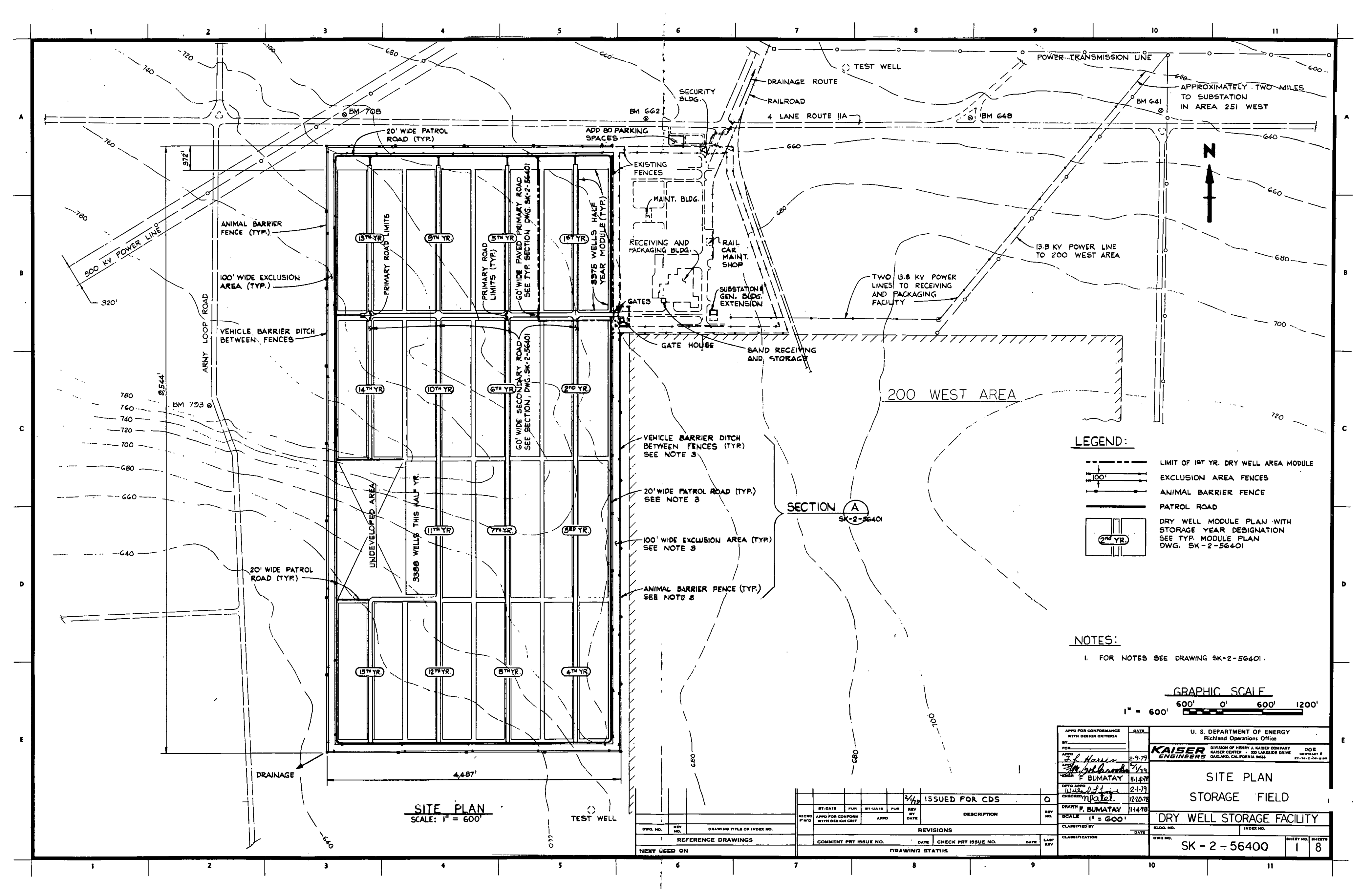




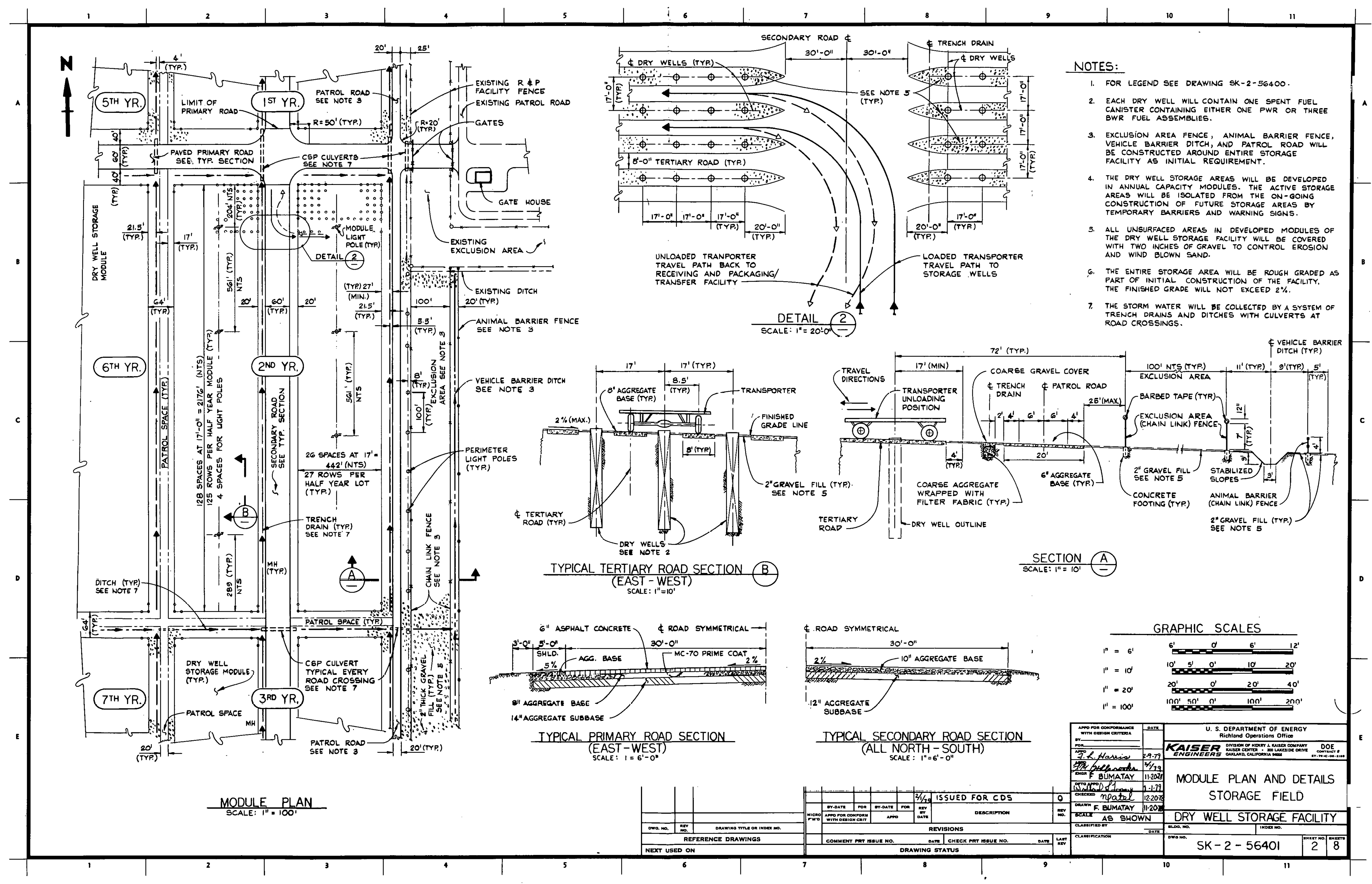




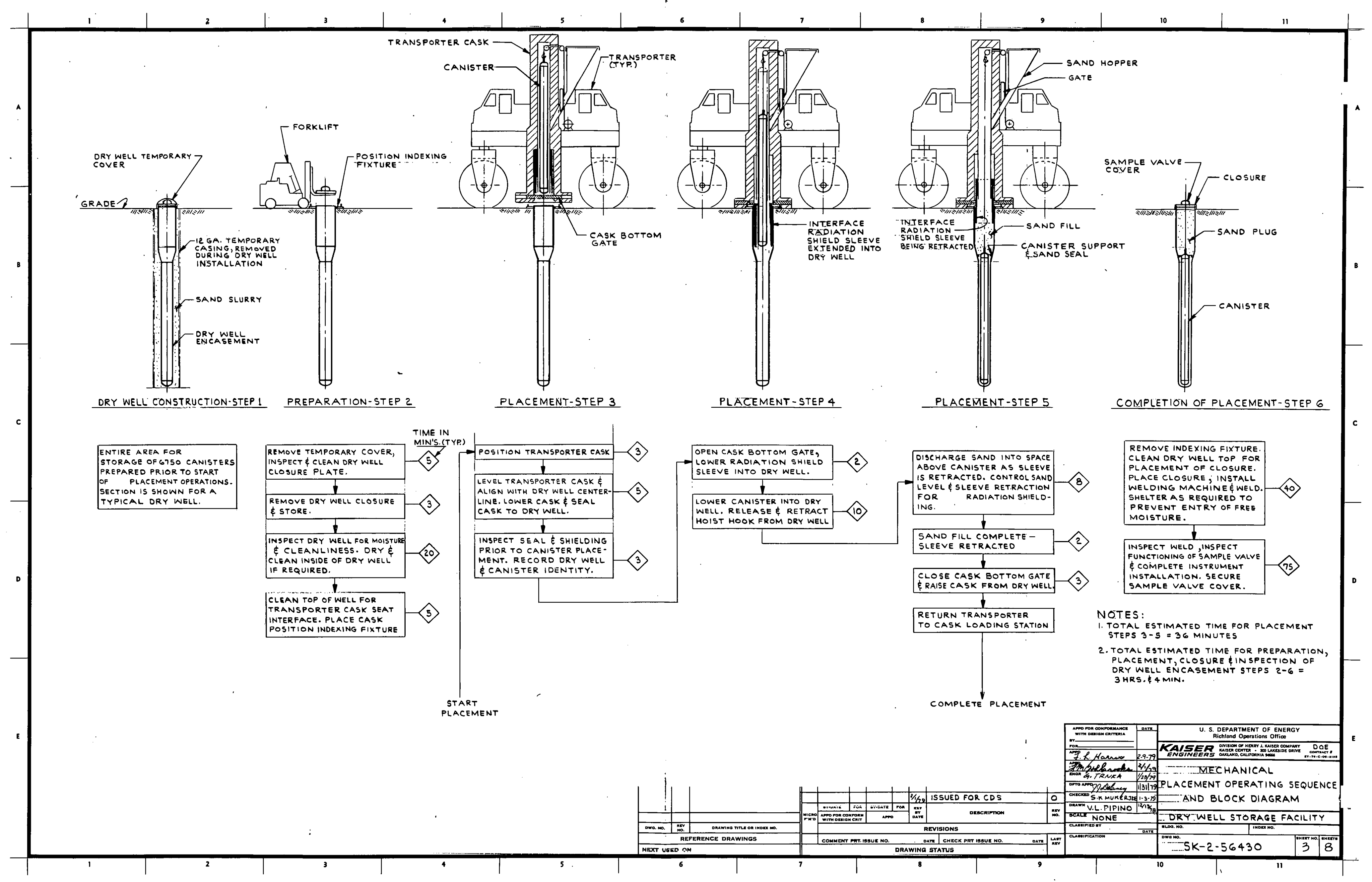




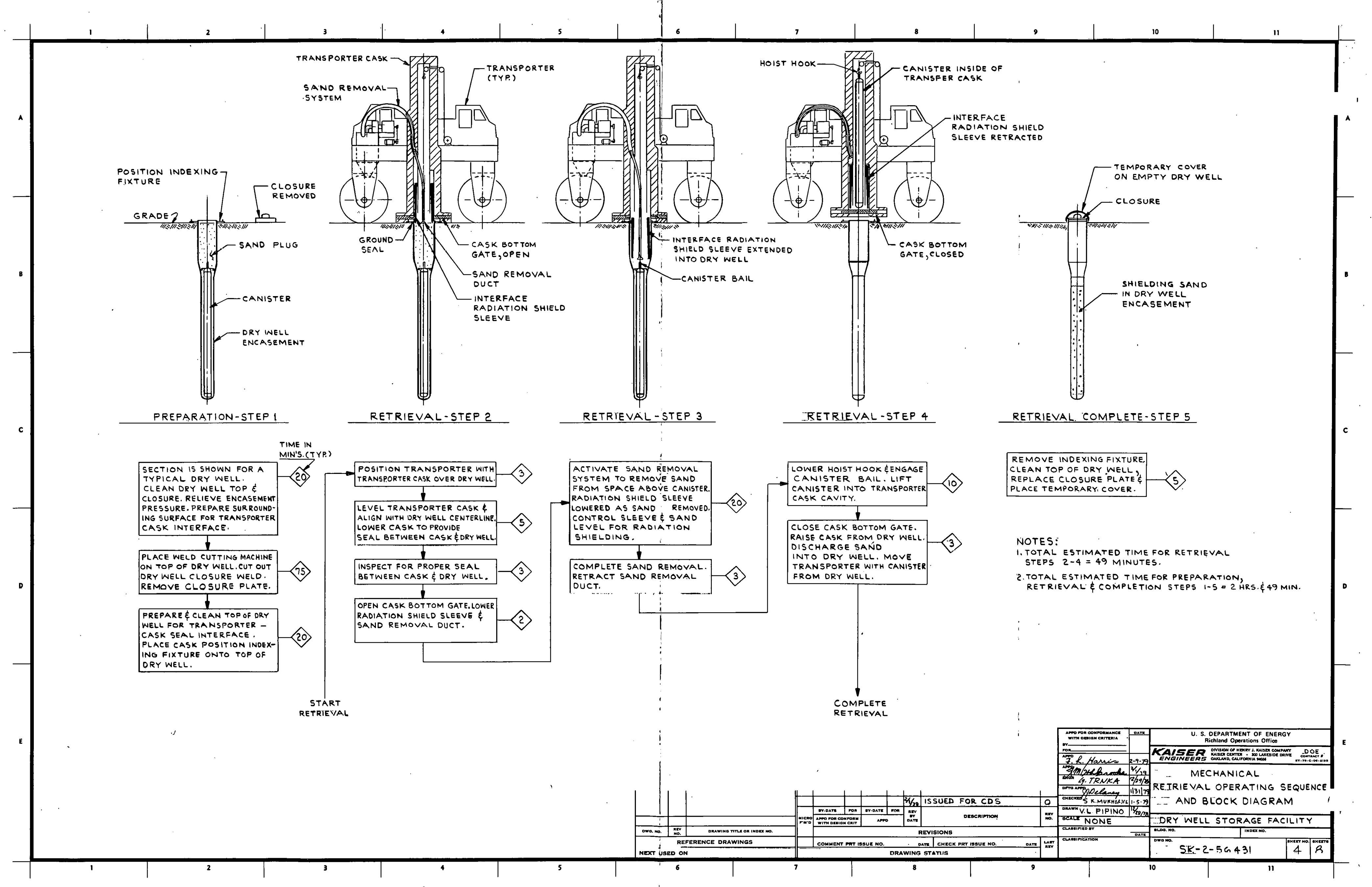




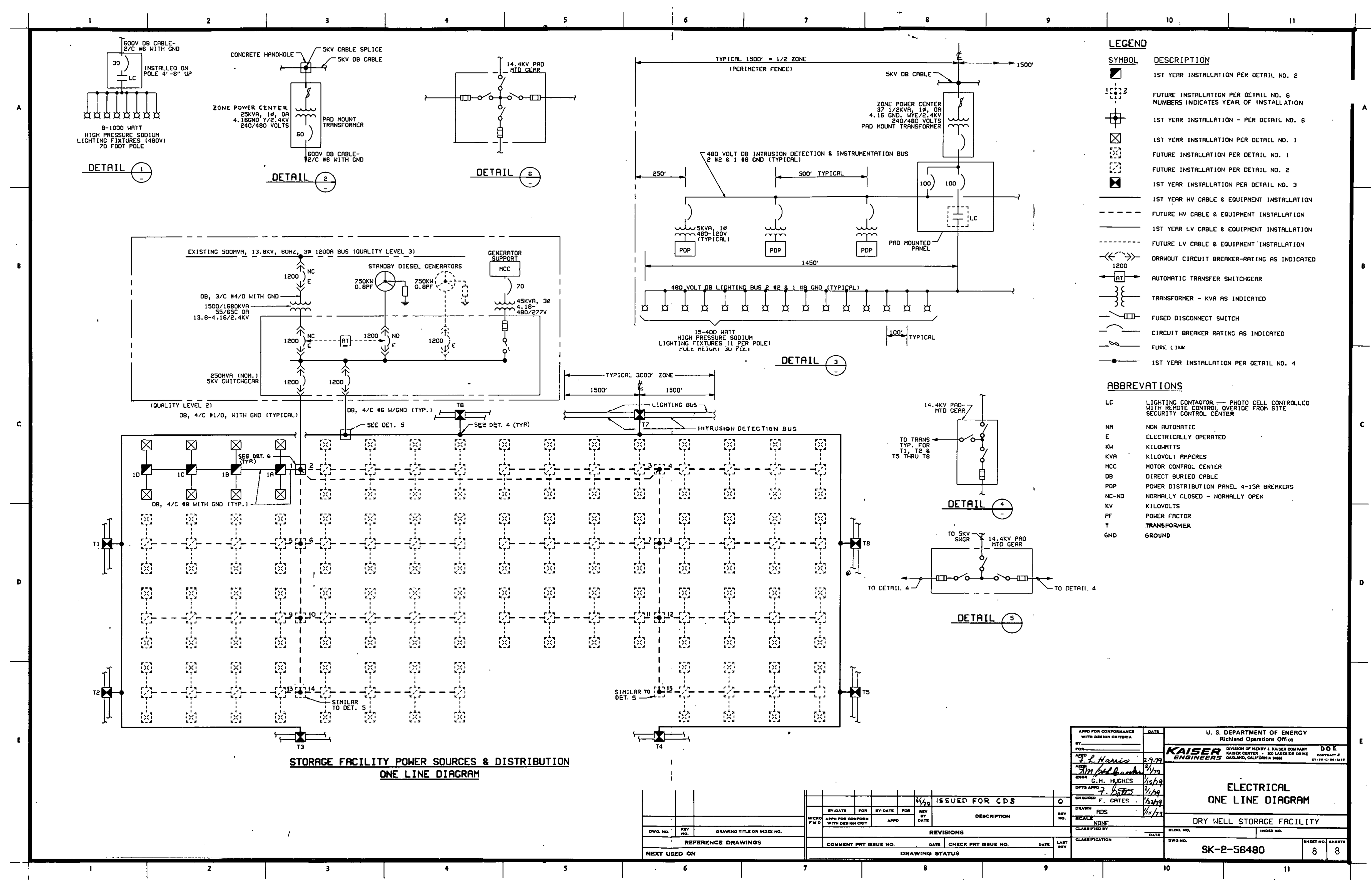

